Giovanne Santana de Oliveira

\title{
Análise da coagulação sanguínea com a administração profilática da desmopressina em cirurgias cardíacas valvares.
}

Tese apresentada à Faculdade de Medicina da Universidade de São Paulo para obtenção do título de Doutor em Ciências.

Programa de Anestesiologia Orientadora: Profa. Dra. Filomena Regina Barbosa Gomes Galas 


\section{Dados Internacionais de Catalogação na Publicação (CIP)}

Preparada pela Biblioteca da

Faculdade de Medicina da Universidade de São Paulo

Creprodução autorizada pelo autor

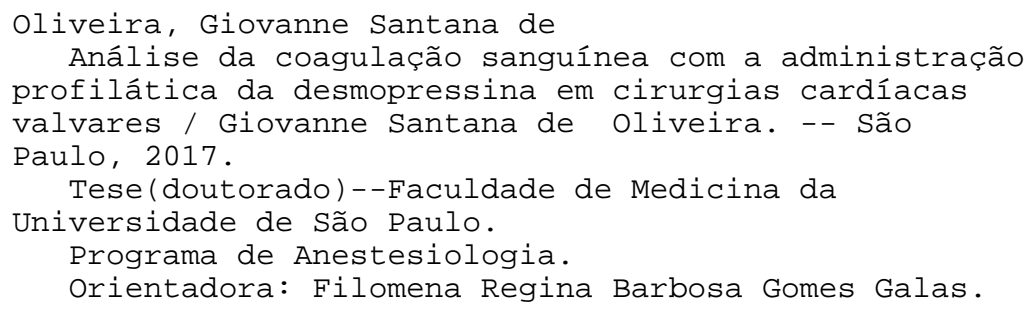

Descritores: 1.Cirurgia cardíaca 2.Hemostáticos 3. Coagulação sanguínea 4. Perda sanguínea cirúrgica 5.Transfusão de sangue 6.Complicações pós-operatórias $\mathrm{USP} / \mathrm{FM} / \mathrm{DBD}-449 / 17$ 
Dedicatória 
Aos meus pais Raimundo Oliveira Silva e Fátima Maria de Santana Oliveira e meu irmão Thiago Oliveira Silva, que acreditaram e investiram em minha educação com todo amor e carinho desde a mais tenra idade.

À minha esposa Rayssa, companheira de todas as horas, circunstâncias e ocasiões. Meu muito obrigado! 
Agradecimentos 
À Deus, pelo dom da vida e pelas oportunidades a mim ofertadas.

À minha família, que sempre esteve torcendo por mim.

À Prof. ${ }^{a}$ Dr. ${ }^{a}$ Filomena Regina Barbosa Gomes Galas, personagem fundamental no desenvolvimento desta tese, pelas orientações e apoio durante todo o trabalho.

Aos professores Dr. ${ }^{a}$ Ludhmila Abrahao Hajjar, Dr. ${ }^{a}$ Marilde Piccioni, Dr. Fábio Gaiotto pelas suas contribuições na realização desse projeto.

Aos professores Dr. Taylor Schineider, Dr. Antônio Mauro Vieira, Dr. Antônio Carlos Aguiar Brandão e o Dr. Adilson de Oliveira Fraga, por todos os ensinamentos, orientações e acolhimento que tive o privilégio de receber dos senhores.

Às enfermeiras Lígia Câmara, Jaqueline Jardim e Dr. ํㅗ Suely Pereira Zeferino, que tanto colaboraram para execução do estudo.

À equipe de Anestesiologia do InCor-FMUSP, composta por verdadeiros amigos e da qual tive a honra de ser parte integrante por três magníficos anos de minha vida. 
Aos amigos que passaram por meus caminhos e fizeram meus dias mais felizes e suaves.

Aos pacientes, pela essencial participação.

A todos aqueles que contribuíram, direta ou indiretamente, para a concretização desta pesquisa. 
Epígrafe 
"Só as paixões, as grandes paixões, podem elevar a alma às grandes realizações". 
Normatização adotada 
Esta tese está de acordo com as seguintes normas, em vigor no momento de sua publicação:

Referências: adaptado de International Committee of Medical Journals Editors (Vancouver).

Universidade de São Paulo. Faculdade de Medicina. Divisão de Biblioteca e Documentação. Guia de apresentação de dissertações, teses e monografias. Elaborado por Anneliese Carneiro da Cunha, Maria Julia de A.L.Freddi, Maria F.Crestana, Marinalva de Souza Aragão, Suely Campos Cardoso, Valéria Vilhena. $3^{a}$ ed. São Paulo: Divisão de Biblioteca e Documentação; 2011.

Abreviatura dos títulos e periódicos de acordo com List of Journals Indexed in Index Medicus. 
Sumário 
Lista de abreviaturas e siglas

Lista de tabelas

Lista de figuras

Resumo

Abstract

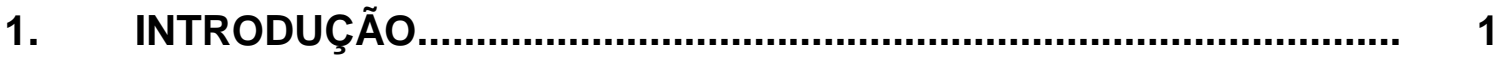

2. OBJETIVOS

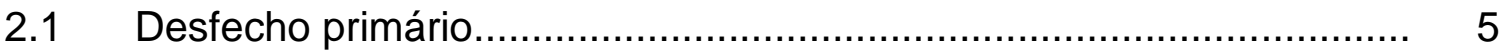

$2.2 \quad$ Desfecho secundário..................................................................... 5

3. REVISÃO DA LITERATURA........................................................ 6

4. MÉTODOS............................................................................... 14

4.1 Pacientes do estudo........................................................ 15

4.1.1 Critérios de inclusão................................................................. 16

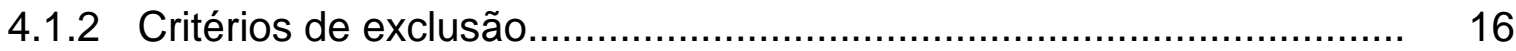

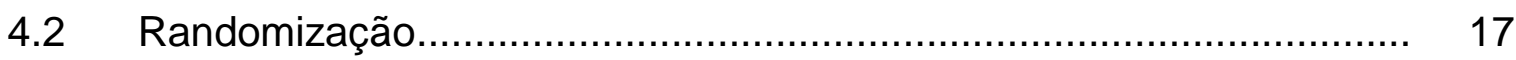

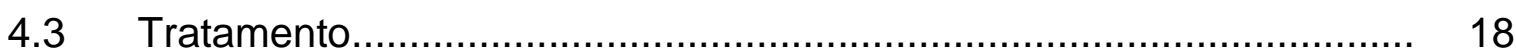

4.4 Desenho do estudo............................................................... 19

4.5 Coleta dos exames laboratoriais .................................................. 20

4.6 Procedimento cirúrgico e admissão na unidade de terapia intensiva................................................................................... 20

4.7 Avaliação dos dados clínicos e demográficos, e coleta de dados 22

4.8 Definição das complicações clínicas e desfechos............................... 24 
4.9 Descrição dos testes laboratoriais................................................... 26

4.10 Análise estatística................................................................... 30

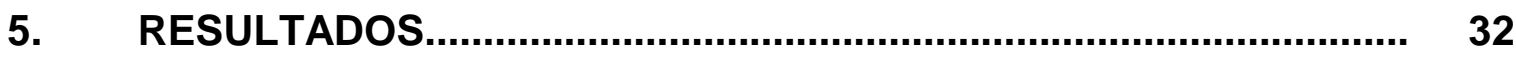

$5.1 \quad$ População do Estudo.................................................................. 33

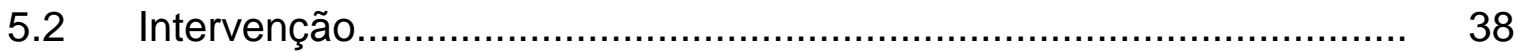

5.2.1 Análise Laboratorial............................................................... 38

5.3 Eficácia do DDAVP em reduzir o sangramento.................................. 62

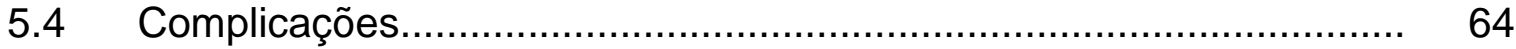

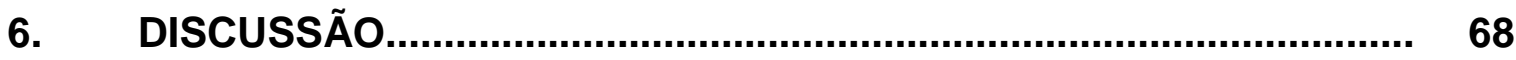

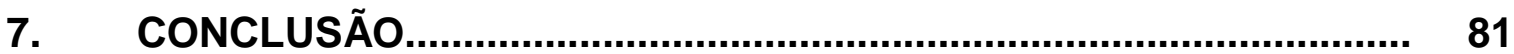

8. ANEXOS

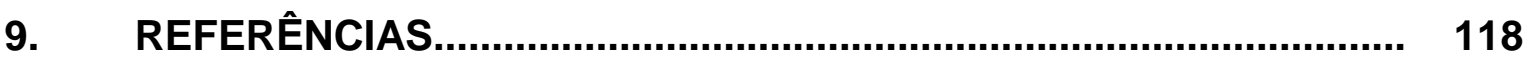




\section{Listas}




\begin{tabular}{ll} 
AAS & Ácido Acetilsalicílico \\
AKIN & Acute Kidney Injury Network \\
AVC & Acidente Vascular Cerebral \\
CAPPesq & Comissão de Ética para Análise de Projetos de Pesquisa \\
CEC & Circulação extracorpórea \\
CFT & Tempo de Formação do Coágulo \\
Cm & Centímetro \\
CNPq & Conselho Nacional de Desenvolvimento Científico e \\
CKMB & Tecnológico \\
CT & Fração MB da creatinofosfoquinase \\
DDAVP & Tempo de Coagulação \\
dL & Desmopressina \\
et al. & Decilitro \\
EuroSCORE & e outros \\
FAPESP & European System for Cardiac Operative Risk \\
FC & Fundação de Amparo à Pesquisa do Estado de São Paulo \\
FEVE & Frequência Cardíaca \\
FiO 2 & Fração de Ejeção do Ventrículo Esquerdo \\
FvW & Fração Inspirada de Oxigênio \\
G & Fator de von Willebrand \\
Hb & Grama \\
\hline Hemoglobina
\end{tabular}




\begin{tabular}{ll} 
HCFMUSP & Hospital das Clínicas da Faculdade de Medicina da \\
& Universidade de São Paulo \\
$\mathrm{Ht}$ & Hematócrito \\
IC $95 \%$ & Infarto Agudo do Miocárdio \\
IMC & Intervalo de Confiança de 95\% \\
InCor & Índice de Massa Corporal \\
INR & Instituto do Coração \\
IQ 25-75\% & Razão Normatizada Internacional \\
IRA & Intervalo Interquartil 25 - 75\% \\
$\mathrm{Kg}$ & Insuficiência Renal Aguda \\
$\mathrm{L}$ & Quilograma \\
$\mathrm{m}$ & Litro \\
$\mathrm{MCF}$ & Metro \\
$\mu \mathrm{mg}$ & Firmeza Máxima do Coágulo \\
$\mathrm{mg}$ & Micrograma \\
$\mathrm{min}$ & Miligrama \\
$\mathrm{mL}$ & Minuto \\
$\mathrm{ML}$ & Mililitro \\
$\mathrm{mm}$ & Lise Máxima do Coágulo \\
$\mathrm{mg}$ & Nilímetro \\
\hline $\mathrm{mmg}$ &
\end{tabular}


$\mathrm{P}$

PEEP

PFC

$\mathrm{pH}$

PIBIC

PO

POAP

POC

$\mathrm{POI}$

RPM

S

$\mathrm{SvO} 2$

TCA

TCLE

TP

TRALI

TTPa

U

UTI

$<$

$>$

${ }^{\circ} \mathrm{C}$

$=$
Probabilidade de significância

Pressão Positiva Expiratória Final

Plasma Fresco Congelado

Potencial Hidrogeniônico

Programa Institucional de Bolsas de Iniciação Científica

Pós - operatório

Pressão de Oclusão da Artéria Pulmonar

Point of Care

Pós - operatório Imediato

Rotações por Minuto

Segundo

Saturação Venosa de Oxigênio

Tempo de Coagulação Ativada

Termo de Consentimento Livre e Esclarecido

Tempo de Protombina

Injúria Pulmonar Aguda relacionada à Transfusão

Tempo de Tromboplastina Parcial Ativado

Unidade

Unidade de Terapia Intensiva

Menor

Maior

Grau Celsius

Igual 
Tabela 1 - Características pré-operatórias (demográficas, clínicas e laboratoriais) dos pacientes.

Tabela 2 - Características intra-operatórias (clínicas e laboratoriais) dos pacientes.

Tabela 3 - Tipos de cirurgia valvar em relação à intervenção.

Tabela 4 - $\quad$ Análise laboratorial 39

Tabela 5 - $\quad$ Dados do ROTEM® $($ INTEM T0) ................................ 44

Tabela 6 - $\quad$ Dados do ROTEM® $($ INTEM T1) ............................... 44

Tabela 7 - $\quad$ Dados do ROTEM® (INTEM T2) ................................. 45

Tabela 8 - $\quad$ Dados do ROTEM® $($ EXTEM T0).............................. 45

Tabela 9 - $\quad$ Dados do ROTEM® $($ EXTEM T1) .............................. 46

Tabela 10 - $\quad$ Dados do ROTEM® $($ EXTEM T2)................................ 46

Tabela 11 - Dados do ROTEM® (FIBTEM T0)............................ 47

Tabela 12 - Dados do ROTEM® $($ FIBTEM T1) ............................. 47

Tabela 13 - $\quad$ Dados do ROTEM® $($ FIBTEM T2)............................... 48

Tabela 14 - Correlação do tipo valvar (aórtica ou mitral) e níveis de Fator VIII.

Tabela 15 - Correlação do tipo de valva (aórtica ou mitral) e níveis de FVW.

Tabela 16 - Análise laboratorial dos pacientes submetidos a correção do defeito valvar mitral.

Tabela 17 - Análise laboratorial dos pacientes submetidos a correção do defeito valvar aórtico.

Tabela 18 - Dados do ROTEM® (INTEM T0) no grupo mitral. 
Tabela 19 - Dados do ROTEM® (INTEM T1) no grupo mitral............. 53

Tabela 20 - $\quad$ Dados do ROTEM® (INTEM T2) no grupo mitral.............. 54

Tabela 21 - Dados do ROTEM ${ }^{\circledR}$ (EXTEM T0) no grupo mitral............. 54

Tabela 22 - Dados do ROTEM® (EXTEM T1) no grupo mitral............. 55

Tabela 23 - $\quad$ Dados do ROTEM $\circledast$ (EXTEM T2) no grupo mitral............. 55

Tabela 24 - Dados do ROTEM® (FIBTEM T0) no grupo mitral............ 56

Tabela 25 - Dados do ROTEM ${ }^{\circledR}$ (FIBTEM T1) no grupo mitral............ 56

Tabela 26 - $\quad$ Dados do ROTEM ${ }^{\circledR}$ (FIBTEM T2) no grupo mitral............ 57

Tabela 27 - Dados do ROTEM ${ }^{\circledR}$ (INTEM T0) no grupo aórtico............ 57

Tabela 28 - $\quad$ Dados do ROTEM® (INTEM T1) no grupo aórtico............ 58

Tabela 29 - Dados do ROTEM® (INTEM T2) no grupo aórtico............ 58

Tabela 30 - Dados do ROTEM ${ }^{\circledR}$ (EXTEM T0) no grupo aórtico........... 59

Tabela 31 - Dados do ROTEM $\circledast$ (EXTEM T1) no grupo aórtico........... 59

Tabela 32 - $\quad$ Dados do ROTEM® (EXTEM T2) no grupo aórtico........... 60

Tabela 33 - $\quad$ Dados do ROTEM ${ }^{8}$ (FIBTEM T0) no grupo aórtico.......... 60

Tabela 34 - $\quad$ Dados do ROTEM® (FIBTEM T1) no grupo aórtico.......... 61

Tabela 35 - $\quad$ Dados do ROTEM ${ }^{8}$ (FIBTEM T2) no grupo aórtico.......... 61

Tabela 36 - Relação do controle volêmico com os grupos desmopressina e controle............................................. 62

Tabela 37 - Correlação entre o tipo de cirurgia valvar, débito dos drenos e transfusão sanguínea........................................ 64

Tabela 38 - Correlação entre tipo valvar, débito dos drenos e transfusão sanguínea com os grupos desmopressina e 
controle......

Tabela 39 - Desfechos clínicos em relação aos grupos (DDAVP e controle)

Tabela 40 - Fármacos inotrópicos e vasoativos em relação aos grupos desmopressina e controle.

Tabela 41 - Sódio e diurese dos grupos desmopressina e controle..... 
Figura 1 - Fluxograma do desenho do estudo.................................. 19

Figura 2 - Fluxograma da população do estudo................................... 34

Figura 3 - Relação dos valores do lactato entre os dois grupos (desmopressina e controle).

Figura 4 - Relação desmopressina e níveis de Fator VIII nos três tempos de coleta.

Figura 5 - Relação desmopressina e níveis de $F v W$ nos três tempos de coleta

Figura 6 - Relação desmopressina e agregação adrenalina nos três tempos de coleta.

Figura 7 - Relação desmopressina e agregação ADP nos três tempos de coleta.

Figura 8 - Relação do balanço sanguíneo entre os dois grupos (DDAVP e controle).

Figura 9 - Incidência de desfechos em relação aos grupos $D D A V P$ e controle. 
Oliveira GS. Análise da coagulação sanguínea com a administração profilática da desmopressina em cirurgias cardíacas valvares [tese]. São Paulo: Faculdade de Medicina, Universidade de São Paulo; 2017.

Introdução: A desmopressina, análogo sintético do hormônio hipotalâmico vasopressina, é utilizada em determinadas condições hematológicas hereditárias melhorando a função plaquetária e aumentando os níveis dos fatores de von Willebrand ( $F v W$ e Fator VIII. Entretanto, sua administração na população geral é controversa, necessitando de mais estudos para elucidar sua eficácia como agente hemostático. Objetivo: O objetivo do presente estudo foi avaliar a coagulação sanguínea, clínica e laboratorialmente, após administração profilática da desmopressina em cirurgias cardíacas valvares. Métodos: Estudo clínico prospectivo e randomizado realizado no Instituto do Coração (InCor) do Hospital das Clínicas da Faculdade de Medicina da Universidade de São Paulo (HC-FMUSP). Foram incluídos 108 pacientes adultos submetidos à cirurgia cardíaca valvar, no período de fevereiro de 2015 a novembro de 2016. Os pacientes foram randomizados e alocados para a administração profilática da desmopressina ou para o grupo controle, na admissão hospitalar. Imediatamente após a reversão da heparina, administrouse a demopressina no grupo da intervenção ou solução placebo no grupo controle. Foram coletadas amostras sanguíneas em três momentos diferentes em todos os participantes do estudo. O desfecho foi a análise da coagulação sanguínea e do sangramento perioperatório através dos exames laboratoriais, 
débito sanguíneo dos drenos cirúrgicos e do consumo de hemocomponentes em 48 horas. Resultados: Dos pacientes incluídos no estudo, 54 foram alocados no grupo da intervenção e 54, no grupo controle. Quanto ao desfecho primário, os níveis sanguíneos do Fator VIII no tempo $2 \mathrm{~h}(236,5 \pm 62,9$ vs. $232,3 \pm 66,7, P=0,015)$ foram significativamente diferentes entre os dois grupos (DDAVP e controle), respectivamente. Os demais testes clássicos da coagulação, assim como a análise viscoelástica e de agregação plaquetária mantiveram-se homogêneos em todos os tempos de coleta entre os dois grupos. O débito dos drenos cirúrgicos, balanço sanguíneo e consumo de hemocomponentes $[10 \%(21,3)$ vs. $15 \%(28,8), P=0,526]$ não apresentaram diferenças significativas entre os grupos DDAVP e controle. $O$ tempo de ventilação mecânica apresentou diferença relevante entre os grupos DDAVP e o controle [897 (820 - 1011) vs. 1010 (846 - 1268), $P=0,031]$, respectivamente. Não houve diferença em relação à incidência de complicações, tempo de internação hospitalar e de UTI ou mesmo de mortalidade em 30 dias. Conclusões: A utilização profilática da desmopressina em cirurgias cardíacas valvares não se mostrou eficaz em exercer efeito hemostático em relação ao grupo controle no presente estudo.

Descritores: cirurgia cardíaca; hemostáticos; coagulação sanguínea; perda sanguínea cirúrgica; transfusão sanguínea; complicações pós-operatórias. 
Abstract 
Oliveira GS. Analysis of blood coagulation after prophylactic use of desmopressin in heart valve surgeries [thesis]. São Paulo: "Faculty of Medicine, University of São Paulo"; 2017.

Introduction: Desmopressin, a synthetic vasopressin analogue, is used in certain hereditary hematologic conditions, improving platelet function and increasing the levels of von factor and factor VIII. However, its use in general population is still controversial, requiring further studies to elucidate its efficacy as a haemostatic agent. Objective: To evaluate blood coagulation, through clinical and laboratorial analysis, after prophylactic use of desmopressin in heart valve surgeries. Methods: A prospective and randomized clinical study was performed in the Heart Institute (InCor) of Hospital das Clínicas, from the Faculty of Medicine, University of São Paulo (HC-FMUSP). A total of 108 adult patients undergoing heart valve surgeries were enrolled from February 2015 to November 2016. Patients were randomly assigned to the prophylactic use of desmopressin or to the control group at the time of hospital admission. Immediately after heparin reversal, demopressin was given in the intervention group or placebo solution in the control group. Blood samples were collected at three different times in all study participants. Blood coagulation and perioperative bleeding were analysed using laboratorial tests, blood flow through surgical drains and the consumption of blood components within 48 hours. Results: From 108 patients included in the study, 54 were allocated to the intervention group and 54 in the control group. Regarding the primary 
endpoint, blood levels of Factor VIII at Time $2 \mathrm{~h}(236.5 \pm 62.9$ vs. $232.3 \pm 66.7$, $P=0.015)$ were significantly different between the two groups (desmopressin and control), respectively. Classical coagulation tests, as well as viscoelastic and platelet aggregation tests, remained homogeneous at all collection times between the two groups. Flow rate of surgical drains, blood balance and consumption of blood components [10\% (21.3) vs. $15 \%(28,8), P=0.526]$ did not present significant differences between the DDAVP and control groups. Mechanical ventilation time presented a significant difference between the desmopressin and control groups [897 (820 - 1011) vs. 1010 (846 - 1268), $\mathrm{P}=0.031]$, respectively. There was no difference in incidence of complications, length of hospital and ICU stay or even mortality in 30 days. Conclusions: The prophylactic use of desmopressin in heart valve surgeries was not effective in exerting haemostatic effect compared to the control group in this study.

Descriptors: cardiac surgery; hemostatics; blood coagulation; blood loss surgical; blood transfusion; postoperative complications. 
1. Introdução 
O sangramento em cirurgias cardíacas para a correção de defeitos valvares com a utilização de circulação extracorpórea (CEC) é condição sine quanon e de caráter multifatorial. Relaciona-se ao nível de complexidade do procedimento cirúrgico, utilização de heparina, hipotermia, fibrinólise, dano à microvasculatura, CEC, hemodiluição e perdas sanguíneas. Estima-se que 10 a $60 \%$ dos pacientes submetidos à cirurgia, necessitem de transfusão sanguínea ${ }^{1}$.

Tanto a transfusão de hemocomponentes (concentrado de hemácias, plasma fresco congelado, plaquetas e crioprecipitado) como também o sangramento são conhecidos fatores de risco independentes para disfunção orgânica e mortalidade ${ }^{2}$.

Pesquisas estão sendo realizadas visando à substituição ou redução do uso de hemocomponentes. Desenvolvimento de produtos sintéticos do sangue, como também a realização do diagnóstico preciso e precoce da condição hemostática do doente estão entre as principais medidas.

A tendência atual é obter as respostas por meio do diagnóstico global da coagulação sanguínea (estratégia teranóstica), através de testes inovadores (testes viscoelásticos e de função plaquetária), e com foco no corrente modelo celular da coagulação ${ }^{3}$.

Dentre os produtos sintéticos, a desmopressina, um análogo sintético do hormônio hipotalâmico vasopressina, é utilizada em determinadas condições hematológicas hereditárias melhorando a função plaquetária e aumentando os níveis dos fatores de von Willebrand (FVW) e Fator VIII ${ }^{1,3}$. 
O presente estudo analisou a coagulação sanguínea, sob o olhar do modelo celular da coagulação, com a administração profilática da desmopressina em cirurgias cardíacas valvares. 
2. Objetivos 
Avaliar a coagulação sanguínea, clínica e laboratorialmente, após administração profilática da desmopressina em cirurgias cardíacas valvares.

\subsection{Desfecho primário}

Investigar a eficácia da administração profilática da desmopressina nos parâmetros da coagulação sanguínea e no sangramento perioperatório.

\subsection{Desfechos secundários}

Volume sanguíneo nos drenos cirúrgicos em 48 horas.

Taxa de transfusão de hemocomponentes em 48 horas.

Incidência de reoperação por sangramento em 48 horas

Acidente Vascular Cerebral (AVC)

Infarto Agudo do Miocárdio (IAM)

Taxa de infecção

Taxa de Insuficiência Renal (AKIM)

Tempo de administração de drogas vasoativas

Tempo de internação hospitalar

Tempo de ventilação mecânica

Tempo de Unidade de Terapia Intensiva (UTI)

Mortalidade em 30 dias 
3. Revisão da Literatura 
O processo de hemostasia pode ser considerado como regulador do sangramento; processo antitrombogênico, de remodelagem e cicatrização de tecidos em equilíbrio harmônico entre os sistemas anticoagulante e prócoagulante ${ }^{4}$.

Pacientes com disfunção valvar podem apresentar coagulopatia devido à alteração do fluxo laminar, inflamação, disfunção endotelial e plaquetária, promovidas pelo efeito mecânico da passagem do sangue sob pressões e fluxos anormais da valva acometida ${ }^{5,6,7}$. Além disso, necessitam fazer uso profilático de medicamentos antiplaquetários pelas condições de remodelamento miocárdico e arrítmicas associadas ${ }^{8}$. Pacientes com estenose aórtica ou mitral severa, defeito do septo ventricular e persistência do ducto arterioso podem também adquirir doença de von Willebrand tipo $2 \mathrm{~A}$ por proteólise acentuada do $F v W^{9,10,11}$.

O FvW é uma glicoproteína multimérica de alto peso molecular, produzida pelas células endoteliais e megacariócitos. É armazenado nos grânulos alfa dos megacariócitos, plaquetas e nos corpos de Weibel-Palade das células endoteliais de onde é secretado. No plasma, os multímeros do FvW são clivados por uma protease denominada ADAMTS13 (disintegrin-like and metalloprotease with trombospondin type 1 motifs) $)^{1,4}$.

O FvW tem duas funções principais: (1) ligar-se ao colágeno presente no subendotélio e nas plaquetas, promovendo a formação do tampão plaquetário no local da lesão endotelial; e (2) ligar e transportar o Fator VIII, protegendo-o da degradação proteolítica no plasma ${ }^{4}$. 
O FvW liga-se às plaquetas por meio da glicoproteína plaquetária lb Gplb (adesão plaquetária). Os multímeros de alto peso molecular ligam-se a Gplb com maior afinidade que os de baixo peso molecular. Após a ativação plaquetária, uma outra glicoproteína plaquetária, a Gpllb/llla, também se liga ao FvW permitindo a aderência das plaquetas entre si (agregação plaquetária) $)^{4}$.

Não obstante, o tratamento que é efetuado para correção de tais defeitos valvares usualmente requer cirurgia cardíaca com CEC.

A CEC promove distúrbios hemostáticos multifatoriais e que podem ser atribuídos à alteração do endotélio vascular, síndrome de isquemia e reperfusão, inflamação e hipotermia ${ }^{12}$. Ocasiona ainda redução no número e na funcionalidade plaquetária por hemodiluição, forças de cisalhamento, alteração do fluxo laminar e por consumo ${ }^{13}$.

A exposição do sangue às superfícies não endoteliais do circuito da CEC promove ativação por contato da coagulação através do Fator XII que, por sua vez, inicia a via intrínseca da cascata da coagulação, além de ativar os sistemas das calicreínas-bradicininas, fibrinolítico e complemento ${ }^{14}$. A utilização de heparina, como anticoagulante do sistema de CEC, contribui para a disfunção plaquetária ${ }^{15}$.

Nesse contexto, leucócitos levados para as áreas de isquemia promovem a liberação de interleucinas inflamatórias e radicais livres que produzem lise celular, liberação de citocinas e endotoxinas, amplificando a reação inflamatória, como também promovem obstrução mecânica na microcirculação $^{16}$. 
O tipo e a complexidade da cirurgia podem desencadear distúrbios metabólicos que nem sempre são facilmente corrigidos, tais como: acidose metabólica, distúrbios eletrolíticos e injúrias orgânicas que corroboram para uma pior evolução clínica desses quadros.

Estima-se que 10 a $60 \%$ dos pacientes submetidos a cirurgias cardíacas recebam transfusões sanguíneas ${ }^{17}$. Sangramento excessivo pode ocorrer em até $11 \%$ dos pacientes, o que propicia aumento da reabordagem cirúrgica, alterações dilucionais, aumento do consumo de hemocomponentes, infecção, aumento do tempo de permanência na Unidade de Terapia Intensiva (UTI), fibrinólise e disfunção plaquetária ${ }^{18}$.

Efeitos adversos da transfusão de sangue alogênico incluem imunossupressão, Injúria Pulmonar Aguda Relacionada à Transfusão (TRALI), transmissão de doenças infecciosas, reações transfusionais, distúrbios eletrolíticos e ácido-básicos relacionados aos conservantes e tempo de estocagem, sepses, aumento do tempo de permanência e dos custos hospitalares ${ }^{19,20}$.

Diante disso, desenvolveram-se alternativas visando à substituição ou redução do uso de hemocomponentes. Estratégias multimodais com esse propósito passaram a ser estimuladas e implementadas. Dentre as quais, destacam-se os agentes antifibrinolíticos, cujo emprego encontra indicação sobretudo em cirurgias que utilizam CEC, visto que a hiperfibrinólise é um dos mais importantes contribuintes para o aumento do sangramento em cirurgias cardíacas $^{20}$.

Entre os três fármacos antifibrinolíticos existentes, dois deles são agentes sintéticos derivados da lisina e amplamente recomendados: ácido 
épsilon amino capróico, que tem menor potência farmacológica e menos efeitos colaterais; e o ácido tranexâmico, que tem maior potência farmacológica, porém com efeitos neurológicos indesejáveis que são dose-dependentes ${ }^{17}$. A aprotinina é o terceiro fármaco da classe.

A aprotinina é um inibidor não específico da serinoprotease com potente ação antifibrinolítica; contudo, foi retirado do mercado em 2007 após estudos demonstrarem aumento do risco de eventos cardiovasculares, renais e cerebrovasculares $^{21}$. Recentemente reintroduzido no Canadá com indicações muito restritas, aguarda por resultados de grandes estudos para nova validação do custo-benefício ${ }^{22}$.

Produtos recombinantes ou purificados da coagulação sanguínea (complexo protrombínico, Fator VIIr, Fator XIII, fibrinogênio) mostram-se muito promissores como substitutos de hemocomponentes, porém ainda de reduzida disponibilidade pelo alto custo financeiro ${ }^{13}$.

Por outro lado, ainda não existem alternativas que substituam a transfusão de plaquetas quando necessário. As plaquetas exercem papel central no atual modelo celular da coagulação ${ }^{23}$. Portanto, para um adequado processo de hemostasia ocorrer, é necessário que as plaquetas estejam em número e qualidade adequados.

A transfusão de plaquetas, mais que qualquer outro hemoderivado, está associada a risco de infecção ${ }^{24}$. Estima-se que cerca de $20 \%$ de todas as transfusões de plaquetas ocorram no perioperatório de cirurgias cardíacas. As indicações de transfusão permanecem incertas e pouco criteriosas. Mesmo os testes point-of-care não estabelecem ainda parâmetros de indicação bem 
definidos e, assim, a transfusão de plaquetas usualmente ocorre de forma profilática e empírica $^{24}$.

Com esse mesmo objetivo, a desmopressina também tem sido amplamente investigada como instrumento alternativo para o controle do sangramento perioperatório, principalmente em cirurgias de grande porte. É um análogo do hormônio hipotalâmico vasopressina (1-deamino-8-D-arginina vasopressina ou desmopressina acetato) seletivo ao receptor $\mathrm{V} 2$, de baixo custo e poucos efeitos adversos (hipotensão durante administração, retenção urinária, hiponatremia e efeitos tromboembólicos com resultados conflitantes) ${ }^{6}$; age aumentando os níveis plasmáticos de Fator VIII e do FvW autólogos ${ }^{25}$. Admite-se que a desmopressina eleve os níveis do FvW plasmático por meio da indução da secreção do conteúdo dos grânulos de estoque da célula endotelial (corpos de Weibel-Palade). Embora o mecanismo de incremento do Fator VIII seja pouco elucidado, é aceito que esteja relacionado com a função de transporte realizada pelo $F V W$ secretado $^{26,27}$. Relaciona-se também com o aumento direto da concentração de serotonina plaquetária e tromboxano A2, promovendo, assim, melhora na agregação e adesão plaquetária ${ }^{28}$.

Utilizado classicamente em pacientes portadores de hemofilia A e doença de von Willebrand, a desmopressina diminui o tempo de sangramento em outras condições, tais como: uremia, doença hepática crônica, ingestão de ácido acetilsalicílico (AAS) e outros defeitos plaquetários (trombastenia de Glanzmann, síndrome de Bernard-Soulier e outras) ${ }^{29}$.

A utilização da desmopressina para controle do sangramento perioperatório mostrou-se benéfica apenas em pacientes que apresentavam disfunção plaquetária congênita ou adquirida. Na população geral, o uso 
profilático não é indicado por apresentar resultados inconclusivos ${ }^{30,31}$. Sugerese a importância de mais estudos clínicos, controlados e randomizados para definir o real papel da desmopressina no sangramento perioperatório ${ }^{32}$.

Nesse cenário, métodos diagnósticos convencionais, tais como: tempo de protombina (TP), contagem plaquetária, d-dímero e concentração de fibrinogênio possuem grandes limitações. São demorados, analisam a formação do coágulo de forma fragmentada e são realizados em plasma geralmente pobre em plaquetas ${ }^{4}$. Além disso, não raro, os testes de coagulação estão alterados após a cirurgia cardíaca, pois estão associados a concentrações reduzidas dos fatores de coagulação protrombínicos, mas não necessariamente com diminuição da geração da trombina ${ }^{4}$.

A tendência atual é obter as respostas dentro do contexto terapêutico e com um diagnóstico global da condição hemostática do doente (estratégia teranóstica), através de testes inovadores (testes viscoelásticos e de função plaquetária), e com foco no corrente modelo celular da coagulação; a esta metodologia denominamos point-of-care ${ }^{6,33}$.

O tromboelastograma (TEG) e a tromboelastometria rotacional (ROTEM) permitem um diagnóstico mais preciso dos distúrbios da coagulação, por apresentarem rápida avaliação do tempo de coagulação, trombocitopenia, hipofibrinogemia e fibrinólise ${ }^{12}$.

A tromboelastometria (ROTEM®, TEM International GmbH, Munich, Germany) é um teste de viscoelasticidade no sangue total, mensurando 0 início do tempo de coagulação, dinâmica da formação, firmeza e estabilidade do coágulo. Utiliza um painel de reagentes específicos que proporciona a avaliação simutânea das vias de coagulação intrínseca (INTEM), extrínseca 
(EXTEM), polimerização da fibrina (FIBTEM), inibidores diretos da trombina (ECATEM) e da fibrinólise (APTEM), além da influência da heparina quando se faz presente, por exemplo, durante a CEC (HEPTEM $)^{17}$.

Por todo o exposto, a busca por agentes hemostáticos sintéticos, de baixo custo e reduzidos efeitos colaterais e que promovam redução do sangramento cirúrgico e o consumo de hemocomponentes, pode contrubuir com redução da morbidade em cirurgias cardíacas. 
O protocolo do estudo e o Termo de Consentimento Livre e Esclarecido (TCLE) foram submetidos à Comissão Científica do Instituto do Coração (InCor) e aprovados pela Comissão de Ética para Análise de Projetos de Pesquisa (CAPPesq) do Hospital das Clínicas da Faculdade de Medicina da Universidade de São Paulo (HCFMUSP), em sessão de 22 de outubro de 2013, sob o no 0635/2013 (Anexo A). Foram obtidas as anuências no TCLE (Anexo B) de todos os pacientes participantes do estudo ou de seus parentes mais próximos, quando os pacientes se apresentavam incapacitados em fornecê-las. A pesquisa foi financiada pela Fundação de Amparo à Pesquisa do Estado de São Paulo (FAPESP) sob o identificador 2014/03785-1(Anexo C). Houve o desdobramento da pesquisa para o Programa Institucional de Bolsas de Iniciação Científica (PIBIC) do Conselho Nacional de Desenvolvimento Científico e Tecnológico (CNPq) sob o 031/2016 (Anexo D).

O estudo foi registrado no Clinical Trials.gov, sob o identificador NCT 03343418.

Trata-se de um estudo clínico, prospectivo, randomizado, unicêntrico e duplamente encoberto.

\subsection{Pacientes do estudo}

Pacientes com idade maior do que 18 anos submetidos à cirurgia cardíaca eletiva de correção valvar, no Instituto do Coração do Hospital das Clínicas da Faculdade de Medicina da Universidade de São Paulo, que preencheram os critérios de inclusão, foram randomizados para uma das duas estratégias de tratamento: Desmopressina ou controle. 
Estão listados abaixo os critérios de inclusão e exclusão do estudo:

\subsubsection{Critérios de inclusão}

a) Cirurgia cardíaca eletiva para correção de defeito valvar com circulação extracorpórea;

b) Idade maior de que 18 anos;

\subsubsection{Critérios de exclusão}
a) Infecção;
b) Insuficiência renal crônica com creatinina maior que 2 mg/dL;
c) Reoperação cardíaca;
d) Índice de massa corporal (IMC) > 35;
e) Fração de ejeção (FE) < 40\%;
f) Anemia com hematócrito < 35\%;
d) Coagulopatia (história prévia ou tempo de protombina maior que 14,8 segundos);

e) Uso de terapia antiplaquetária em até dez dias prévios à cirurgia (exceto o ácido acetilsalicílico (AAS) e enoxaparina que poderão ser utilizados em doses profiláticas até 24 horas antes do procedimento cirúrgico);
f) Cardiopatias graves associadas;
g) Recusa em participar do estudo;
h) Cirurgia de emergência; 
i) Procedimentos combinados (revascularização, defeitos congênitos e cirurgia da aorta);

j) Disfunção hepática (bilirrubina total maior que 1,5 mg/dL);

I) Plaquetopenia (menor que $100000 / \mathrm{mm}^{3}$ );

\subsection{Randomização}

$\mathrm{Na}$ noite anterior à cirurgia, a equipe de enfermagem do estudo avaliava os pacientes quanto aos critérios de elegibilidade. Preenchendo os critérios de inclusão, o paciente foi convidado a participar do estudo; o mesmo recebeu o TCLE para a apreciação e teve dirimidas quaisquer dúvidas concernentes à sua participação na pesquisa. Para o presente estudo, seguiram-se os preceitos estabelecidos pela resolução 422/12 do Ministério da Saúde.

No dia da cirurgia, os pacientes foram alocados no grupo de tratamento. Envelopes opacos feitos a partir de uma tabela de números randômicos foram preparados e os mesmos abertos para determinar sequencialmente o grupo de tratamento dos pacientes

Houve cegamento dos pacientes e dos investigadores que analisaram os desfechos da pesquisa. Os mesmos não foram informados a qual grupo 0 paciente estava alocado; desta forma, não houve como o investigador influenciar na seleção dos pacientes. 


\subsection{Tratamento}

As estratégias utilizadas foram baseadas em estudos prévios com pacientes cirúrgicos para determinação da eficácia do fármaco DDAVP quanto de sua ação hemostática ${ }^{9,29,30,32}$.

No período após circulação extracorpórea (CEC) e imediatamente após a administração da protamina, para reversão dos efeitos da heparina, foi realizada a intervenção do estudo. Neste momento, o paciente era randomizado para um dos dois tratamentos:

Grupo desmopressina: foi administrado de forma profilática a desmopressina na dose de $0,3 \mu \mathrm{g} / \mathrm{kg}$ de peso do paciente diluído em $100 \mathrm{ml}$ de soro fisiológico a 0,9\% em 15 minutos.

Grupo controle: recebia $100 \mathrm{ml}$ de soro fisiológico a $0,9 \%$ infundidos em 15 minutos.

As soluções do estudo foram preparadas pela equipe de enfermagem não cega em bolsas idênticas, identificadas apenas com o nome do paciente, nome do estudo e número de randomização.

Caso houvesse, durante a infusão da desmopressina, hipotensão arterial acentuada (principal reação adversa da administração da desmopressina), a infusão seria administrada de forma mais gradual, em 30 minutos. Caso mantivesse a hipotensão arterial ou quaisquer outras reações adversas que pudessem estar relacionadas com a administração da desmopressina, a sua infusão seria imediatamente suspensa e medidas gerais para restaurar as condições hemodinâmicas do doente seriam prontamente executadas pelo anestesiologista assistente e o paciente seria retirado do 
presente estudo. Não houve, nenhum tipo de intercorrência relacionada com a infusão do fármaco.

\subsection{Desenho do estudo}

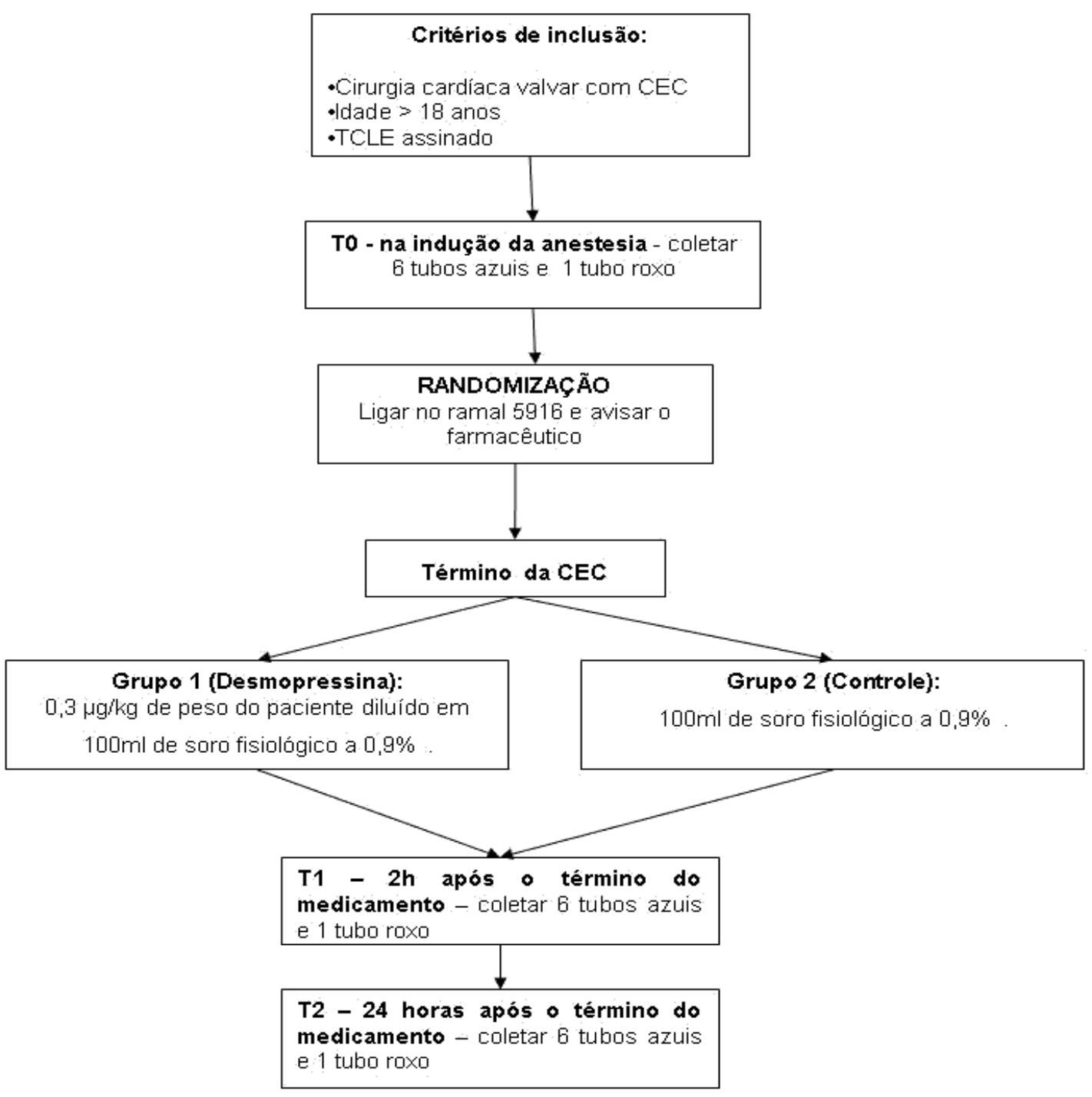

Figura 1- Fluxograma do desenho do estudo 


\subsection{Coleta dos exames laboratoriais}

Os exames laboratoriais foram coletados pelo médico anestesiologista assistente ou pela equipe de enfermagem no centro de terapia intensiva pós cirúrgica. As coletas foram realizadas em três tempos:

T0: na indução da anestesia

T1: duas horas após a administração profilática da desmopressina ou placebo.

T2: 24 horas após a administração da desmopressina.

\subsection{Procedimento cirúrgico e admissão na unidade de terapia intensiva}

A medicação pré-anestésica padronizada consistiu na administração de bromazepam $3 \mathrm{mg}$ via oral 8 horas antes da cirurgia. Todos os pacientes foram monitorizados com cardioscópio contínuo de cinco derivações, oximetria de pulso, analisador de gases, sonda vesical de demora, pressão arterial invasiva em artéria radial, termômetro esofágico e cateter venoso central ou cateter de artéria pulmonar inserido pela veia jugular interna ou pela veia subclávia, quando aplicável.

A indução da anestesia foi realizada com etomidato $0,2 \mathrm{mg} / \mathrm{Kg}$, midazolam $0,05 \mathrm{mg} / \mathrm{Kg}$, fentanil 3 a $5 \mu \mathrm{g} / \mathrm{Kg}$ e pancurônio $0,1 \mathrm{mg} / \mathrm{Kg}$ como bloqueador neuromuscular, todos por via intravenosa. Após a intubação orotraqueal, o paciente foi mantido em ventilação controlada com fração inspirada de oxigênio $\left(\mathrm{FiO}_{2}\right)$ suficiente para manter saturação arterial de 
oxigênio acima de 95\%, volume corrente de $6 \mathrm{ml} / \mathrm{kg}$, pressão positiva no final da expiração ("PEEP") de 5 a 8 mmHg em sistema circulatório valvular com absorvedor de $\mathrm{CO}_{2}$. A profilaxia antibiótica foi realizada com cefuroxima $1,5 \mathrm{~g}$ à indução anestésica e dose adicional de 750 mg após 4 horas do início do procedimento cirúrgico por via intravenosa. Todos os pacientes receberam terapia anti-fibrinolítica com ácido épsilon aminocapróico 100 mg/kg à indução anestésica e mantido por durante todo o procedimento cirúrgico em infusão contínua em 50mg/kg/h.

A administração de fármacos inotrópicos e vasoativos foi guiada por parâmetros hemodinâmicos, de acordo com o protocolo específico da instituição.

A equipe de cirurgiões foi homogênea (quatro cirurgiões da equipe cirúrgica especializada em doença valvar, que garantiram a técnica de inserção e técnica cirúrgica padronizadas).

A anticoagulação foi realizada com dose inicial de heparina $500 \mathrm{U} / \mathrm{Kg}$ (unidades/kilograma) administrada em veia central antes do início da CEC, com um tempo de coagulação ativado (TCA) necessariamente acima de 400 segundos. Heparina adicional poderia ser utilizada durante a CEC para alcançar o alvo do TCA.

Uma bomba centrífuga (Medtronic Biomedicus, Minneapolis, MN) foi utilizada para CEC. Circuito extracorpóreo contendo um oxigenador de membrana microporoso de polipropileno (Braile, São José do Rio Preto, SP, Brasil) integrado a um reservatório venoso de cardiotomia. O prime do oxigenador foi constituído de $1500 \mathrm{~mL}$ de solução de Ringer com lactato, manitol a $20 \%$ na dose de $1 \mathrm{~g} / \mathrm{Kg}$ e $10000 \mathrm{U}$ de heparina. Durante a CEC, a 
temperatura corporal foi mantida entre 28 e $32 \stackrel{\circ}{\circ}$ (graus Celsius). Durante a hipotermia, o manuseio dos gases sanguíneos foi realizado através da regulação "alfa-stat" na gasometria arterial. Durante a CEC, o fluxo contínuo foi mantido entre 2 a 2,4 L/min/m² e pressão arterial média entre 50 e $80 \mathrm{mmHg}$. A proteção miocárdica foi realizada por meio de cardioplegia cristalóide anterógrada intermitente. A cardioplegia foi repetida a cada 20 a 30 minutos. Ao final da CEC, a heparina foi revertida através da administração de protamina em uma relação de $1: 1$, e protamina adicional poderia ser administrada até alcançar os níveis iniciais do TCA.

Sangramento, associado a distúrbios da coagulação, foram tratados de acordo com o protocolo institucional para tratamento de coagulopatias. Durante o ato cirúrgico, os níveis de glicemia foram mantidos entre 140 e $180 \mathrm{mg} / \mathrm{dL}$ e, se necessário, insulina regular intravenosa contínua era administrada.

Todos os pacientes foram transferidos para a UTI cirúrgica após o procedimento cirúrgico, antes da recuperação da anestesia e sob ventilação mecânica. Os pacientes foram extubados na UTI cirúrgica, após recuperação

completa da anestesia, estando estáveis hemodinamicamente, com a temperatura controlada e gases arteriais dentro da normalidade. Os pacientes receberam alta da UTI quando preenchiam critérios de alta, de acordo com protocolo específico da instituição.

\subsection{Avaliação dos dados clínicos e demográficos, e coleta de dados}

Um instrumento de coleta de dados foi criado para obtenção e organização das informações exigidas pelo estudo (Anexo E). 
Após a inclusão, foram obtidos dados clínicos e demográficos de cada paciente. Informação necessária para avaliação de gravidade foi obtida, sendo calculados os índices EuroSCORE I (critério de inclusão) aditivo e logístico (calculados usando a versão online disponível no site: www.euroscore.org).

Dados pré-operatórios: Foram obtidos por meio de anamnese e avaliação do prontuário dos pacientes dados sobre a história clínica, antecedentes pessoais, comorbidades, medicações prévias e dados antropométricos. Exames laboratoriais coletados na admissão ou até 12 horas antes da cirurgia eram avaliados (hemoglobina, hematócrito, glicemia, creatinina, TTPa, TP, INR e contagem de plaquetas). O ecocardiograma préoperatório foi analisado para registro da função ventricular esquerda.

Dados intraoperatórios: Foram coletados hemoglobina, hematócrito, contagem de plaquetas, gasometria arterial e venosa, cálcio iônico, TCA, TTPa, INR, TP, fibrinogênio, D-dímero, fator VIllc, Fator de von Willebrand, agregação plaquetária com ADP e adrenalina e Tromboelastograma (ROTEM®) com os testes INTEM, EXTEM e FIBTEM de testes laboratoriais. Dados clínicos como, tipo de procedimento cirúrgico realizado, tempos de anestesia, cirurgia e CEC, diurese, temperatura esofágica, balanços hídrico e sanguíneo, utilização de drogas inotrópicas e vasoativas, infusão de líquidos, terapia hemostática e transfusão sanguínea foram coletados no início da cirurgia (T0) e duas horas após a administração do DDAVP ou placebo (T1). Eventos clinicamente significativos tais como sangramento e instabilidade hemodinâmica importantes também foram coletados. 
Dados pós-operatórios: Foram coletados hemoglobina, hematócrito, contagem de plaquetas, gasometria arterial e venosa, cálcio iônico, TCA, TTPa, INR, TP, fibrinogênio, D-dímero, fator VIllc, Fator de von Willebrand, agregação plaquetária com $\mathrm{ADP}$ e adrenalina e tromboelastograma (ROTEM®) com os testes INTEM, EXTEM e FIBTEM de testes laboratoriais após 24h do início da cirurgia (T2). Débito sanguíneo nos drenos cirúrgicos, balanço hídrico e sanguíneo, transfusão sanguínea e terapia hemostática eram avaliados no pós- operatório imediato, 24h e 48h após a admissão na UTI.

Durante o período de internação hospitalar, foram registrados dados sobre transfusão de hemocomponentes, medicações administradas, tempo de ventilação mecânica, tempo de internação em UTI e hospitalar, infecção, complicação neurológica (AVC) ou cardiovascular (IAM) e necessidade de diálise e/ou intervenção cirúrgica, ocorrência de complicações clínicas e óbito.

Após a alta hospitalar, foi feito contato telefônico com os pacientes ao final dos 30 dias de pós-operatório, para obtenção de informações sobre intercorrências clínicas, reinternações hospitalares e óbito.

\subsection{Definição das complicações clínicas e desfechos}

Sangramento: Foi definido como clinicamente significativo quando as perdas sanguíneas excediam 100 a $300 \mathrm{~mL} / \mathrm{h}$, após admissão na UTI ${ }^{34}$. A reoperação era indicada caso houvesse sangramento de $500 \mathrm{~mL}$ na primeira hora de admissão; $300 \mathrm{~mL}$ por duas horas consecutivas ou quando a perda sanguínea fosse maior que $1 \mathrm{~L}$ nas primeiras oito horas de pós operatório ${ }^{35}$. 
Insuficiência renal aguda (IRA): Definida através da classificação de AKIN (Acute Kidney Injury Network), que caracteriza a lesão renal aguda como uma redução abrupta (em 48 horas) na função renal, caracterizada por elevação absoluta da creatinina maior ou igual a $0,3 \mathrm{mg} / \mathrm{dL}(\geq 26,4 \mu \mathrm{mol} / \mathrm{L})$; aumento percentual da creatinina maior ou igual a $50 \%$ (1,5 vezes a creatinina basal); ou redução do débito urinário para menor que $0,5 \mathrm{ml} / \mathrm{kg} / \mathrm{h}$ por seis horas ou mais ${ }^{36}$. A necessidade de diálise foi baseada em indicação clínica e avaliação laboratorial diária.

Acidente vascular cerebral (AVC): Déficit neurológico novo, reversível ou não, acompanhado de início abrupto que não se resolveu em 24 horas, causado por um distúrbio de suprimento sanguíneo cerebral compatível à exames de imagem (tomografia computadorizada ou ressonância nuclear magnética) ${ }^{37}$.

Infarto agudo do miocárdio (IAM): Foi considerado quando houve elevação de enzimas cardíacas (CKMB 10 vezes superior ao valor de referência e/ou troponina I a 5 vezes superior ao valor de referência, durante as primeiras 48 horas após a cirurgia, associado a um dos seguintes critérios: aparecimento de nova onda $Q$ patológica, oclusão arterial coronariana nova documentada angiograficamente, ou evidência de déficit segmentar novo ${ }^{38}$.

Infecção: Infecções novas, sepse e choque séptico. Pneumonia foi diagnosticada se estivesse presente aparecesse infiltrado pulmonar novo, persistente, ou progressivo à radiografia de tórax associado a pelo menos , 2 
dos seguintes critérios: temperatura maior ou igual a $38^{\circ} \mathrm{C}$; contagem de leucócitos maior que 12000 células $/ \mathrm{mm}^{3}$ ou menor que 3000 células $/ \mathrm{mm}^{3}$; ou secreção endotraqueal purulenta. A infecção de corrente sanguínea foi definida por isolamento do mesmo microorganismo em hemocultura periférica e na cultura de ponta do cateter removido. Infecção de ferida operatória definida pela presença de hiperemia e secreção purulenta local, associada ou não à infecção sistêmica ${ }^{39}$.

Choque séptico: Pacientes que apresentem critérios da síndrome da resposta inflamatória sistêmica, apresentando um foco infeccioso suspeito ou confirmado, associado à hipotensão refratária com necessidade de fármaco vasopressor ${ }^{40}$.

Mortalidade: Óbito durante a internação da cirurgia ou óbito ocorrido após a alta hospitalar até 30 dias após o procedimento, exceto se a causa da morte não seja claramente relacionada à cirurgia.

\subsection{Descrição dos testes laboratoriais}

Agregação Plaquetária por transmitância de Luz

O teste de Agregação Plaquetária avalia a função plaquetária in vitro por sistema óptico ou turbidimétrico. As amostras foram coletadas em tubo com citrato de sódio $3,2 \%$ e centrifugadas por 4 a 6 minutos em 1000 a 1500 rpm para obtenção de plasma rico em plaquetas (PRP). O equipamento AggRAM (Helena Laboratories) detecta a transmissão luminosa através do plasma citratado rico em plaquetas em suspensão. À medida que as plaquetas se 
agregam por adição de um agente agregante (Adenosina 5'difosfato, Adrenalina e Ácido Araquidônico), ocorre diminuição da turbidez e um aumento proporcional da transmissão de luz detectado por uma célula fotoelétrica e registrado sob curva de agregação plaquetária por um registrador acoplado ao equipamento. Os resultados são expressos em amplitude de agregação, estabelecida para cada agente agregante ou qualitativamente (normoagregante, hipoagregante ou hiperagregante). O teste é realizado dentro de 4 horas após a coleta das amostras em temperatura ambiente.

\section{Fator VIII}

As amostras foram coletadas em tubo com anticoagulante citrato de sódio a 3,2\% e centrifugadas por 10 minutos a 3000 rpm. As dosagens foram realizadas em equipamento automatizado (DestinyMaxTM, Ireland) e kit específico (TriniCLOT) por metodologia óptica. O resultado é expresso em atividade (\%), faixa de normalidade de $50-150 \%$.

\section{FvW}

O FvW é um polímero protéico plasmático dosado em plasma citratado e congelado através de teste imunoturbidimétrico. Valores de referência (50$160 \%$ ). 
Tromboelastometria

A tromboelastometria avalia a dinâmica da formação do coágulo, ou seja, o processo global da coagulação com a participação das plaquetas, células sanguíneas e proteínas da coagulação. A amostra é coletada em tubo com anticoagulante citrato de sódio a 3,2\% e processada em até 30 minutos após a coleta. Nesta pesquisa, foi utilizado o método ROTEM (tromboelastometria rotacional), com os seguintes reagentes: INTEM, EXTEM, FIBTEM.

A análise pelos sistemas ROTEM e os seus parâmetros mais importantes incluem (parâmetros adicionais podem ser calculados assim como os derivativos da curva):

Tempo de coagulação (CT): determina os níveis de anticoagulação ou deficiência de fatores de coagulação; valores de referência em segundos. Com o INTEM o valor de referência (100-240 segundos); EXTEM (38-79 segundos).

Tempo de formação do coágulo (CFT): determina a qualidade do coágulo e sua consistência; valor de referência com INTEM (30-110 segundos); EXTEM (34-159 segundos).

Ângulo alfa: determina se o paciente apresenta hipercoagulabilidade ou hipocoagulabilidade; valores de referência com o INTEM (70-83 graus); EXTEM (63-83 graus).

Dureza máxima do coágulo (MCF): determina a interação e a participação da fibrina e das plaquetas; valores de referência com o INTEM e EXTEM (50-72 mm). 
Lise máxima ( $\mathrm{ML})$ : determina o porcentual de lise do coágulo e consequentemente identifica a hiperfibrinólise; valores de referência $(<15 \%)$ para INTEM e EXTEM.

EXTEM : avalia o fator tecidual, deficiências dos fatores da coagulação, desordens de polimerização da fibrina e desordens plaquetárias;

FIBTEM: avalia o fibrinogênio e o inibidor de plaquetas;

INTEM: avalia deficiências dos fatores da coagulação, desordens de polimerização da fibrina e desordens plaquetárias.

\section{Tempo de Coagulação Ativado (TCA)}

Utilizou-se o aparelho de modelo Cascade POC da Helena Laboratories (Beaumont - Texas - USA). Valores de referência (80-120 segundos).

\section{Tempo de Protrombina (TP)}

O teste consiste na adição de tromboplastina (fator tecidual) e posterior mensuração do tempo de coágulo. As amostras coletadas em tubos contendo citrato de sódio a 3,8\% são centrifugadas a 3.000 rpm por 10 minutos. 0 plasma obtido é processado em equipamento TcoagDestinyMax, Ireland e kit específico (TcoagTriniCLOT). Metodologia coagulométrica (ótica ou mecânica). Os resultados do TP são expressos em segundos, atividade da protrombina e relação normatizada internacional $(\mathrm{RNI})$. O cálculo do RNI é obtido através da divisão do TP do paciente pelo TP do controle normal, elevado ao ISI (índice de 
normatização internacional). O ISI define a sensibilidade da tromboplastina, sendo essencial a padronização próxima de 1.0, com variação em até 1.2. Valor de referência (11,0-14,6 segundos)

Tempo de Tromboplastina Parcial Ativado (TTPA)

O TTPA é realizado por adição de tromboplastina parcial a cefalina, substância carregada negativamente e ativador da via intrínseca. O cloreto de cálcio é adicionado e o tempo necessário para formar o coágulo é medido. O teste é realizado por método coagulométrico em equipamento TcoagDestinyMaxTM, Ireland. Os resultados são expressos em segundos e o cálculo da relação do TTPA do paciente pelo TTPA do controle normal. Valores de referência (25-39 segundos).

Contagem de plaquetas

O sangue total é coletado em tubo com anticoagulante EDTA e processado por método eletrônico automatizado (ADVIA 120, Siemens), baseado na medição da impedância elétrica. Valores de referência (150000$\left.450000 \mathrm{~mm}^{3}\right)$.

\subsection{Análise estatística}

Para o cálculo amostral, foram definidos: alfa ( $\alpha$ ) de $5 \%$, poder de $80 \%$, incidência de $60 \%{ }^{9}$ ao sangramento pós-operatório e redução absoluta 
da incidência de $30 \%{ }^{40}$, chegando a um n de 49 pacientes para cada grupo (98 pacientes no total). Adicionando 10\% por possíveis perdas, o tamanho amostral final é de 108, sendo 54 pacientes em cada grupo.

Os dados foram analisados com o auxílio do software GraphPad Prism 6.0 (GraphPad Software, CA, USA) e os resultados foram expressos como média \pm desvio padrão para as variáveis com distribuição normal; utilizou-se mediana e os valores de percentis $25 \%$ e $75 \%$ para as variáveis que não apresentaram distribuição normal.

Variáveis contínuas foram comparadas com o teste t de Student (para as variáveis com distribuição normal) ou teste de Mann-Whitney (para as variáveis sem distribuição normal). As variáveis categóricas foram analisadas de acordo com o teste exato de Fisher ou Qui-quadrado. Foram considerados estatisticamente significantes os valores de $p<0,05$ e todos os testes foram bicaudais. 


\subsection{População do Estudo}

Foram avaliados 780 pacientes internados no Instituto do Coração do Hospital das Clínicas da Faculdade de Medicina da Universidade de São Paulo (InCor - HCFMUSP), entre fevereiro de 2015 e novembro de 2016 para a inclusão no estudo.

Destes, 108 indivíduos preencheram os critérios de inclusão, não apresentaram nenhum critério de exclusão, assinaram o TCLE e foram incorporados ao estudo. Sendo que 54 foram alocados para o grupo DDAVP e 54 pacientes foram alocados para o grupo controle. Não houve perda de seguimento em nenhum dos grupos durante o período do estudo (Figura 2). 


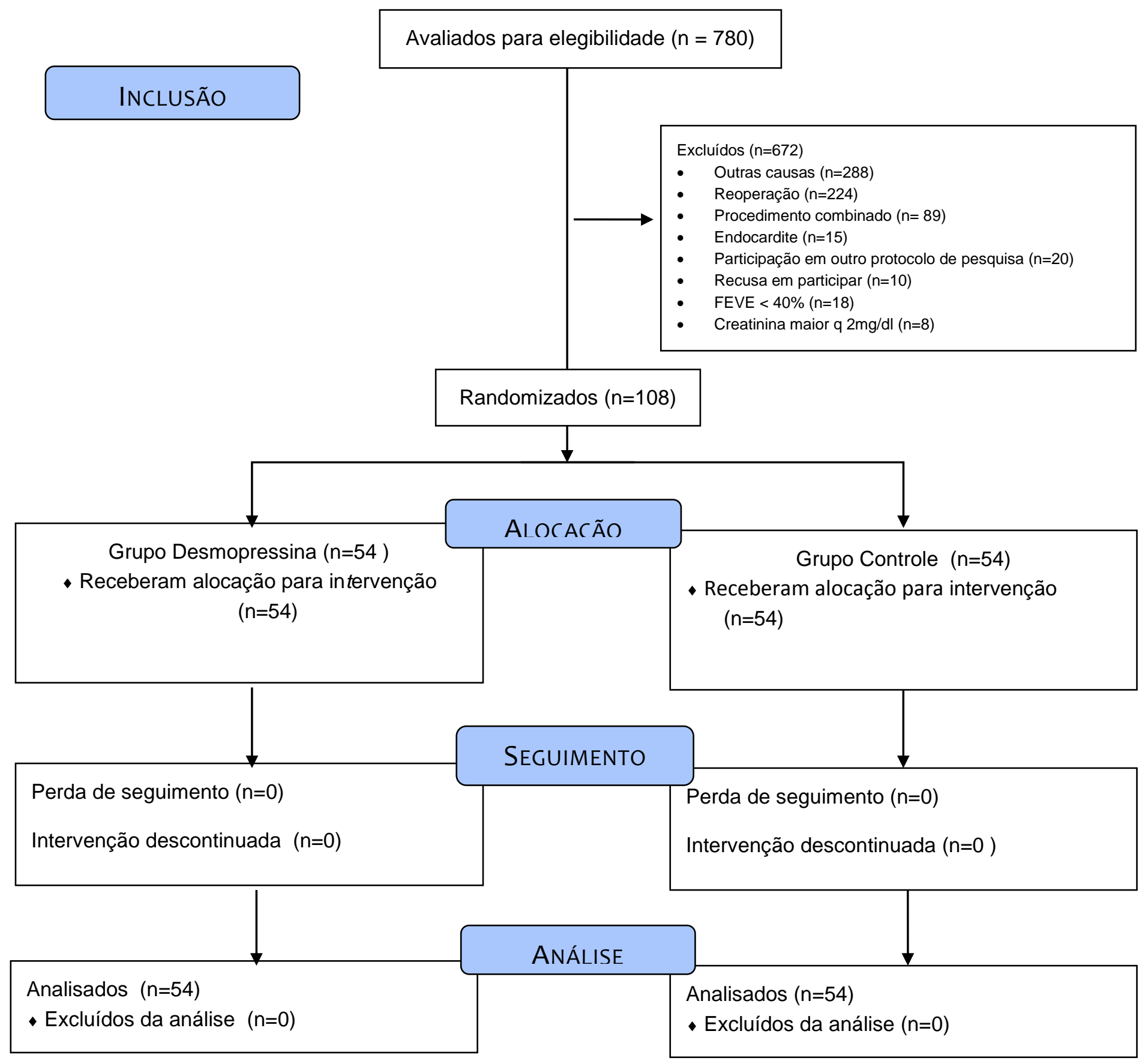

Figura 2- Fluxograma da população do estudo. 
Os grupos foram homogêneos no que se referem às características pré-operatórias (demográficas, clínicas e laboratoriais) (tabela 1). A idade média foi de 50,0 $(44,7$ - 60,0) anos no grupo desmopressina e de 52,0 $(40,5$ $65,0)$ anos no grupo controle $(P=0,911)$; houve predomínio do sexo feminino (59,3\% vs. $64,8 \%$, respectivamente; $P=0,551)$, em ambos os grupos. O IMC dos pacientes foi $25,3(22,4$ - 27,7) no grupo desmopressina e 24,1 (22,6 $27,7) \mathrm{kg} / \mathrm{m}^{2}$ no grupo controle $(P=0,647)$.

Dentre as comorbidades, a insuficiência cardíaca (IC) apresentou-se em $94,4 \%$ no grupo desmopressina vs. $92,4 \%$, no grupo controle $(P=0,677)$; Hipertensão Arterial Pulmonar em $20,4 \%$ vs. $33,3 \% \quad(P=0,128)$; diabetes mellitus em $5,6 \%$ vs. $7,46 \%$ ( $P=0,695)$; e hipotireoidismo em $7,4 \%$ vs. $1,8 \%$ $(P=0,364)$, respectivamente. Quanto à avaliação de risco pré-operatório, a maioria dos pacientes apresentou predomínio da classe funcional III da New York Heart Association em ambos os grupos (55,7\% vs. 46,9\%). A FE 63,0 $(57,7-67,2)$ vs. $63,0(59,0-67,0)(P=0,761)$ e o EuroSCORE [2 (1-3) vs. $3(1-$ 5) $(P=0,039)]$ entre os grupos desmopressina e controle.

Os valores laboratoriais de hemoglobina $[13,7(12,8-14,6)$ vs. 13,9 $(13,3-14,9) \mathrm{g} / \mathrm{dL}, \mathrm{P}=0,756)$, contagem de plaquetas [221 (176 - 244) vs. 218 $\left.(181-249) \times 10^{3} / \mathrm{mm}^{3}, P=0,918\right]$, TP $[11,6(11,2-12,5)$ vs. $11,6(11,0-12,1)$ segundos, $\mathrm{P}=0,104)$, TTPa $[29,9(27,0$ - 32,5) vs. $28,5(26,8-30,3)$ segundos, $P=0,05)$ e INR $[1,1(1,0-1,1)$ vs. $1,1(1,0-1,1)$ segundos, $P=0,650]$, apresentaram-se homogêneos em relação aos grupos desmopressina e controle, respectivamente. 
Tabela 1- Características pré-operatórias (demográficas, clínicas e laboratoriais) dos pacientes.

\begin{tabular}{|c|c|c|c|c|}
\hline Variável & Desmopressina(54) & Controle (54) & $\mathrm{P}$ & \\
\hline Idade (anos) & $55,0(44,7-60,0)$ & $52,0(40,5-65,0)$ & 0,911 & \\
\hline Sexo (Masculino) $-\mathrm{n}(\%)$ & $22(40,7)$ & $19(35,2)$ & 0,551 & $*$ \\
\hline $\mathrm{HAS}-\mathrm{n}(\%)$ & $33(61,1)$ & $22(40,7)$ & 0,034 & $*$ \\
\hline Tabagismo - n (\%) & $2(3,7)$ & $5(9,2)$ & 0,437 & $* *$ \\
\hline $\mathrm{IC}-\mathrm{n}(\%)$ & $51(94,4)$ & $49(92,4)$ & 0,677 & $*$ \\
\hline Índice de massa corpórea, $\mathrm{kg} / \mathrm{m}^{2}$ & $25,3(22,4-27,7)$ & $24,1(22,6-27,7)$ & 0,647 & \\
\hline $\operatorname{FEVE}(\%)$ & $63,0(57,7-67,2)$ & $63,0(59,0-67,0)$ & 0,761 & \\
\hline \multicolumn{5}{|c|}{ Avaliação laboratorial no pré-operatório } \\
\hline Hemoglobina (g/dL) & $13,7(12,8-14,6)$ & $13,9(13,3-14,9)$ & 0,756 & \\
\hline Plaquetas $\left(1.000 / \mathrm{mm}^{3}\right)$ & $212(176-244)$ & $215(181-249)$ & 0,918 & \\
\hline $\mathrm{TP}(\mathrm{s})$ & $11,6(11,2-12,5)$ & $11,6(11,0-12,1)$ & 0,104 & \\
\hline $\mathrm{TTPa}(\mathrm{s})$ & $29,9(27,0-32,5)$ & $28,5(26,8-30,3)$ & 0,050 & \\
\hline INR & $1,1(1,0-1,1)$ & $1,1(1,0-1,1)$ & 0,650 & \\
\hline \multicolumn{5}{|l|}{ Co-morbidades - n (\%) } \\
\hline Diabetes mellitus & $3(5,6)$ & $4(7,4)$ & 1,000 & $* *$ \\
\hline IAM prévio & $4(7,4)$ & $0(0)$ & 0,118 & $* *$ \\
\hline Anticoagulantes & $20(37)$ & $19(35)$ & 0,841 & \\
\hline Antiagregantes plaquetários & $3(5,6)$ & $3(5,3)$ & 1,000 & $* *$ \\
\hline Hipertensão arterial pulmonar & $11(20,4)$ & $18(33,3)$ & 0,128 & \\
\hline Hipotireodismo & $4(7,4)$ & $1(1,8)$ & 0,364 & $* *$ \\
\hline EuroSCORE & $2(1-3)$ & $3(1-5)$ & 0,039 & \\
\hline \multicolumn{5}{|l|}{ ICC classe funcional (NYHA) } \\
\hline I & $2(3,8)$ & $3(6,1)$ & 0,271 & $*$ \\
\hline II & $21(40,4)$ & $20(40,8)$ & & \\
\hline III & $29(55,7)$ & $23(46,9)$ & & \\
\hline IV & $0(0)$ & $3 \quad(6,1)$ & & \\
\hline
\end{tabular}

* Teste de qui-quadrado, ** Teste exato de Fisher, teste $t$-Student, teste de Mann-Whitney; $\mathrm{p}<0,05$ foi considerado significante

Variáveis com distribuição normal são apresentadas como média \pm desvio padrão

Variáveis que não tem distribuição normal são apresentadas como mediana, percentis 25 e 75 por cento (entre parênteses); $\mathrm{n}(\%)$ = valor absoluto e percentual dos pacientes

EuroScore = "European System for Cardiac Operative Risk Evaluation"; NYHA = "New York Heart Association" 
Quanto às características intraoperatórias, não houve diferença entre os grupos desmopressina e controle, no que concerne ao tempo cirúrgico, tempo de circulação extracorpórea e valores do TCA inicial e pós administração de protamina. O balanço hídrico, balanço sanguíneo e a diurese intraoperatórios seguiram o mesmo padrão de homogeneidade entre os dois grupos, assim como a utilização de fármacos inotrópicos e vasoativos administrados durante a cirurgia (tabela 2).

Tabela 2- Características intra-operatórias (clínicas e laboratoriais) dos pacientes.

\begin{tabular}{llll}
\hline Variável & Desmopressina (54) & Controle (54) & $\mathrm{P}$ \\
\hline Tempo de cirurgia (mim) & $257(227-286)$ & $265(237-286)$ & 0,461 \\
Tempo de CEC (mim) & $89,9 \pm 26,5$ & $81,2 \pm 22,7$ & 0,068 \\
TCA Inicial (s) & $116(108-135)$ & $116(108-129)$ & 0,663 \\
TCA pós Protamina & $114(103-126)$ & $112(108-128)$ & 0,707 \\
Balanço Hídrico (mL) & $2475 \pm 960$ & $2598 \pm 913$ & 0,498 \\
Balanço Sanguineo $(\mathrm{mL})$ & $-300,0(-350,0 /-147,5)$ & $-242,0(-314,0 /-147,5)$ & 0,224 \\
Diurese (mL) & $1400(1100-1800)$ & $1550(1100-2000)$ & 0,464 \\
Norepinefrina & $11(20,4)$ & $13(24,1)$ & $0,643 *$ \\
Nitroglicerina & $6(11,1)$ & $4(7,4)$ & $0,526 * *$ \\
Nitroprussiato & $31(57,4)$ & $29(53,7)$ & $0,698 *$ \\
Epinefrina & $7(12,9)$ & $4(7,4)$ & $0,339 * *$
\end{tabular}

Teste de $t$-Student, Mann-Whitney; $\mathrm{p}<0,05$ foi considerado significante

Variáveis com distribuição normal são apresentadas como média \pm desvio padrão

Variáveis que não tem distribuição normal são apresentadas como mediana, percentis 25 e 75 por cento (entre parênteses); $\mathrm{n}(\%)$ = valor absoluto e percentual dos pacientes

* Teste de qui-quadrado, ** Teste exato de Fisher

Quanto ao tipo de cirurgia valvar, houve predomínio de cirurgias da valva mitral $(57,4 \%$ vs. $50,9 \%, P=0,589)$ seguida de cirurgias na valva aórtica $(29,7 \%$ vs. $37,8 \%, P=0,524)$ sem diferenças entre os dois grupos (tabela 3$)$. 
Tabela 3- Tipos de cirurgia valvar em relação à intervenção.

\begin{tabular}{lllll}
\hline Variável & Desmopressin (54) & Controle (53) & $\mathrm{P}$ & \\
\hline Tipo de cirurgia Valvar & $31(57,4)$ & $27(50,9)$ & 0,589 & $*$ \\
Mitral & $16(29,7)$ & $20(37,8)$ & $0,524^{\#}$ & $*$ \\
Aórtico & $1(1,8)$ & $0(0)$ & & \\
Tricúspide & $5(9,3)$ & $6(11,3)$ & \\
Mitral + Aórtico & $1(1,8)$ & $0(0)$ & \\
Mitral + Tricúspide & * & & \\
Teste de qui-quadrado, ** Teste exato de Fisher; p<0,05 foi considerado significante \\
n $(\%)=$ valor absoluto e percentual dos pacientes. \# comparação entre o grupo mitral e aórtico. \\
Dados de 1 paciente estão faltando.
\end{tabular}

\subsection{Intervenção}

\subsubsection{Análise Laboratorial}

Estão representados, na tabela 4, os valores dos principais exames laboratoriais do presente estudo. Foram realizadas coletas em três tempos estabelecidos na metodologia: T0 (início do procedimento cirúrgico), T1 (2h após a administração da desmopressina ou placebo) e T2 (24h após a administração da desmopressina ou placebo). A análise laboratorial mostra que não houve diferença significativa entre os valores da saturação venosa de oxigênio (SvO2) e da hemoglobina entre os dois grupos (desmopressina e controle) nos tempos de coleta. Entretanto, a dosagem do lactato sanguíneo apresentou diferença entre os grupos do estudo nos momentos T1 [24,5 (18,7 $40,2)$ vs. $20,0(14,0-28,0) \mathrm{mg} / \mathrm{dL}, P=0,016]$ e T2 $[24,5(17,0-33,2)$ vs. 18,0 $(14,7$ - 27,5) $\mathrm{mg} / \mathrm{dL}, P=0,033$ ] (tabela 4). 
Exames laboratoriais que classicamente avaliam a coagulação sanguínea, tais como INR, TTPA, Fibrinogênio e D-dímero não apresentaram diferenças em nenhum dos tempos de coleta entre os grupos desmopressina e controle. Todavia, o TP $[14,1(12,9$ - 15,2) vs. $13,4(12,1-14,5)$ segundos, $\mathrm{P}=0,007]$ no Tempo 24h (T2), apresentou diferença significativa entre os grupos, respectivamente (tabela 4).

A avaliação da função plaquetária, realizada através do teste de agregação plaquetária com adição do $A D P$ ou da adrenalina como agentes inicializadores do fenômeno da agregação, não mostrou diferenças relevantes entre os dois grupos do estudo (tabela 4).

Os níveis sanguíneos do Fator VIII no tempo T1 (263,5 $\pm 62,9$ vs. 232,3 $\pm 66,7, P=0,015)$ foram significativamente diferentes entre os dois grupos (desmopressina e controle), respectivamente (tabela 4).

Tabela 4- Análise laboratorial.

\begin{tabular}{|c|c|c|c|}
\hline Variável & Desmopressina (54) & Controle (54) & $\mathrm{P}$ \\
\hline \multicolumn{4}{|l|}{$\mathrm{SvO} 2(\%)$} \\
\hline Т 0 & $74,5 \pm 9,1$ & $75,0 \pm 9,1$ & 0,797 \\
\hline $\mathrm{T} 1$ & $82,7 \pm 8,0$ & $82,3 \pm 6,6$ & 0,771 \\
\hline Т 2 & $70,8 \pm 9,4$ & $72,7 \pm 9,1$ & 0,286 \\
\hline \multicolumn{4}{|l|}{ Lactato (mg/dL) } \\
\hline T 0 & $14(10-17)$ & $13(10-16)$ & 0,182 \\
\hline $\mathrm{T} 1$ & $24,5(18,7-40,2)$ & $20,0(14,0-28,0)$ & 0,016 \\
\hline T 2 & $24,5(17,0-33,2)$ & $18,0(14,7-27,5)$ & 0,033 \\
\hline \multicolumn{4}{|l|}{ Hemoglobina (g/dL) } \\
\hline Т 0 & $13,4 \pm 1,5$ & $13,0 \pm 1,7$ & 0,182 \\
\hline $\mathrm{T} 1$ & $11,6 \pm 1,4$ & $11,9 \pm 1,6$ & 0,281 \\
\hline T 2 & $12,1 \pm 1,8$ & $11,9 \pm 1,6$ & 0,530 \\
\hline
\end{tabular}


Tabela 4- Análise laboratorial (Continuação)

\begin{tabular}{rlll}
\hline Variável & Desmopressina (54) & Controle (54) & P \\
\hline TTPA (s) & & & \\
T 0 & $30,0(28,0-32,3)$ & $29,0(27,2-30,9)$ & 0,059 \\
T 1 & $29,0(27,6-31,8)$ & $30,2(26,9-32,4)$ & 0,552 \\
T 2 & $29,7(27,1-33,4)$ & $28,8(27,3-30,4)$ & 0,117
\end{tabular}

$\mathrm{TP}(\mathrm{s})$

$\begin{array}{llll}\text { T } 0 & 12,4 \pm 0,8 & 12,5 \pm 1,0 & 0,781 \\ \text { T } 1 & 14,2 \pm 1,5 & 13,6 \pm 1,8 & 0,119 \\ \text { T } 2 & 14,1(12,9-15,2) & 13,4(12,1-14,5) & 0,007\end{array}$

INR

$\begin{array}{cccc}\text { T } 0 & 1,13 \pm 0,07 & 1,12 \pm 0,09 & 0,712 \\ \text { T } 1 & 1,34 \pm 0,14 & 1,24 \pm 0,16 & 0,115 \\ \text { T } 2 & 1,3(1,2-1,4) & 1,2(1,1-1,3) & 0,169\end{array}$

D - dímero (ng/L)

Fibrinogênio (mg/dL)

$\begin{array}{rlll}\text { T } 0 & 301,4 \pm 65,6 & 306,5 \pm 54,4 & 0,668 \\ \text { T } 1 & 245,2 \pm 70,8 & 240,7 \pm 51,7 & 0,731 \\ \text { T } 2 & 426,1 \pm 132,4 & 393,3 \pm 65,1 & 0,182\end{array}$

Agregação ADP

T 0

$\mathrm{T} 1$

T 2

Agregação Adrenalina

T 0
T 1
T 2

Fator VIII (\%)

$$
\begin{aligned}
& 73,0(53,5-83,4) \\
& 64,5 \pm 15,6 \\
& 63,4 \pm 16,4
\end{aligned}
$$$$
41,4(20,6-79,8)
$$$$
37,2 \pm 19,2
$$$$
37,8 \pm 13,0
$$$$
\text { 148,0 (116,0 - 184,5) }
$$$$
263,5 \pm 62,9
$$$$
145,0(105,0-204,3)
$$$$
232,3 \pm 66,7
$$

0,922 0,015 
Tabela 4- Análise laboratorial

\begin{tabular}{lllll}
\hline Variável & & Desmopressina (54) & Controle (54) & P \\
\hline \multirow{2}{*}{ T 0 } & $151,0 \pm 52,9$ & $158,2 \pm 48,9$ & 0,477 \\
T 1 & $288,6(214,4-386,4)$ & $286,7(208,3-390,8)$ & 0,845 \\
& T 2 & $326,4(221,7-399,0)$ & $340,2(221,0-413,1)$ & 0,539
\end{tabular}

Teste de qui-quadrado, exato de Fisher, $t$-Student, Mann-Whitney; p<0,05 foi considerado significante

Variáveis com distribuição normal são apresentadas como média \pm desvio padrão

Variáveis que não tem distribuição normal são apresentadas como mediana, percentis 25 e 75 por cento (entre parênteses); $\mathrm{n}(\%)=$ valor absoluto e percentual dos pacientes

$\mathrm{Na}$ figura 3, visualiza-se a comparação da dosagem do lactato sanguíneo nos tempos de coleta entre os grupos desmopressina e controle. No tempo $2 \mathrm{~h}$ (T1) e 24h (T2), há diferença estatisticamente significativa nos níveis de lactato sanguíneo entre os dois grupos do estudo.

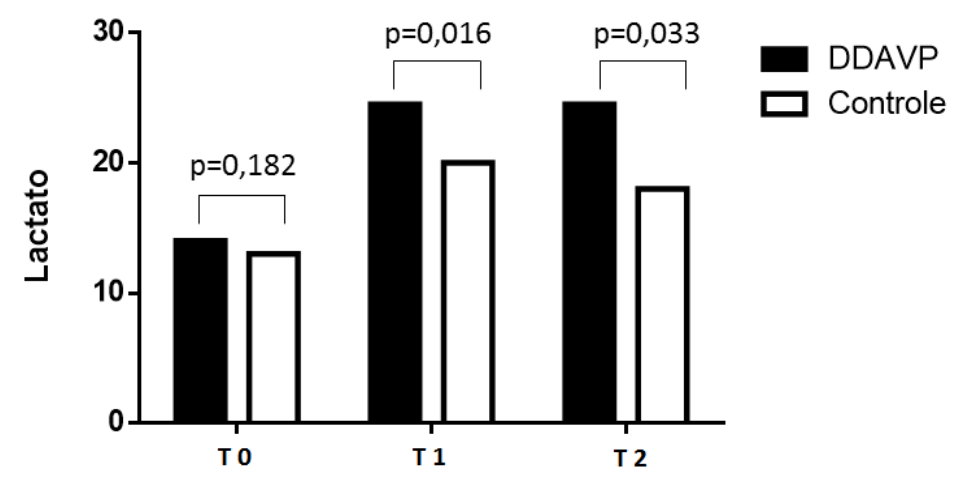

Figura 3- Relação dos valores do lactato entre os dois grupos (desmopressina e controle). 
As figuras 4 e 5 ilustram os níveis sanguíneos do Fator VIII e FvW, entre os grupos desmopressina e controle, com diferença estatisticamente significativa entre os grupos apenas para o Fator VIII em T1 (2h). A relação da agregação plaquetária com adrenalina e ADP, sem diferenças significativas quanto à administração profilática de desmopressina, é demonstrada nas figuras 6 e 7.

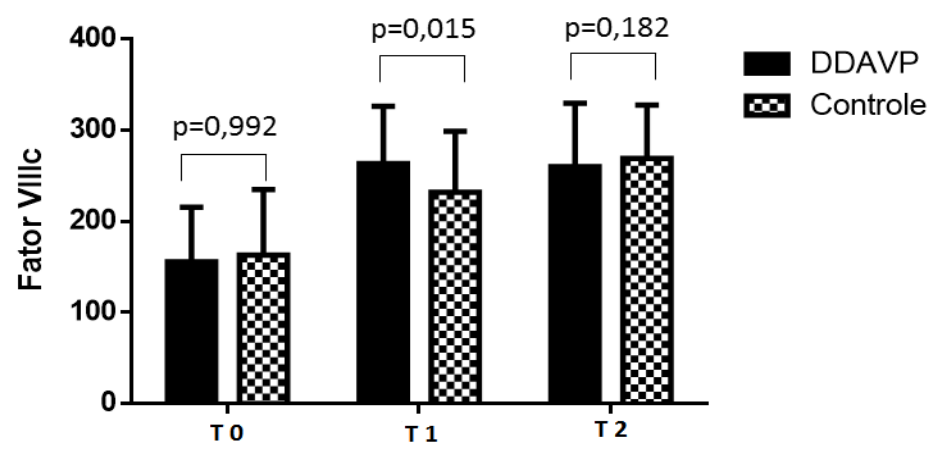

Figura 4- Relação desmopressina e níveis de Fator VIII nos três tempos de coleta

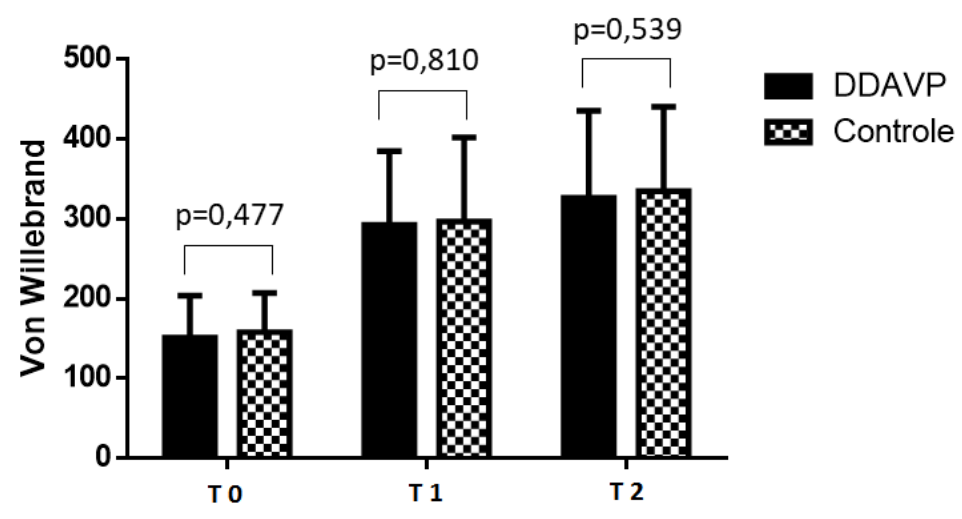

Figura 5- Relação desmopressina e níveis de FvW nos três tempos de coleta. 


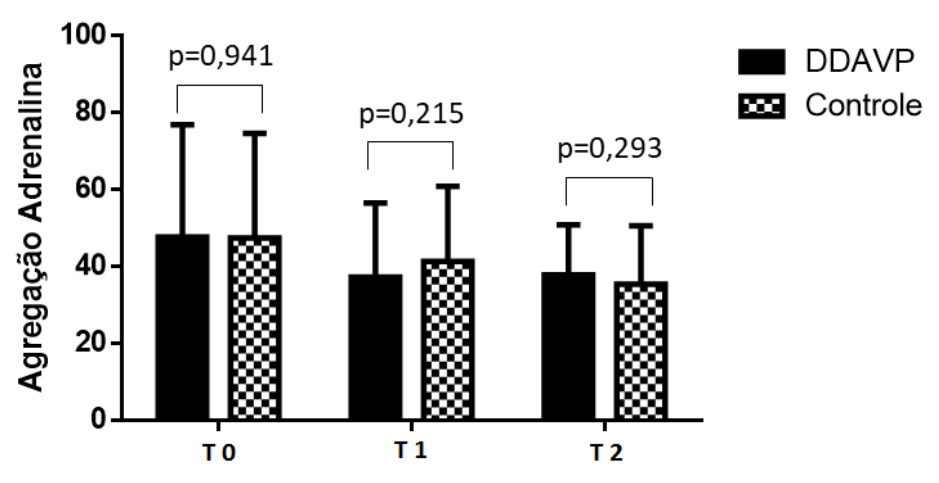

Figura 6- Relação desmopressina e agregação adrenalina nos três tempos de coleta.

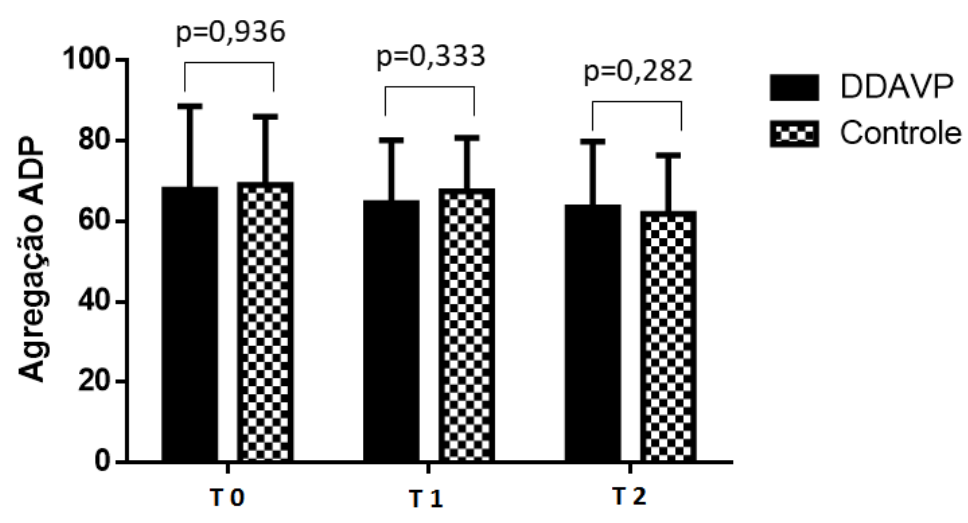

Figura 7- Relação desmopressina e agregação $A D P$ nos três tempos de coleta.

A análise tromboelastrométrica da coagulação foi realizada através do ROTEM®. Os testes viscoelásticos foram realizados utilizando os reagentes INTEM, EXTEM e FIBTEM nos três tempos de coletas de exames laboratoriais (T0, T1 e T2). De maneira geral, não houve diferenças significativas dos testes viscoelásticos em relação aos dois grupos do estudo (desmopressina e controle) (Tabelas 5 a 13). 
Tabela 05- Dados do ROTEM® (INTEM T0).

\begin{tabular}{llll}
\hline Variável & Desmopressina $(54)$ & Controle (54) & $\mathrm{P}$ \\
\hline INTEM (T0) & & & \\
$C T(\mathrm{~s})$ & $166,0(152,3-178,5)$ & $157,5(140,5-180,5)$ & 0,232 \\
$C F T(\mathrm{~s})$ & $64,5(55,0-82,5)$ & $68,0(61,0-82,2)$ & 0,349 \\
Ângulo $\alpha$ & $77,0(73,7-79,0)$ & $77,0(74,2-78,0)$ & 0,507 \\
A5 $(\mathrm{mm})$ & $48,0(43,0-52,7)$ & $47,0(44,0-51,0)$ & 0,380 \\
A10 $(\mathrm{mm})$ & $58,0(53,0-61,2)$ & $57,0(53,0-60,7)$ & 0,485 \\
MCF $(\mathrm{mm})$ & $64,0(60,7-66,2)$ & $64,0(60,0-66,7)$ & 0,948 \\
A20 $(\mathrm{mm})$ & $63,0(60,0-66,0)$ & $63,0(59,0-66,0)$ & 0,629 \\
A30 $(\mathrm{mm})$ & $64,0(60,0-66,0)$ & $63,0(59,0-66,7)$ & 0,667 \\
ML $(\%)$ & $6,0(4,0-8,0)$ & $5,0(2,0-8,0)$ & 0,199 \\
LI30 $(\%)$ & $100(99-100)$ & $100(99-100)$ & 0,559 \\
\hline
\end{tabular}

Teste de qui-quadrado, exato de Fisher, $t$-Student, Mann-Whitney; $\mathrm{p}<0,05$ foi considerado significante

Variáveis com distribuição normal são apresentadas como média \pm desvio padrão

Variáveis que não tem distribuição normal são apresentadas como mediana, percentis 25 e 75 por cento (entre parênteses); n (\%) = valor absoluto e percentual dos pacientes

Tabela 06- Dados do ROTEM® (INTEM T1).

\begin{tabular}{llll}
\hline Variável & Desmopressina (54) & Controle (54) & $\mathrm{P}$ \\
\hline$\underline{I N T E M(\mathrm{~T} 1)}$ & & & \\
$C T(\mathrm{~s})$ & $187,0(156,0-196,0)$ & $190,0(173,5-215,5)$ & 0,019 \\
$C F T(\mathrm{~s})$ & $90,0(72,0-109,0)$ & $94,0(81,0-113,5)$ & 0,407 \\
Ângulo $\alpha$ & $73,0(70,0-76,0)$ & $72,0(69,0-75,0)$ & 0,194 \\
A5 (mm) & $40,0(36,0-44,0)$ & $39,0(36,0-45,0)$ & 0,804 \\
A10 (mm) & $50,0(47,0-55,0)$ & $50,0(47,0-55,0)$ & 0,859 \\
$M C F(\mathrm{~mm})$ & $59,9 \pm 5,5$ & $59,8 \pm 6,0$ & 0,926 \\
A20 (mm) & $57,7 \pm 5,9$ & $57,6 \pm 6,2$ & 0,862 \\
A30 (mm) & $59,5 \pm 5,6$ & $61,0 \pm 5,9$ & 0,819 \\
ML (\%) & $2,0(1,0-3,0)$ & $2,0(1,0-3,0)$ & 0,178 \\
LI30 (\%) & $100(100-100)$ & $100(100-100)$ & 0,238
\end{tabular}

Teste de qui-quadrado, exato de Fisher, $t$-Student, Mann-Whitney; p<0,05 foi considerado significante Variáveis com distribuição normal são apresentadas como média \pm desvio padrão

Variáveis que não tem distribuição normal são apresentadas como mediana, percentis 25 e 75 por cento (entre parênteses); $\mathrm{n}(\%)=$ valor absoluto e percentual dos pacientes 
Tabela 07- Dados do ROTEM® (INTEM T2).

\begin{tabular}{llll}
\hline Variável & Desmopressina (54) & Controle (54) & P \\
\hline$\underline{I N T E M(T 2)}$ & & & \\
$C T(\mathrm{~s})$ & $67,0(60,5-77,0)$ & $66,0(59,0-73,0)$ & 0,374 \\
$C F T(\mathrm{~s})$ & $84,0(66,5-104,0)$ & $81,0(72,0-97,0)$ & 0,954 \\
Ângulo $\alpha$ & $77,0(64,0-79,0)$ & $77,0(75,0-79,0)$ & 0,705 \\
A5 (mm) & $45,1 \pm 6,7$ & $44,7 \pm 6,5$ & 0,749 \\
A10 (mm) & $55,8 \pm 6,8$ & $56,2 \pm 6,2$ & 0,460 \\
$M C F(\mathrm{~mm})$ & $64,2 \pm 4,9$ & $64,8 \pm 5,5$ & 0,361 \\
A20 (mm) & $62,8 \pm 5,1$ & $63,1 \pm 5,6$ & 0,415 \\
A30 (mm) & $64,1 \pm 4,9$ & $64,7 \pm 5,4$ & 0,368 \\
ML (\%) & $4,5 \pm 2,4$ & $3,8 \pm 2,6$ & 0,103 \\
LI30 (\%) & $100(100-100)$ & $100(100-100)$ & 0,808
\end{tabular}

Teste de qui-quadrado, exato de Fisher, $t$-Student, Mann-Whitney; $\mathrm{p}<0,05$ foi considerado significante

Variáveis com distribuição normal são apresentadas como média \pm desvio padrão

Variáveis que não tem distribuição normal são apresentadas como mediana, percentis 25 e 75 por cento (entre parênteses); $\mathrm{n}(\%)$ = valor absoluto e percentual dos pacientes

Tabela 08- Dados do ROTEM® (EXTEM T0).

\begin{tabular}{llll}
\hline Variável & Desmopressina (54) & Controle $(54)$ & $\mathrm{P}$ \\
\hline$\underline{\text { EXTEM }(\mathrm{T} 0)}$ & & & \\
$C T(\mathrm{~s})$ & $62,0(53,0-74,2)$ & $61,0(55,2-69,0)$ & 0,671 \\
$C F T(\mathrm{~s})$ & $71,5(62,0-90,5)$ & $74,5(62,2-92,2)$ & 0,695 \\
Ângulo $\alpha$ & $77,0(73,0-78,0)$ & $76,0(72,2-78,0)$ & 0,439 \\
A5 $(\mathrm{mm})$ & $50,0(43,7-52,2)$ & $49,0(44,0-52,0)$ & 0,673 \\
A10 $(\mathrm{mm})$ & $60,0(54,7-62,2)$ & $59,0(54,2-61,7)$ & 0,641 \\
$M C F(\mathrm{~mm})$ & $67,0(62,0-68,2)$ & $67,0(63,0-68,7)$ & 0,993 \\
A20 $(\mathrm{mm})$ & $66,0(61,0-68,0)$ & $65,0(62,0-67,5)$ & 0,689 \\
A30 (mm) & $67,0(62,0-68,2)$ & $67,0(63,0-68,0)$ & 0,842 \\
ML $(\%)$ & $5,5(4,0-8,0)$ & $5,0(3,0-7,7)$ & 0,409 \\
LI30 $(\%)$ & $100(100-100)$ & $100(100-100)$ & 0,454
\end{tabular}

Teste de qui-quadrado, exato de Fisher, $t$-Student, Mann-Whitney; $\mathrm{p}<0,05$ foi considerado significante

Variáveis com distribuição normal são apresentadas como média \pm desvio padrão

Variáveis que não tem distribuição normal são apresentadas como mediana, percentis 25 e 75 por cento (entre parênteses); $\mathrm{n}(\%)$ = valor absoluto e percentual dos pacientes 
Tabela 09- Dados do ROTEM® (EXTEMT1).

\begin{tabular}{llll}
\hline Variável & $\begin{array}{l}\text { Desmopressina } \\
\text { EXTEM (T1) }\end{array}$ & Controle (54) & $\mathrm{P}$ \\
\hline$C T(\mathrm{~s})$ & $74,0(61,0-82,0)$ & $69,5(59,2-82,7)$ & 0,482 \\
$C F T(\mathrm{~s})$ & $97,0(77,0-114,0)$ & $92,0(78,7-115,8)$ & 0,883 \\
Ângulo $\alpha$ & $73,0(69,0-76,0)$ & $73,0(69,2-75,0)$ & 0,748 \\
A5 (mm) & $41,9 \pm 6,8$ & $41,9 \pm 6,8$ & 0,679 \\
A10 (mm) & $52,4 \pm 6,5$ & $52,4 \pm 6,5$ & 0,788 \\
MCF (mm) & $61,8 \pm 5,5$ & $62,1 \pm 5,8$ & 0,639 \\
A20 (mm) & $59,4 \pm 5,8$ & $59,6 \pm 5,9$ & 0,771 \\
A30 (mm) & $61,5 \pm 5,5$ & $61,9 \pm 5,7$ & 0,646 \\
ML (\%) & $2,0(1,0-4,0)$ & $1,0(0,0-3,0)$ & 0,044 \\
LI30 (\%) & $100(100-100)$ & $100(100-100)$ & 0,495 \\
\hline
\end{tabular}

Teste de qui-quadrado, exato de Fisher, $t$-Student, Mann-Whitney; $\mathrm{p}<0,05$ foi considerado significante

Variáveis com distribuição normal são apresentadas como média \pm desvio padrão

Variáveis que não tem distribuição normal são apresentadas como mediana, percentis 25 e 75 por cento (entre parênteses); $\mathrm{n}(\%)$ = valor absoluto e percentual dos pacientes

Tabela 10- Dados do ROTEM® (EXTEM T2).

\begin{tabular}{llll}
\hline Variável & Desmopressina (54) & Controle (54) & $\mathrm{P}$ \\
\hline$\underline{\text { EXTEM }(\mathrm{T} 2)}$ & & & \\
$C T(\mathrm{~s})$ & $168,0(153,8-184,5)$ & $156,0(148,0-167,0)$ & 0,021 \\
$C F T(\mathrm{~s})$ & $77,5(66,7-94,5)$ & $77,0(64,0-88,0)$ & 0,663 \\
Ângulo $\alpha$ & $77,0(74,0-78,2)$ & $77,0(75,0-78,0)$ & 0,755 \\
A5 $(\mathrm{mm})$ & $43,0(38,5-48,0)$ & $44,0(41,0-49,0)$ & 0,471 \\
A10 $(\mathrm{mm})$ & $54,0(49,0-59,0)$ & $55,0(52,0-60,0)$ & 0,281 \\
$M C F(\mathrm{~mm})$ & $61,5 \pm 5,1$ & $62,7 \pm 5,4$ & 0,135 \\
A20 (mm) & $59,5(57,0-64,2)$ & $62,0(59,0-66,0)$ & 0,146 \\
A30 (mm) & $61,0(57,5-65,0)$ & $62,0(59,0-67,0)$ & 0,128 \\
ML $(\%)$ & $4,3 \pm 2,5$ & $3,9 \pm 2,9$ & 0,294 \\
LI30 (\%) & $100(99,7-100)$ & $100(100-100)$ & 0,393
\end{tabular}

Teste de qui-quadrado, exato de Fisher, $t$-Student, Mann-Whitney; p<0,05 foi considerado significante Variáveis com distribuição normal são apresentadas como média \pm desvio padrão

Variáveis que não tem distribuição normal são apresentadas como mediana, percentis 25 e 75 por cento (entre parênteses); n $(\%)=$ valor absoluto e percentual dos pacientes 
Tabela 11- Dados do ROTEM® (FIBTEM T0).

\begin{tabular}{llll}
\hline Variável & Desmopressina (54) & Controle (54) & P \\
\hline FIBTEM (T0) & & & \\
CT $(s)$ & $60,5(51,7-70,0)$ & $56,0(50,0-64,0)$ & 0,158 \\
CFT (s) & $382,0(229,5-1549)$ & $505,5(225,5-1245)$ & 0,878 \\
Ângulo $\alpha$ & $74,0(68,7-77,0)$ & $76,0(71,5-78,0)$ & 0,351 \\
A5 (mm) & $15,0(12,0-17,0)$ & $16,0(13,0-18,0)$ & 0,232 \\
A10 (mm) & $17(13-18,2)$ & $17,0(14,0-20,0)$ & 0,367 \\
MCF (mm) & $18,5(15,0-21,0)$ & $19,0(15,0-21,0)$ & 0,604 \\
A20 (mm) & $18,0(15,0-20,2)$ & $18,0(15,0-21,0)$ & 0,636 \\
A30 (mm) & $19,0(15,0-20,2)$ & $19,0(15,0-21,0)$ & 0,574 \\
ML (\%) & $0,0(0,0-0,0)$ & $0,0(0,0-0,0)$ & 0,481 \\
LI30 (\%) & $100(100-100)$ & $100(100-100)$ & 0,551 \\
\hline
\end{tabular}

Teste de qui-quadrado, exato de Fisher, $t$-Student, Mann-Whitney; $<<0,05$ foi considerado significante Variáveis com distribuição normal são apresentadas como média \pm desvio padrão

Variáveis que não tem distribuição normal são apresentadas como mediana, percentis 25 e 75 por cento (entre parênteses); $\mathrm{n}(\%)=$ valor absoluto e percentual dos pacientes

Tabela 12- Dados do ROTEM® (FIBTEM T1).

\begin{tabular}{llll}
\hline Variável & Desmopressina (54) & Controle (54) & P \\
\hline FIBTEM $(\mathrm{T} 1)$ & & & \\
CT $(s)$ & $68,0(57,0-79,0)$ & $66,0(56,0-77,0)$ & 0,727 \\
$C F T(s)$ & $1255,0 \pm 994,0$ & $975,5 \pm 829,6$ & 0,555 \\
Ângulo $\alpha$ & $71,0(67,0-75,0)$ & $71,0(67,0-74,0)$ & 0,627 \\
A5 $(\mathrm{mm})$ & $13,0(11,0-16,0)$ & $13,0(10,0-15,0)$ & 0,756 \\
A10 $(\mathrm{mm})$ & $15,0(12,0-17,0)$ & $14,0(10,5-17,0)$ & 0,571 \\
MCF $(\mathrm{mm})$ & $16,0(13,0-19,0)$ & $15,0(12,0-19,0)$ & 0,686 \\
A20 $(\mathrm{mm})$ & $15,0(12,0-18,0)$ & $15,0(11,0-18,0)$ & 0,500 \\
A30 $(\mathrm{mm})$ & $16,0(13,0-19,0)$ & $15,0(12,0-18,7)$ & 0,416 \\
ML $(\%)$ & $0,0(0,0-0,0)$ & $0,0(0,0-0,0)$ & 0,492 \\
LI30 $(\%)$ & $100(100-100)$ & $100(100-100)$ & 0,999 \\
\hline
\end{tabular}

Teste de qui-quadrado, exato de Fisher, $t$-Student, Mann-Whitney; $\mathrm{p}<0,05$ foi considerado significante

Variáveis com distribuição normal são apresentadas como média \pm desvio padrão

Variáveis que não tem distribuição normal são apresentadas como mediana, percentis 25 e 75 por cento (entre parênteses); $\mathrm{n}(\%)=$ valor absoluto e percentual dos pacientes 
Tabela 13- Dados do ROTEM® (FIBTEM T2).

\begin{tabular}{llll}
\hline Variável & Desmopressina (54) & Controle (54) & P \\
\hline FIBTEM (T2) & & & \\
CT (s) & $61,0(54,0-73,5)$ & $60,0(55,0-67,0)$ & 0,750 \\
$C F T(\mathrm{~s})$ & $342,5(109,8-727,0)$ & $352,0(133,0-871,5)$ & 0,666 \\
Ângulo $\alpha$ & $77,5(74,2-79,0)$ & $78,0(75,2-79,0)$ & 0,701 \\
A5 (mm) & $19,5 \pm 5,1$ & $19,3 \pm 4,2$ & 0,832 \\
A10 (mm) & $21,0(17,5-24,5)$ & $21,0(19,0-24,0)$ & 0,968 \\
MCF (mm) & $24,0(19,7-28,0)$ & $23,0(21,0-29,0)$ & 0,648 \\
A20 (mm) & $23,0(19,5-26,0)$ & $22,0(20,0-28,0)$ & 0,768 \\
A30 (mm) & $24,0(20,5-27,7)$ & $23,0(21,0-29,0)$ & 0,904 \\
ML (\%) & $0,0(0,0-0,0)$ & $0,0(0,0-0,0)$ & 0,721 \\
LI30 (\%) & $100(100-100)$ & $100(100-100)$ & 0,490 \\
\hline
\end{tabular}

Teste de qui-quadrado, exato de Fisher, $t$-Student, Mann-Whitney; $\mathrm{p}<0,05$ foi considerado significante Variáveis com distribuição normal são apresentadas como média \pm desvio padrão

Variáveis que não tem distribuição normal são apresentadas como mediana, percentis 25 e 75 por cento (entre parênteses); $\mathrm{n}(\%)=$ valor absoluto e percentual dos pacientes

A análise dos níveis plasmáticos do FVIII e do FvW entre os dois principais subtipos valvares operados (mitral e aórtico) revelou valores plasmáticos de FVIII e FvW menores nos tempos T0 e T1 no grupo aórtico em relação ao mitral, o que foi estatisticamente significativo (tabelas 14 e 15).

Tabela 14- Correlação do tipo valvar (aórtica ou mitral) e níveis de Fator VIII.

\begin{tabular}{rlll}
\hline Variável & Mitral (58) & Aórtico (36) & P \\
\hline Fator VIIIc (\%) & & & \\
T 0 & $162(129,5-209,8)$ & $126(98-152)$ & 0,0009 \\
T 1 & $268,5 \pm 63,1$ & $220,7 \pm 57,4$ & 0,0005 \\
T 2 & $256,5(217-340)$ & $204,5(206,0-277,3)$ & 0,089
\end{tabular}

Teste de qui-quadrado, exato de Fisher, $t$-student, Mann-Whitney; p<0,05 foi considerado significante Variáveis com distribuição normal são apresentadas como média \pm desvio padrão

Variáveis que não tem distribuição normal são apresentadas como mediana, percentis 25 e 75 por cento (entre parênteses); $\mathrm{n}(\%)$ = valor absoluto e percentual dos pacientes 
Tabela 15- Correlação do tipo de valva (aórtica ou mitral) e níveis de FvW.

\begin{tabular}{lllll}
\hline Variável & \multicolumn{1}{l}{ Mitral (58) } & Aórtico (36) & P \\
\hline$F v W(\%)$ & & & \\
& T 0 & $163,9 \pm 52,8$ & $138,1 \pm 44,7$ & 0,021 \\
& T 1 & $307,4(214,8-405,4)$ & $216,3(206,7-299,7)$ & 0,005 \\
& T 2 & $331,6(221-419,7)$ & $340,2(220,1-371,5)$ & 0,465
\end{tabular}

Teste de qui-quadrado, exato de Fisher, $t$ - Student, Mann-Whitney; $\mathrm{p}<0,05$ foi considerado significante Variáveis com distribuição normal são apresentadas como média \pm desvio padrão

Variáveis que não tem distribuição normal são apresentadas como mediana, percentis 25 e 75 por cento (entre parênteses); $\mathrm{n}(\%)$ = valor absoluto e percentual dos pacientes

Diante da diferença significativa apresentada nos níveis plasmáticos do FVIII e do FvW entre os doentes submetidos à cirurgia de correção valvar aórtica e mitral, realizou-se uma análise laboratorial completa da coagulação sanguínea entre os dois tipos de correção valvar em relação à intervenção (desmopressina) e o controle (tabelas 16 e 17). Os pacientes submetidos à cirurgia para correção do defeito valvar mitral apresentaram valores do TP maiores no grupo da intervenção (desmopressina) em relação ao controle.

Tabela 16- Análise laboratorial dos pacientes submetidos a correção do efeito valvar mitral.

\begin{tabular}{rlll}
\hline Variável & Desmopressina (31) & Controle (27) & $\mathrm{P}$ \\
\hline Hemoglobina (g/dL) & & & \\
T 0 & $13,3 \pm 1,2$ & $13,1 \pm 1,8$ & 0,718 \\
T 1 & $11,6 \pm 1,3$ & $12,2 \pm 1,5$ & 0,161 \\
T 2 & $12,0 \pm 1,9$ & $12,1 \pm 1,6$ & 0,914
\end{tabular}


Tabela 16- Análise laboratorial dos pacientes submetidos a correção do defeito valvar mitral.(Continuação)

\begin{tabular}{lllll}
\hline Variável & & Desmopressina (31) & Controle (27) & P \\
\hline TTPA (s) & & & & \\
& T 0 & $29,7(27,6-32,3)$ & $28,6(25,9-30,7)$ & 0,138 \\
& T 1 & $29,0(27,6-30,6)$ & $29,7(26,6-31,2)$ & 0,771 \\
& T 2 & $30,5(27,3-34,0)$ & $29,0(27,7-30,8)$ & 0,342
\end{tabular}

$\mathrm{TP}(\mathrm{s})$

$\begin{array}{llll}\text { T } 0 & 12,5 \pm 0,8 & 12,5 \pm 0,8 & 0,873 \\ \text { T } 1 & 14,2 \pm 1,5 & 13,3 \pm 1,2 & 0,024 \\ \text { T } 2 & 14,3(13,1-16,0) & 13,4(12,5-14,7) & 0,031\end{array}$

INR

$\begin{array}{llll}\text { T } 0 & 1,14 \pm 0,08 & 1,13 \pm 0,07 & 0,568 \\ \text { T } 1 & 1,2(1,2-1,4) & 1,2(1,1-1,3) & 0,460 \\ \text { T } 2 & 1,3(1,2-1,4) & 1,2(1,1-1,3) & 0,245\end{array}$

D-dímero (ng/L)

$\begin{array}{llll}\text { T } 0 & 411(215-826) & 379(251-836) & 0,596 \\ \text { T 1 } & 863(503-1062) & 672(490-1089) & 0,613 \\ \text { T 2 } & 848(568,5-1375) & 839(543,5-1296) & 0,962\end{array}$

Fibrinogênio $(\mathrm{mg} / \mathrm{dL})$

$\begin{array}{llll}\text { T } 0 & 302,7 \pm 71,7 & 304,0 \pm 49,2 & 0,937 \\ \text { T } 1 & 245,2 \pm 70,8 & 240,7 \pm 51,7 & 0,855 \\ \text { T 2 } & 408,0(375,5-454,0) & 402,0(359,5-429,0) & 0,340\end{array}$

Agregação ADP

$\begin{array}{llll}\text { T } 0 & 70,5 \pm 20,3 & 70,2 \pm 17,4 & 0,868 \\ \text { T 1 } & 63,9 \pm 17,3 & 71,9 \pm 12,0 & 0,060 \\ \text { T 2 } & 68,5(51,5-76,2) & 67,4(59,0-73,6) & 0,931\end{array}$

Agregação Adrenalina

$\begin{array}{llll}\text { T } 0 & 41,5(19,3-80,0) & 47,8(21,9-76,1) & 0,892 \\ \text { T 1 } & 28,4(23,1-42,8) & 40,3(28,7-57,2) & 0,094 \\ \text { T 2 } & 36,9(28,0-48,8) & 33,0(26,1-47,4) & 0,402\end{array}$

Fator VIII (\%)

T 0

$\mathrm{T} 1$

T 2
$162,0(131,0-199,0)$

$276,4 \pm 55,6$

$267,4 \pm 74,7$
$167,0(118,0-222,0)$

0,748

$258,7 \pm 71,2$

0,277

$280,7 \pm 60,1$ 
Tabela 17- Análise laboratorial dos pacientes submetidos a correção do defeito valvar aórtico.

\begin{tabular}{rllll}
\hline Variável & & DDAVP (16) & Controle (20) & P \\
\hline Hemoglobina (g/dL) & & & \\
& T 0 & $13,7 \pm 1,7$ & $12,9 \pm 1,8$ & 0,238 \\
& T 1 & $11,6 \pm 1,2$ & $12,1 \pm 1,5$ & 0,269 \\
& T 2 & $12,1(10,8-12,6)$ & $12,1(10,9-13,2)$ & 0,735 \\
TTPA (s) & & & \\
& T 0 & $30,9 \pm 3,4$ & $29,2 \pm 3,1$ & 0,181 \\
& T 1 & $28,4(27,4-31,9)$ & $31,2(27,6-33,2)$ & 0,322 \\
& T 2 & $29,0(26,9-32,3)$ & $28,6(26,5-30,1)$ & 0,483
\end{tabular}

$\mathrm{TP}(\mathrm{s})$

$\begin{array}{llll}\text { T } ~ & 12,1 \pm 0,6 & 12,5 \pm 1,2 & 0,308 \\ \text { T 1 } & 13,8(12,7-14,9) & 12,9(12,5-14,2) & 0,799 \\ \text { T 2 } & 13,4(12,4-14,2) & 12,5(11,8-14,3) & 0,486\end{array}$

INR

$\begin{array}{llll}\text { T } 0 & 1,10 \pm 0,04 & 1,12 \pm 0,11 & 0,675 \\ \text { T 1 } & 1,2(1,2-1,4) & 1,2(1,1-1,3) & 0,722 \\ \text { T 2 } & 1,2(1,1-1,3) & 1,1(1,1-1,3) & 0,531\end{array}$

D-dímero (ng/L)

$\begin{array}{llll}\text { T } ~ & 355(234-586) & 278(182-856) & 0,751 \\ \text { T 1 } & 517(316-760.5) & 763,5(421,3-1131) & 0,076 \\ \text { T 2 } & 880(442-1229) & 704(507-997) & 0,777\end{array}$

Fibrinogênio (mg/dL)

$\begin{array}{llll}\text { T } 0 & 393,8 \pm 65,9 & 318,4 \pm 63,4 & 0,589 \\ \text { T } 1 & 235,9 \pm 49,1 & 247,9 \pm 61,5 & 0,925 \\ \text { T 2 } & 427(368-440) & 418(355-446 & 0,520\end{array}$

Agregação ADP

$\begin{array}{llll}\text { T } 0 & 69,6(36,7-77,5) & 73,4(51,8-82,9) & 0,225 \\ \text { T 1 } & 63,9 \pm 12,6 & 63,2 \pm 12,4 & 0,866 \\ \text { T 2 } & 64,3 \pm 15,5 & 58,4 \pm 11,9 & 0,213\end{array}$


Tabela 17- Análise laboratorial dos pacientes submetidos a correção do defeito valvar aórtico. (Continuação)

\begin{tabular}{lllll}
\hline Variável & & DDAVP $(16)$ & Controle (20) & P \\
\hline Agregação Adrenalina & & & \\
& T 0 & $27,3(19,1-50,8)$ & $50,0(19,0-75,0)$ & 0,267 \\
T 1 & $37,4 \pm 17,1$ & $40,3 \pm 20,1$ & 0,751 \\
T 2 & $36,1 \pm 10,1$ & $34,6 \pm 11,5$ & 0,707 \\
Fator VIII (\%) & & & \\
& & & & 0,711 \\
T 0 & $124,0(98,0-152,0)$ & $138,0(97,2-151,8)$ & 0,107 \\
T 1 & $239,8 \pm 70,2$ & $204,6 \pm 38,9$ & 0,625 \\
FvW (\%) & $252,3 \pm 69,9$ & $243,0 \pm 36,4$ & 0,333 \\
& & & & 0,873 \\
T 0 & $129,7 \pm 43,5$ & $145,1 \pm 45,7$ & 0,793 \\
\hline
\end{tabular}

Teste de qui-quadrado, exato de Fisher, $t$-Student, Mann-Whitney; p<0,05 foi considerado significante

Os dados da tromboelastografia para cada um dos grupos cirúrgicos (mitral e aórtico) em relação à intervenção (desmopressina) e controle foram igualmente avaliados (tabelas 18 a 35). Observou-se um padrão de homogeneidade entre os grupos sobre todos os tempos e análises realizadas através do ROTEM®. 
Tabela 18- Dados do ROTEM® (INTEM T0) no grupo mitral.

\begin{tabular}{llll}
\hline Variável & Desmopressina (31) & Controle (27) & P \\
\hline$\underline{I N T E M(T 0)}$ & & $157,0 \quad(140,3$ & - \\
& & \\
$C T(\mathrm{~s})$ & $164,0(136,0-174,0)$ & $192,3)$ & 0,990 \\
$C F T(\mathrm{~s})$ & $60,0(53,0-82,5)$ & $69,0(61,7-80,0)$ & 0,142 \\
Ângulo $\alpha$ & $78,0(73,5-79,0)$ & $77,0(74,7-77,2)$ & 0,086 \\
A5 (mm) & $49,0(42,5-55,0)$ & $47,0(44,0-51,2)$ & 0,299 \\
A10 (mm) & $58,0(53,0-62,5)$ & $57,0(53,7-60,5)$ & 0,499 \\
$M C F(\mathrm{~mm})$ & $63,8 \pm 4,9$ & $63,4 \pm 4,8$ & 0,883 \\
A20 (mm) & $63,1 \pm 5,3$ & $62,5 \pm 5,3$ & 0,714 \\
A30 (mm) & $63,2 \pm 4,8$ & $63,0 \pm 5,1$ & 0,860 \\
ML (\%) & $6,0(4,5-8,5)$ & $5,0(2,0-7,2)$ & 0,116 \\
LI30 (\%) & $100(99-100)$ & $100(99-100)$ & 0,312 \\
\hline
\end{tabular}

Teste de qui-quadrado, exato de Fisher, $t$-Student, Mann-Whitney; $\mathrm{p}<0,05$ foi considerado significante Variáveis com distribuição normal são apresentadas como média \pm desvio padrão

Variáveis que não tem distribuição normal são apresentadas como mediana, percentis 25 e 75 por cento (entre parênteses); $\mathrm{n}(\%)$ = valor absoluto e percentual dos pacientes

Tabela 19- Dados do ROTEM® (INTEM T1) no grupo mitral.

\begin{tabular}{llll}
\hline Variável & Desmopressina (31) & Controle (27) & P \\
\hline$\underline{I N T E M(T 1)}$ & & & \\
$C T(\mathrm{~s})$ & $174,0 \pm 30,5$ & $192,8 \pm 31,0$ & 0,025 \\
$C F T(\mathrm{~s})$ & $91,8 \pm 31,1$ & $100,5 \pm 30,6$ & 0,296 \\
Ângulo $\alpha$ & $73,5(70,0-77,2)$ & $72,0(68,0-75,0)$ & 0,226 \\
A5 (mm) & $41,3 \pm 7,4$ & $38,5 \pm 9,5$ & 0,477 \\
A10 (mm) & $51,4 \pm 7,2$ & $50,1 \pm 7,2$ & 0,784 \\
$M C F(\mathrm{~mm})$ & $60,3 \pm 5,9$ & $60,0 \pm 5,9$ & 0,817 \\
A20 (mm) & $58,2 \pm 6,4$ & $57,8 \pm 6,0$ & 0,785 \\
A30 (mm) & $59,0(55,7-65,2)$ & $61,0(56,0-63,0)$ & 0,853 \\
ML $(\%)$ & $2,0(1,0-3,0)$ & $2,0(1,0-4,0)$ & 0,989 \\
LI30 (\%) & $100(100-100)$ & $100(100-100)$ & 0,999
\end{tabular}

Teste de qui-quadrado, exato de Fisher, $t$-Student, Mann-Whitney; p<0,05 foi considerado significante

Variáveis com distribuição normal são apresentadas como média \pm desvio padrão

Variáveis que não tem distribuição normal são apresentadas como mediana, percentis 25 e 75 por cento (entre parênteses); n $(\%)=$ valor absoluto e percentual dos pacientes 
Tabela 20- Dados do ROTEM® (INTEM T2) no grupo mitral.

\begin{tabular}{llll}
\hline Variável & Desmopressina (31) & Controle (27) & P \\
\hline INTEM (T2) & & & \\
CT (s) & $67,0(61,0-78,0)$ & $65,0(58,0-73,0)$ & 0,345 \\
CFT (s) & $80,0(64,0-104,0)$ & $76,0(73,0-91,5)$ & 0,659 \\
Ângulo $\alpha$ & $77,0(74,0-79,0)$ & $78,0(75,0-79,0)$ & 0,643 \\
A5 (mm) & $43,0(40,0-50,0)$ & $46,0(43,0-51,0)$ & 0,399 \\
A10 (mm) & $55,0(52,0-62,0)$ & $58,0(55,0-62,0)$ & 0,313 \\
MCF (mm) & $64,4 \pm 5,0$ & $66,0 \pm 5,1$ & 0,263 \\
A20 (mm) & $63,1 \pm 5,2$ & $64,4 \pm 5,6$ & 0,424 \\
A30 (mm) & $64,2 \pm 4,9$ & $65,9 \pm 5,2$ & 0,244 \\
ML (\%) & $5(3-6)$ & $4(2-6)$ & 0,341 \\
LI30 (\%) & $100(100-100)$ & $100(100-100)$ & 0,867
\end{tabular}

Teste de qui-quadrado, exato de Fisher, $t$-Student, Mann-Whitney; p<0,05 foi considerado significante

Variáveis com distribuição normal são apresentadas como média \pm desvio padrão

Variáveis que não tem distribuição normal são apresentadas como mediana, percentis 25 e 75 por cento (entre parênteses); $\mathrm{n}(\%)$ = valor absoluto e percentual dos pacientes

Tabela 21- Dados do ROTEM® (EXTEM T0) no grupo mitral.

\begin{tabular}{llll}
\hline Variável & Desmopressina (31) & Controle $(27)$ & $\mathrm{P}$ \\
\hline$\underline{\text { EXTEM }(\mathrm{T} 0)}$ & & & \\
$C T(\mathrm{~s})$ & $63,0(53,0-76,0)$ & $58,0(54,7-69,2)$ & 0,393 \\
$C F T(\mathrm{~s})$ & $67,0(60,0-92,2)$ & $74,5(59,5-93,2)$ & 0,809 \\
Ângulo $\alpha$ & $77,5(73,7-79,0)$ & $75,0(72,7-78,0)$ & 0,298 \\
A5 $(\mathrm{mm})$ & $50,5(42,7-53,0)$ & $48,5(44,0-55,0)$ & 0,673 \\
A10 $(\mathrm{mm})$ & $60,5(53,7-63,0)$ & $58,5(54,0-64,2)$ & 0,697 \\
$M C F(\mathrm{~mm})$ & $67,5(61,7-68,2)$ & $67,0(63,0-68,7)$ & 0,765 \\
A20 (mm) & $66,5(60,7-68,0)$ & $65,0(61,7-69,2)$ & 0,996 \\
A30 (mm) & $68,0(61,7-68,2)$ & $66,5(63,0-69,2)$ & 0,828 \\
ML $(\%)$ & $6,0(4,0-8,0)$ & $5,0(2,0-8,0)$ & 0,146 \\
LI30 (\%) & $100(100-100)$ & $100(100-100)$ & 0,999
\end{tabular}

Teste de qui-quadrado, exato de Fisher, $t$-Student, Mann-Whitney; $\mathrm{p}<0,05$ foi considerado significante

Variáveis com distribuição normal são apresentadas como média \pm desvio padrão

Variáveis que não tem distribuição normal são apresentadas como mediana, percentis 25 e 75 por cento (entre parênteses); $\mathrm{n}(\%)$ = valor absoluto e percentual dos pacientes 
Tabela 22- Dados do ROTEM® (EXTEM T1) no grupo mitral.

\begin{tabular}{llll}
\hline Variável & Desmopressina (31) & Controle (27) & $\mathrm{P}$ \\
\hline$\underline{\text { EXTEM }(\mathrm{T} 1)}$ & & & \\
$C T(\mathrm{~s})$ & $79,2 \pm 22,9$ & $73,1 \pm 19,9$ & 0,443 \\
$C F T(\mathrm{~s})$ & $88,0(70,7-114,3)$ & $92,0(81,0-112,0)$ & 0,543 \\
Ângulo $\alpha$ & $74,0(70,5-77,0)$ & $73,0(70,0-75,0)$ & 0,428 \\
A5 $(\mathrm{mm})$ & $42,5 \pm 7,4$ & $41,9 \pm 7,0$ & 0,753 \\
A10 $(\mathrm{mm})$ & $53,0 \pm 7,1$ & $52,6 \pm 6,8$ & 0,753 \\
$M C F(\mathrm{~mm})$ & $62,2 \pm 5,9$ & $62,4 \pm 5,8$ & 0,908 \\
A20 (mm) & $59,9 \pm 6,4$ & $59,8 \pm 6,2$ & 0,984 \\
A30 (mm) & $62,0 \pm 5,9$ & $62,3 \pm 5,7$ & 0,759 \\
ML $(\%)$ & $2,5(1,0-4,2)$ & $1,0(0,0-4,0)$ & 0,233 \\
LI30 $(\%)$ & $100(100-100)$ & $100(100-100)$ & 0,999 \\
\hline Teste & & &
\end{tabular}

Teste de qui-quadrado, exato de Fisher, $t$-Student, Mann-Whitney; $<<0,05$ foi considerado significante

Variáveis com distribuição normal são apresentadas como média \pm desvio padrão

Variáveis que não tem distribuição normal são apresentadas como mediana, percentis 25 e 75 por cento (entre parênteses); $\mathrm{n}(\%)$ = valor absoluto e percentual dos pacientes

Tabela 23- Dados do ROTEM® (EXTEM T2) no grupo mitral.

\begin{tabular}{llll}
\hline Variável & Desmopressina (31) & Controle (27) & P \\
\hline$\underline{E X T E M(T 2)}$ & & & \\
$C T(\mathrm{~s})$ & $165,0(151,0-175,0)$ & $150,5(157,0-181,5)$ & 0,767 \\
$C F T(\mathrm{~s})$ & $69,5(62,5-93,7)$ & $72,0(62,5-88,5)$ & 0,828 \\
Ângulo $\alpha$ & $77,0(74,2-79,0)$ & $76,0(74,0-78,5)$ & 0,501 \\
A5 (mm) & $44,7 \pm 6,5$ & $45,3 \pm 6,4$ & 0,737 \\
A10 (mm) & $55,1 \pm 6,0$ & $56,0 \pm 6,0$ & 0,464 \\
$M C F(\mathrm{~mm})$ & $62,4 \pm 5,0$ & $63,2 \pm 5,2$ & 0,458 \\
A20 (mm) & $62,5(57,2-65,7)$ & $63,0(60,0-66,0)$ & 0,401 \\
A30 (mm) & $62,1 \pm 4,9$ & $63,0 \pm 5,3$ & 0,422 \\
ML (\%) & $4,6 \pm 2,5$ & $4,6 \pm 3,1$ & 0,758 \\
LI30 (\%) & $100(99,2-100)$ & $100(99,5-100)$ & 0,878 \\
\hline
\end{tabular}

Teste de qui-quadrado, exato de Fisher, $t$-Student, Mann-Whitney; $\mathrm{p}<0,05$ foi considerado significante

Variáveis com distribuição normal são apresentadas como média \pm desvio padrão

Variáveis que não tem distribuição normal são apresentadas como mediana, percentis 25 e 75 por cento (entre parênteses); $\mathrm{n}(\%)$ = valor absoluto e percentual dos pacientes 
Tabela 24- Dados do ROTEM® (FIBTEM T0) no grupo mitral.

\begin{tabular}{llll}
\hline & Desmopressina & & \\
Variável & $(31)$ & Controle (27) & $\mathrm{P}$ \\
\hline$\underline{\text { FIBTEM }(\mathrm{T} 0)}$ & & & \\
$C T(\mathrm{~s})$ & $61,0(50,5-76,0)$ & $54,0(49,0-63,5)$ & 0,088 \\
$C F T(\mathrm{~s})$ & $1017 \pm 973,3$ & $956,0 \pm 791,0$ & 0,870 \\
Ângulo $\alpha$ & $70,2 \pm 6,1$ & $70,5 \pm 5,5$ & 0,890 \\
A5 $(\mathrm{mm})$ & $12,9 \pm 3,5$ & $12,6 \pm 3,5$ & 0,777 \\
A10 $(\mathrm{mm})$ & $14,1 \pm 3,7$ & $12,9 \pm 3,8$ & 0,129 \\
$M C F(\mathrm{~mm})$ & $15,8 \pm 4,6$ & $15,4 \pm 4,5$ & 0,604 \\
A20 $(\mathrm{mm})$ & $15,4 \pm 4,0$ & $14,9 \pm 4,2$ & 0,686 \\
A30 $(\mathrm{mm})$ & $16,5(12,0-20,0)$ & $15,0(12,0-17,0)$ & 0,516 \\
ML (\%) & $0,0(0,0-0,0)$ & $0,0(0,0-0,0)$ & 0,950 \\
LI30 (\%) & $100(100-100)$ & $100(100-100)$ & 0,473
\end{tabular}

Teste de qui-quadrado, exato de Fisher, $t$-Student, Mann-Whitney; $\mathrm{p}<0,05$ foi considerado significante

Variáveis com distribuição normal são apresentadas como média \pm desvio padrão

Variáveis que não tem distribuição normal são apresentadas como mediana, percentis 25 e 75 por cento (entre parênteses); $\mathrm{n}(\%)$ = valor absoluto e percentual dos pacientes

Tabela 25- Dados do ROTEM® (FIBTEM T1) no grupo mitral.

\begin{tabular}{|c|c|c|c|}
\hline Variável & Desmopressina (31) & Controle (27) & $\mathrm{P}$ \\
\hline \multicolumn{4}{|c|}{ FIBTEM (T1) } \\
\hline$C T(\mathrm{~s})$ & $67,5(57,0-78,2)$ & $65,0(58,0-78,0)$ & 0,564 \\
\hline$C F T(\mathrm{~s})$ & $1320,0(424,3-2552)$ & $739,5(260,5-1841)$ & 0,507 \\
\hline Ângulo $\alpha$ & $70,2 \pm 6,1$ & $70,5 \pm 5,5$ & 0,890 \\
\hline A5 (mm) & $12,9 \pm 3,5$ & $12,6 \pm 3,5$ & 0,777 \\
\hline $\mathrm{A} 10(\mathrm{~mm})$ & $14,1 \pm 3,7$ & $13,9 \pm 3,8$ & 0,129 \\
\hline$M C F(\mathrm{~mm})$ & $15,8 \pm 4,6$ & $15,4 \pm 4,5$ & 0,604 \\
\hline A20 (mm) & $15,4 \pm 4,0$ & $14,9 \pm 4,2$ & 0,686 \\
\hline $\mathrm{A} 30(\mathrm{~mm})$ & $16,5(12,0-20,0)$ & $15,0(12,0-17,0)$ & 0,516 \\
\hline $\operatorname{ML}(\%)$ & $0,0(0,0-0,0)$ & $0,0(0,0-0,0)$ & 0,950 \\
\hline LI30 (\%) & $100(100-100)$ & $100(100-100)$ & 0,999 \\
\hline
\end{tabular}

Teste de qui-quadrado, exato de Fisher, $t$-Student, Mann-Whitney; p<0,05 foi considerado significante

Variáveis com distribuição normal são apresentadas como média \pm desvio padrão

Variáveis que não tem distribuição normal são apresentadas como mediana, percentis 25 e 75 por cento (entre parênteses); $\mathrm{n}(\%)=$ valor absoluto e percentual dos pacientes 
Tabela 26- Dados do ROTEM® (FIBTEM T2) no grupo mitral.

\begin{tabular}{lllr}
\hline Variável & Desmopressina (31) & Controle $(27)$ & P \\
\hline FIBTEM (T2) & & & \\
$C T(\mathrm{~s})$ & $60,5(54,0-71,7)$ & $60,0(53,0-75,0)$ & 0,636 \\
$C F T(\mathrm{~s})$ & $403,0(77,0-783,5)$ & $420,5(139,8-885,3)$ & 0,901 \\
Ângulo $\alpha$ & $78,5(76,0-80,0)$ & $77,5(75,0-79,2)$ & 0,457 \\
A5 (mm) & $19,0(16,2-24,5)$ & $19,0(17,0-22,5)$ & 0,397 \\
A10 (mm) & $22,2 \pm 5,6$ & $21,1 \pm 4,2$ & 0,667 \\
$M C F(\mathrm{~mm})$ & $25,1 \pm 6,0$ & $25,6 \pm 7,1$ & 0,883 \\
A20 (mm) & $23,0(20,0-26,7)$ & $22,0(20,0-28,0)$ & 0,932 \\
A30 (mm) & $23,5(21,2-27,7)$ & $23,0(21,0-29,0)$ & 0,989 \\
ML $(\%)$ & $0,0(0,0-0,0)$ & $0,0(0,0-0,0)$ & 0,625 \\
LI30 (\%) & $100(100-100)$ & $100(100-100)$ & 0,999 \\
\hline
\end{tabular}

Teste de qui-quadrado, exato de Fisher, $t$-Student, Mann-Whitney; $<<0,05$ foi considerado significante

Variáveis com distribuição normal são apresentadas como média \pm desvio padrão

Variáveis que não tem distribuição normal são apresentadas como mediana, percentis 25 e 75 por cento (entre parênteses); $\mathrm{n}(\%)$ = valor absoluto e percentual dos pacientes

Tabela 27- Dados do ROTEM® (INTEM T0) no grupo aórtico.

\begin{tabular}{llll}
\hline Variável & Desmopressina (16) & Controle (20) & $\mathrm{P}$ \\
\hline$\underline{\text { INTEM (T0) }}$ & & & \\
$C T(\mathrm{~s})$ & $175,4 \pm 29,9$ & $158,7 \pm 30,9$ & 0,132 \\
$C F T(\mathrm{~s})$ & $73,5(56,5-94,7)$ & $65,0(61,0-89,0)$ & 0,712 \\
Ângulo $\alpha$ & $75,0(72,7-78,5)$ & $77,0(73,0-78,5)$ & 0,450 \\
A5 (mm) & $45,9 \pm 6,9$ & $46,0 \pm 5,6$ & 0,808 \\
A10 (mm) & $55,8 \pm 6,6$ & $56,2 \pm 4,5$ & 0,921 \\
$M C F(\mathrm{~mm})$ & $61,8 \pm 5,3$ & $62,9 \pm 5,1$ & 0,558 \\
A20 (mm) & $61,2 \pm 5,7$ & $61,8 \pm 4,9$ & 0,746 \\
A30 (mm) & $62,0(59,0-65,0)$ & $62,0(58,0-67,0)$ & 0,611 \\
ML (\%) & $6,0(4,5-7,0)$ & $4,0(2,0-9,0)$ & 0,516 \\
LI30 (\%) & $100(99-100)$ & $100(99-100)$ & 0,999
\end{tabular}

Teste de qui-quadrado, exato de Fisher, $t$-Student, Mann-Whitney; p<0,05 foi considerado significante

Variáveis com distribuição normal são apresentadas como média \pm desvio padrão

Variáveis que não tem distribuição normal são apresentadas como mediana, percentis 25 e 75 por cento (entre parênteses); $\mathrm{n}(\%)=$ valor absoluto e percentual dos pacientes 
Tabela 28- Dados do ROTEM® (INTEM T1) no grupo aórtico.

\begin{tabular}{llll}
\hline Variável & Desmopressina (16) & Controle (20) & P \\
\hline$\underline{I N T E M(T 1)}$ & & & \\
$C T(\mathrm{~s})$ & $188,1 \pm 20,7$ & $193,7 \pm 30,8$ & 0,794 \\
$C F T(\mathrm{~s})$ & $102,5(79,7-118,8)$ & $102,0(84,0-112,0)$ & 0,949 \\
Ângulo $\alpha$ & $71,5(68,5-76,0)$ & $71,0(69,0-73,0)$ & 0,545 \\
A5 $(\mathrm{mm})$ & $37,5(35,5-41,7)$ & $39,0(36,0-44,0)$ & 0,607 \\
A10 $(\mathrm{mm})$ & $49,0 \pm 6,2$ & $49,1 \pm 5,9$ & 0,779 \\
$M C F(\mathrm{~mm})$ & $58,2 \pm 5,8$ & $59,2 \pm 6,1$ & 0,664 \\
A20 $(\mathrm{mm})$ & $56,0 \pm 6,0$ & $56,6 \pm 6,6$ & 0,805 \\
A30 (mm) & $57,9 \pm 5,7$ & $59,0 \pm 5,8$ & 0,587 \\
ML $(\%)$ & $2,0(0,7-3,7)$ & $1,0(0,0-3,0)$ & 0,682 \\
LI30 $(\%)$ & $100(100-100)$ & $100(100-100)$ & 0,424
\end{tabular}

Teste de qui-quadrado, exato de Fisher, $t$-Student, Mann-Whitney; p<0,05 foi considerado significante Variáveis com distribuição normal são apresentadas como média \pm desvio padrão

Variáveis que não tem distribuição normal são apresentadas como mediana, percentis 25 e 75 por cento (entre parênteses); $\mathrm{n}(\%)=$ valor absoluto e percentual dos pacientes

Tabela 29- Dados do ROTEM® (INTEM T2) no grupo aórtico.

\begin{tabular}{llll}
\hline Variável & Desmopressina (16) & Controle (20) & $\mathrm{P}$ \\
\hline INTEM (T2) & & & \\
$C T(\mathrm{~s})$ & $67,6 \pm 10,7$ & $68,7 \pm 8,5$ & 0,649 \\
$C F T(\mathrm{~s})$ & $88,1 \pm 28,4$ & $91,4 \pm 24,6$ & 0,649 \\
Ângulo $\alpha$ & $77,0(73,0-78,0)$ & $77,0(76,0-79,0)$ & 0,775 \\
A5 (mm) & $44,7 \pm 7,7$ & $42,6 \pm 5,4$ & 0,595 \\
A10 (mm) & $54,3 \pm 8,8$ & $54,3 \pm 5,3$ & 0,993 \\
$M C F(\mathrm{~mm})$ & $63,8 \pm 5,8$ & $63,3 \pm 5,5$ & 0,826 \\
A20 (mm) & $62,5 \pm 5,8$ & $61,5 \pm 4,9$ & 0,606 \\
A30 (mm) & $63,9 \pm 5,8$ & $63,3 \pm 5,1$ & 0,751 \\
ML (\%) & $4(3-6)$ & $2(1-5)$ & 0,082 \\
LI30 (\%) & $100(100-100)$ & $100(100-100)$ & 0,999 \\
\hline
\end{tabular}

Teste de qui-quadrado, exato de Fisher, $t$-Student, Mann-Whitney; $\mathrm{p}<0,05$ foi considerado significante

Variáveis com distribuição normal são apresentadas como média \pm desvio padrão

Variáveis que não tem distribuição normal são apresentadas como mediana, percentis 25 e 75 por cento (entre parênteses); $\mathrm{n}(\%)$ = valor absoluto e percentual dos pacientes 
Tabela 30- Dados do ROTEM® (EXTEM T0) no grupo aórtico.

\begin{tabular}{llll}
\hline Variável & Desmopressina (16) & Controle (20) & P \\
\hline$\underline{E X T E M(T 0)}$ & & & \\
$C T(\mathrm{~s})$ & $61,5(53,2-64,2)$ & $65,0(57,0-69,0)$ & 0,214 \\
$C F T(\mathrm{~s})$ & $75,5(65,2-93,0)$ & $76,0(67,0-90,0)$ & 0,935 \\
Ângulo $\alpha$ & $74,5 \pm 4,5$ & $75,0 \pm 3,5$ & 0,920 \\
A5 $(\mathrm{mm})$ & $47,4 \pm 6,4$ & $47,8 \pm 4,8$ & 0,819 \\
A10 $(\mathrm{mm})$ & $57,7 \pm 6,1$ & $58,1 \pm 4,5$ & 0,906 \\
$M C F(\mathrm{~mm})$ & $65,5(60,7-70,0)$ & $67,0(62,0-68,0)$ & 0,793 \\
A20 $(\mathrm{mm})$ & $63,9 \pm 5,3$ & $64,3 \pm 4,1$ & 0,935 \\
A30 $(\mathrm{mm})$ & $65,5(60,7-70,0)$ & $67,0(62,0-67,2)$ & 0,784 \\
ML $(\%)$ & $5,5(3,7-7,2)$ & $4,0(3,0-8,0)$ & 0,807 \\
LI30 $(\%)$ & $100(100-100)$ & $100(100-100)$ & 0,999 \\
\hline
\end{tabular}

Teste de qui-quadrado, exato de Fisher, $t$-Student, Mann-Whitney; $\mathrm{p}<0,05$ foi considerado significante

Variáveis com distribuição normal são apresentadas como média \pm desvio padrão

Variáveis que não tem distribuição normal são apresentadas como mediana, percentis 25 e 75 por cento (entre parênteses); $\mathrm{n}(\%)=$ valor absoluto e percentual dos pacientes

Tabela 31- Dados do ROTEM® (EXTEM T1) no grupo aórtico.

\begin{tabular}{llll}
\hline Variável & Desmopressina (16) & Controle (20) & $\mathrm{P}$ \\
\hline$\underline{\text { EXTEM (T1) }}$ & & & \\
$C T(\mathrm{~s})$ & $73,5 \pm 8,1$ & $75,3 \pm 15,0$ & 0,699 \\
$C F T(\mathrm{~s})$ & $112,0(89,5-120,5)$ & $92,0(81,0-119,0)$ & 0,266 \\
Ângulo $\alpha$ & $70,0 \pm 5,2$ & $72,0 \pm 4,2$ & 0,227 \\
A5 $(\mathrm{mm})$ & $37,5(36,0-45,2)$ & $43,0(38,0-47,0)$ & 0,273 \\
A10 $(\mathrm{mm})$ & $50,5 \pm 6,3$ & $51,9 \pm 6,3$ & 0,369 \\
$M C F(\mathrm{~mm})$ & $60,2 \pm 5,3$ & $61,8 \pm 5,6$ & 0,257 \\
A20 (mm) & $57,6 \pm 5,5$ & $59,0 \pm 5,9$ & 0,361 \\
A30 (mm) & $59,7 \pm 5,3$ & $61,2 \pm 5,7$ & 0,306 \\
ML $(\%)$ & $2,0(0,0-3,5)$ & $1,0(0,0-4,0)$ & 0,143 \\
LI30 $(\%)$ & $100(100-100)$ & $100(100-100)$ & 0,999
\end{tabular}

Teste de qui-quadrado, exato de Fisher, $t$-Student, Mann-Whitney; p<0,05 foi considerado significante Variáveis com distribuição normal são apresentadas como média \pm desvio padrão

Variáveis que não tem distribuição normal são apresentadas como mediana, percentis 25 e 75 por cento (entre parênteses); $\mathrm{n}(\%)=$ valor absoluto e percentual dos pacientes 
Tabela 32- Dados do ROTEM® (EXTEM T2) no grupo aórtico.

\begin{tabular}{llll}
\hline Variável & Desmopressina (16) & Controle (20) & $\mathrm{P}$ \\
\hline$\underline{\text { EXTEM }(\mathrm{T} 2)}$ & & & \\
$C T(\mathrm{~s})$ & $169,5 \pm 22,8$ & $156,5 \pm 17,9$ & 0,044 \\
$C F T(\mathrm{~s})$ & $77,0(68,0-92,0)$ & $80,0(64,0-86,0)$ & 0,912 \\
Ângulo $\alpha$ & $76,5 \pm 2,5$ & $77,0 \pm 2,1$ & 0,430 \\
A5 $(\mathrm{mm})$ & $44,1 \pm 6,5$ & $43,0 \pm 5,6$ & 0,978 \\
A10 $(\mathrm{mm})$ & $54,2 \pm 6,1$ & $53,8 \pm 5,5$ & 0,911 \\
$M C F(\mathrm{~mm})$ & $61,1 \pm 5,1$ & $62,1 \pm 6,1$ & 0,365 \\
A20 (mm) & $60,4 \pm 5,0$ & $60,5 \pm 5,6$ & 0,529 \\
A30 (mm) & $61,0 \pm 5,5$ & $61,8 \pm 6,2$ & 0,453 \\
ML $(\%)$ & $4(3-7)$ & $2(1-3)$ & 0,021 \\
LI30 $(\%)$ & $100(99,2-100)$ & $100(99,0-100)$ & 0,999 \\
\hline
\end{tabular}

Teste de qui-quadrado, exato de Fisher, $t$-Student, Mann-Whitney; $<<0,05$ foi considerado significante

Variáveis com distribuição normal são apresentadas como média \pm desvio padrão

Variáveis que não tem distribuição normal são apresentadas como mediana, percentis 25 e 75 por cento (entre parênteses); $\mathrm{n}(\%)$ = valor absoluto e percentual dos pacientes

Tabela 33- Dados do ROTEM® (FIBTEM T0) no grupo aórtico.

\begin{tabular}{llll}
\hline Variável & Desmopressina (16) & Controle (20) & $\mathrm{P}$ \\
\hline FIBTEM (T0) & & & \\
$C T(\mathrm{~s})$ & $60,0(52,0-63,2)$ & $59,0(53,0-67,0)$ & 0,906 \\
$C F T(\mathrm{~s})$ & $167(83-251)$ & $494(242-873)$ & 0,209 \\
Ângulo $\alpha$ & $74,0(69,0-76,0)$ & $75,0(71,0-77,0)$ & 0,575 \\
A5 $(\mathrm{mm})$ & $14,1 \pm 4,4$ & $15,6 \pm 4,1$ & 0,315 \\
A10 $(\mathrm{mm})$ & $15,3 \pm 4,7$ & $16,8 \pm 4,6$ & 0,264 \\
$M C F(\mathrm{~mm})$ & $16,5(12,7-20,2)$ & $19,0(15,0-21,0)$ & 0,264 \\
A20 $(\mathrm{mm})$ & $16,5(12,7-20,0)$ & $18,0(14,0-21,0)$ & 0,498 \\
A30 $(\mathrm{mm})$ & $16,5(13,7-20,2)$ & $19,0(15,0-22,0)$ & 0,370 \\
ML $(\%)$ & $0,0(0,0-0,0)$ & $0,0(0,0-0,0)$ & 0,962 \\
LI30 $(\%)$ & $100(100-100)$ & $100(100-100)$ & 0,999 \\
\hline
\end{tabular}

Teste de qui-quadrado, exato de Fisher, $t$-Student, Mann-Whitney; p<0,05 foi considerado significante

Variáveis com distribuição normal são apresentadas como média \pm desvio padrão

Variáveis que não tem distribuição normal são apresentadas como mediana, percentis 25 e 75 por cento (entre parênteses); $\mathrm{n}(\%)=$ valor absoluto e percentual dos pacientes 
Tabela 34- Dados do ROTEM® (FIBTEM T1) no grupo aórtico.

\begin{tabular}{llll}
\hline Variável & Desmopressina (16) & Controle $(20)$ & $\mathrm{P}$ \\
\hline$\underline{\text { FIBTEM }(\mathrm{T} 1)}$ & & & \\
CT (s) & $77,3 \pm 28,9$ & $68,1 \pm 12,2$ & 0,582 \\
CFT $(\mathrm{s})$ & $669(85-2182)$ & $607(286-1607)$ & 0,894 \\
Ângulo $\alpha$ & $71,0(67,0-75,0)$ & $72,0(65,0-74,0)$ & 0,550 \\
A5 $(\mathrm{mm})$ & $12.5(9,7-15,2)$ & $13,0(10,0-17,0)$ & 0,941 \\
A10 $(\mathrm{mm})$ & $13,5(10,7-16,5)$ & $14(10-18)$ & 0,794 \\
$M C F(\mathrm{~mm})$ & $15,5(11,0-17,0)$ & $15,0(12,0-19,0)$ & 0,766 \\
A20 $(\mathrm{mm})$ & $14,5(11,0-17,5)$ & $15,0(11,0-19,0)$ & 0,822 \\
A30 $(\mathrm{mm})$ & $15,5(11,0-17,7)$ & $15,0(12,0-19,0)$ & 0,864 \\
ML $(\%)$ & $0,0(0,0-0,0)$ & $0,0(0,0-0,0)$ & 0,244 \\
LI30 $(\%)$ & $100(100-100)$ & $100(100-100)$ & 0,999 \\
\hline
\end{tabular}

Teste de qui-quadrado, exato de Fisher, $t$-Student, Mann-Whitney; p<0,05 foi considerado significante

Variáveis com distribuição normal são apresentadas como média \pm desvio padrão

Variáveis que não tem distribuição normal são apresentadas como mediana, percentis 25 e 75 por cento (entre parênteses); n $(\%)=$ valor absoluto e percentual dos pacientes

Tabela 35- Dados do ROTEM® (FIBTEM T2) no grupo aórtico.

\begin{tabular}{llll}
\hline Variável & Desmopressina (16) & Controle (20) & $\mathrm{P}$ \\
\hline FIBTEM (T2) & & & \\
$C T(\mathrm{~s})$ & $67,0(54,0-78,0)$ & $60,0(56,0-66,0)$ & 0,404 \\
$C F T(\mathrm{~s})$ & $170,0(142,8-512,8)$ & $319,0(108,5-688,5)$ & 0,797 \\
Ângulo $\alpha$ & $74,7 \pm 4.4$ & $77,8 \pm 2,8$ & 0,21 \\
A5 $(\mathrm{mm})$ & $19,0(14,0-22,0)$ & $19,0(17,0-22,0)$ & 0,353 \\
A10 $(\mathrm{mm})$ & $20,2 \pm 4,8$ & $21,2 \pm 4,1$ & 0,530 \\
MCF $(\mathrm{mm})$ & $27,0(17,0-28,0)$ & $24,0(21,0-29,0)$ & 0,750 \\
A20 (mm) & $25,0(17,0-26,0)$ & $23,0(20,0-26,0)$ & 0,661 \\
A30 (mm) & $26,0(17,0-27,2)$ & $24,0(21,0-27,0)$ & 0,992 \\
ML $(\%)$ & $0,0(0,0-0,0)$ & $0,0(0,0-0,0)$ & 0,999 \\
LI30 $(\%)$ & $100(100-100)$ & $100(100-100)$ & 0,999 \\
\hline
\end{tabular}

Teste de qui-quadrado, exato de Fisher, $t$-Student, Mann-Whitney; p<0,05 foi considerado significante

Variáveis com distribuição normal são apresentadas como média \pm desvio padrão

Variáveis que não tem distribuição normal são apresentadas como mediana, percentis 25 e 75 por cento (entre parênteses); $\mathrm{n}(\%)=$ valor absoluto e percentual dos pacientes 


\subsection{Eficácia do DDAVP em reduzir o sangramento}

Analisou-se o balanço sanguíneo, balanço hídrico e débito dos drenos cirúrgicos nos tempos pós-operatório imediato (POI), primeiro e segundo dias de pós-operatórios (PO). Não houve diferença significativa entre o grupo desmopressina em relação ao controle (tabela 36 e figura 8). A necessidade de transfusão de hemocomponentes no perioperatório manteve-se homogênea entre os grupos desmopressina e controle (21,3\% vs. $28,8 \%, P=0,526)$, respectivamente. O concentrado de hemácias foi o mais frequentemente utilizado $(19,1 \%$ vs. $28,8, P=0,317)$, seguido pelo concentrado de plaquetas $(4,3 \%$ v.s 5,8\%, $P=0,907)$ (tabela 36$)$

Tabela 36- Relação do controle volêmico com os grupos desmopressina e controle.

\begin{tabular}{|c|c|c|c|c|}
\hline Variável & Desmopressina (54) & Controle (54) & $\mathrm{P}$ & \\
\hline \multicolumn{5}{|l|}{ Balanço Sanguineo (mL) } \\
\hline POI & $-270,0(-405,0 /-165,0)$ & $-300,5(-365,0 /-204,8)$ & 0,732 & \\
\hline $1^{\circ} \mathrm{PO}$ & $-231,5(-323,0 /-130,0)$ & $-177,5(-285,0 /-132,5)$ & 0,171 & \\
\hline $2^{\circ} \mathrm{PO}$ & $-25,0(-152,5 /-2,2)$ & $-23,0(-122,5 / 0,0)$ & 0,674 & \\
\hline \multicolumn{5}{|l|}{ Balanço Hidrico $(\mathrm{mL})$} \\
\hline POI & $-69,0(-447,5 / 234,3)$ & $-163,5(-737,3 / 240,5)$ & 0,625 & \\
\hline $1^{\circ} \mathrm{PO}$ & $-946,5(-1514 /-353,8)$ & $-794,5(-1518 /-322,3)$ & 0,707 & \\
\hline $2^{\circ} \mathrm{PO}$ & $-180,0(-630,0 / 13,0)$ & $-147,0(-620,0 / 92,0)$ & 0,463 & \\
\hline \multicolumn{5}{|l|}{ Débito dos drenos (mL) } \\
\hline POI & $245,0(150,0-350,0)$ & $250,0(150,0-331,3)$ & 0,838 & \\
\hline $1^{\circ} \mathrm{PO}$ & $200,0(100,0-300,0)$ & $150,0(100,0-267,5)$ & 0,486 & \\
\hline $2^{\circ} \mathrm{PO}$ & $50,0(0,0-150,0)$ & $50,0(0,0-100,0)$ & 0,839 & \\
\hline Transfusão hemocomponentes - $\mathrm{n}$ & & & & $*$ \\
\hline$(\%)$ & $10(21,3)$ & $15(28,8)$ & 0,526 & \\
\hline Concentrado de hemácias & $9(19,1)$ & $15(28,8)$ & 0,317 & $*$ \\
\hline
\end{tabular}


Tabela 36- Relação do controle volêmico com os grupos desmopressina e controle. (Continuação)

\begin{tabular}{cllll}
\hline Variável & Desmopressina (54) & Controle (54) & $\mathrm{P}$ & \\
\hline Plasma fresco congelado & $2(4,3)$ & $1(1,9)$ & 1,000 & $* *$ \\
Concentrado de plaquetas & $2(4,3)$ & $3(5,8)$ & 1,000 & $* *$ \\
Crioprecipitado & $2(4,3)$ & $0(0,0)$ & 0,495 & $* *$
\end{tabular}

Teste de t-Student, Mann-Whitney; * Teste de qui-quadrado; ** Teste exato de Fisher; $\mathrm{p}<0,05$ foi considerado significante

Variáveis com distribuição normal são apresentadas como média \pm desvio padrão

Variáveis que não tem distribuição normal são apresentadas como mediana, percentis 2 5 e 75 por cento (entre parênteses); $n(\%)=$ valor absoluto e percentual dos pacientes

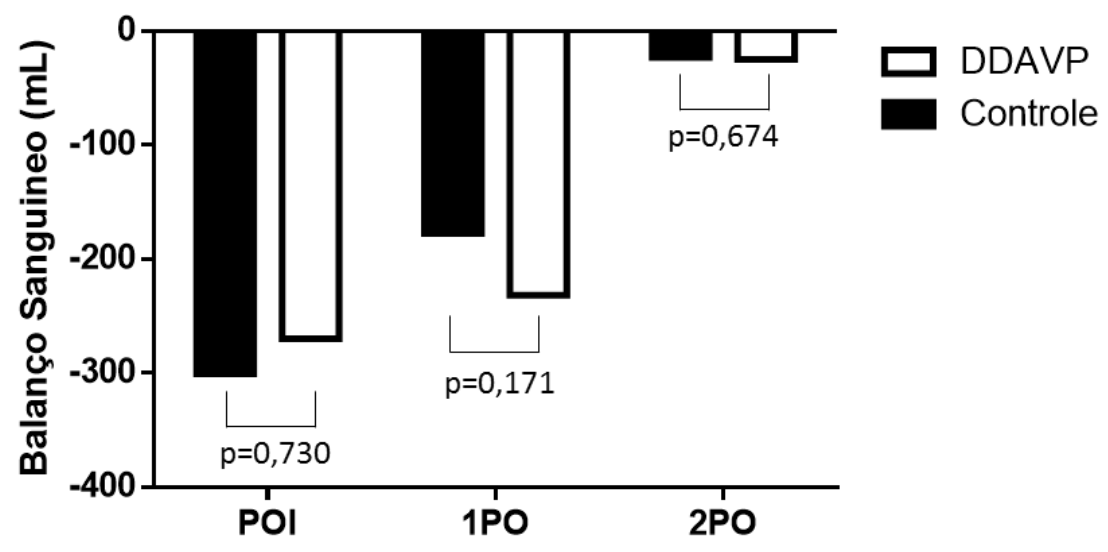

Figura 8- Relação do balanço sanguíneo entre os dois grupos (DDAVP e controle).

Devido à referida diferença estatística dos níveis de Fator VIII e FvW entre os dois principais tipos de cirurgia valvar (mitral e aórtico), investigou-se também cada um dos grupos cirúrgicos valvares quanto ao débito dos drenos cirúrgicos nos tempos $\mathrm{POI}, 1^{\circ}$ e $2^{0} \mathrm{PO}$ e à necessidade de transfusão de hemocomponentes; não houve diferença entre os mesmos em relação a esses critérios (tabela 37). Também não foram observadas divergências entre os 
principais tipos de cirurgias valvares quanto ao emprego da desmopressina em relação ao débito dos drenos cirúrgicos e transfusão sanguínea (tabela 38).

Tabela 37- Correlação entre o tipo de cirurgia valvar, débito dos drenos e transfusão sanguínea.

\begin{tabular}{|c|c|c|c|c|}
\hline Variável & Mitral (58) & Aórtico (36) & $\mathrm{P}$ & \\
\hline \multicolumn{5}{|c|}{ Tipo do débito dos drenos (mL) } \\
\hline POI & $200(145-300)$ & $250(150-358)$ & 0,352 & \\
\hline $1^{\circ} \mathrm{PO}$ & $170(100-280)$ & $150(100-250)$ & 0,742 & \\
\hline $2^{\circ} \mathrm{PO}$ & $50(0-100)$ & $50(0-100)$ & 0,853 & \\
\hline \multicolumn{5}{|c|}{ Necessidade de transfusão sanguínea } \\
\hline Sim & $11(20)$ & $11(35)$ & 0,129 & $*$ \\
\hline
\end{tabular}

* Teste de qui-quadrado, $t$-Student, Mann-Whitney; $\mathrm{p}<0,05$ foi considerado significante

Variáveis com distribuição normal são apresentadas como média \pm desvio padrão

Variáveis que não tem distribuição normal são apresentadas como mediana, percentis 25 e 75 por cento (entre parênteses); $\mathrm{n}(\%)$ = valor absoluto e percentual dos pacientes

Tabela 38- Correlação entre tipo valvar, débito dos drenos e transfusão sanguínea com os grupos desmopressina e controle.

\begin{tabular}{|c|c|c|c|c|c|c|}
\hline \multirow[t]{2}{*}{ Variável } & \multicolumn{2}{|c|}{ Mitral (58) } & \multirow[b]{2}{*}{$\mathrm{P}$} & \multicolumn{2}{|c|}{ Aórtico (36) } & \multirow[b]{2}{*}{$P$} \\
\hline & desmopres (31) & Controle (27) & & desmopressina (16) & Controle (20) & \\
\hline \multicolumn{7}{|c|}{$\begin{array}{l}\text { Tipo do débito } \\
\text { dos drenos (mL) }\end{array}$} \\
\hline POI & $240(150-350)$ & $200(125-260)$ & 0,467 & $225(150-352,5)$ & $250(150-362,5)$ & 0,758 \\
\hline $1^{\circ} \mathrm{PO}$ & $192,1 \pm 130,4$ & $182,3 \pm 130,3$ & 0,778 & $175(100-265)$ & $137,5(100-250)$ & 0,721 \\
\hline $2^{\circ} \mathrm{PO}$ & $50(0-100)$ & $50(0-100)$ & 0,904 & $75(27,5-118,8)$ & $25(0-87,5)$ & 0,169 \\
\hline
\end{tabular}

Necessidade de

transfussão

sanguínea

$\begin{array}{lllllll}\text { Sim } & 7(21,7) & 6(22,2) & 1,000 & 6(37,5) & 5(25,0) & 0,483\end{array}$

Teste de qui-quadrado, exato de Fisher, t-Student, Mann-Whitney; p<0,05 foi considerado significante Variáveis com distribuição normal são apresentadas como média \pm desvio padrão Variáveis que não tem distribuição normal são apresentadas como mediana, percentis 25 e 75 por cento (entre parênteses); $\mathrm{n}(\%)$ = valor absoluto e percentual dos pacientes 


\subsection{Complicações}

Em relação aos desfechos encontrados no presente estudo, demonstrou-se não haver diferenças significativas entre os dois grupos (desmopressina e controle) no número de reoperações. Complicações clínicas tais como IRA, AVC e Síndrome do Baixo Débito Cardíaco também apresentaram valores similares entre os dois grupos. A taxa de mortalidade em 30 dias seguiu a mesma tendência de não significância (figura 9).

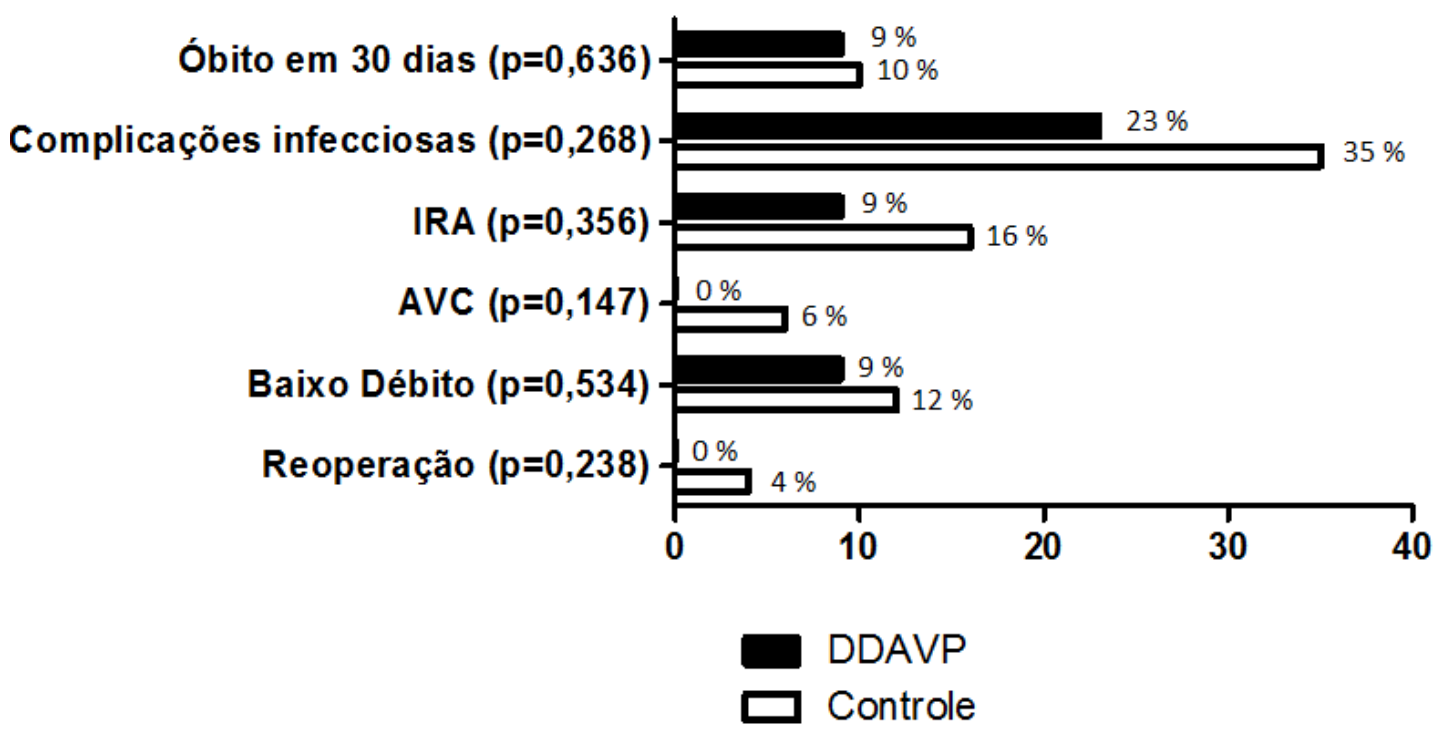

Figura 9- Incidência de desfechos em relação aos grupos $D D A V P$ e controle. 
O tempo de Ventilação Mecânica (VM) apresentou uma diferença relevante entre os grupos demopressina e o controle [897 (820 - 1011) vs. 1010 (846 - 1268) $P=0,031]$, respectivamente. Já quanto ao período de internação hospitalar, internação na UTI e uso de inotrópicos, observaram-se valores semelhantes do ponto de vista estatístico entre os dois grupos (tabela 39).

Tabela 39- Desfechos clínicos em relação aos grupos (DDAVP e controle).

\begin{tabular}{llll}
\hline Variável & Desmopressina (54) & Controle (54) & $\mathrm{P}$ \\
\hline Tempo VM (min) & $897(820-1011)$ & $1010(846-1268)$ & 0,031 \\
Tempo de inotrópico (min) & $1848(1440-2423)$ & $1823(1389-2580)$ & 0,827 \\
Tempo de UTI (dias) & $3(2-4)$ & $4(2-6)$ & 0,135 \\
Tempo de internação (dias) & $10(7-17)$ & $13(9-22)$ & 0,081
\end{tabular}

Teste de Mann-Whitney; $\mathrm{p}<0,05$ foi considerado significante

Variáveis que não tem distribuição normal são apresentadas como mediana, percentis 25 e 75 por cento (entre parênteses)

Em relação à utilização de fármacos vasoativos no pós-operatório (noradrenalina, nitroprussiato e nitroglicerina), os valores foram homogêneos entre os grupos (desmopressina e controle). A dose de administração da dobutamina não diferiu de forma significativa entre os grupos do estudo (tabela 40).

Tabela 40- Fármacos inotrópicos e vasoativos em relação aos grupos desmopressina e controle.

\begin{tabular}{lllll}
\hline Variável & Desmopressina (54) & Controle (54) & $\mathrm{P}$ & \\
\hline Dobutamina (ug/Kg/min) & $6,4(4,4-10,0)$ & $5,3(3,5-10,0)$ & 0,564 & \\
Uso de nitroglicerina $-\mathrm{n}(\%)$ & $6(11,1)$ & $4(7,1)$ & $0,741 * *$ \\
Uso de Nitroprussiato $-\mathrm{n}(\%)$ & $31(57,1)$ & $29(49,3)$ & $0,698 *$ \\
Uso de Norepinefrina $-\mathrm{n}(\%)$ & $11(20,4)$ & $13(24,1)$ & $0,643 *$
\end{tabular}

* Teste de qui-quadrado, ** Teste exato de Fisher, Mann-Whitney; p<0,05 foi considerado significante

Variáveis que não tem distribuição normal são apresentadas como mediana, percentis 25 e 75 por cento (entre parênteses); $\mathrm{n}(\%)=$ valor absoluto e percentual dos pacientes 
Os valores da diurese quantificada nos tempos (T0, T1 e T2) foram equivalentes entre os grupos (desmopressina e controle). O mesmo ocorreu com os valores da dosagem de sódio plasmático (tabela 41).

Tabela 41- Sódio e diurese dos grupos desmopressina e controle.

\begin{tabular}{rlll}
\hline Variável & Desmopressina (54) & Controle (54) & $\mathrm{P}$ \\
\hline $\begin{aligned} \text { Diurese } 24 \mathrm{~h}(\mathrm{~mL}) \\
\text { Sódio }(\mathrm{mmol} / \mathrm{L})\end{aligned}$ & $2312 \pm 703$ & $228 \pm 558$ & 0,563 \\
T 0 & $135,6 \pm 2,8$ & $135,6 \pm 2,5$ & 0,999 \\
T 1 & $137(135-139)$ & $136(134-138)$ & 0,511 \\
T 2 & $138,0(136,0-140,0)$ & $138,0(136,0-140,3)$ & 0,998 \\
\hline
\end{tabular}

Teste de qui-quadrado, exato de Fisher, Mann-Whitney; p<0,05 foi considerado significante

Variáveis que não tem distribuição normal são apresentadas como mediana, percentis 25 e 75 por cento (entre parênteses); $\mathrm{n}(\%)=$ valor absoluto e percentual dos pacientes 
O presente estudo demonstrou que a administração profilática de desmopressina, nos 108 pacientes selecionados e randomizados, submetidos à cirurgia cardíaca com CEC para correção de defeito valvar, não promoveu benefício laboratorial hemostático, assim como não reduziu o sangramento perioperatório e o consumo de hemocomponentes de forma significativa.

Os grupos foram homogêneos no que se refere às características préoperatórias (demográficas, clínicas e laboratoriais). Quanto às características intraoperatórias, não houve diferença entre os grupos desmopressina e controle no que concerne ao tempo cirúrgico, exames laboratoriais e balanços hídrico e sanguíneo. Tais resultados evidenciam que os critérios utilizados na inclusão do estudo foram adequados para a análise dos desfechos e objetivos da pesquisa. Além disso, mostrou que fatores que poderiam interferir diretamente nas análises da pesquisa, mantiveram-se homogêneos entre os dois grupos, sugerindo que a alocação dos participantes, apresentou randomização adequada.

$\mathrm{Na}$ realização de metanálise com estudos clínicos e randomizados, entre 1986 a 2008, Crescenzi et al. ${ }^{32}$ observaram que o uso da desmopressina reduziu a perda sanguínea (cerca de $80 \mathrm{~mL}$ por paciente) e necessidade de transfusão (cerca de 0,3 unidades por paciente), sem redução no número de doentes que receberam transfusão. Não houve diferença estatística entre o grupo controle e o estudado quanto a eventos tromboembólicos. Entretanto, apenas 38 estudos participaram dessa metanálise, sendo que 28 destes envolviam cirurgias cardíacas e apenas três estudos possuíam análise viscoelástica e avaliação da função plaquetária. Além disso, a maioria dos 
estudos apresentava casuística insuficiente para adequado poder estatístico, amostras não uniformes, diversidade de procedimentos cirúrgicos e falta de notificação uniforme do sangramento.

Wademan et al. ${ }^{42}$, numa revisão sistemática, pesquisaram publicações entre 1950 e 2013 que relacionavam a utilização da desmopressina, em cirurgias cardíacas com CEC, com o sangramento pós operatório. Identificaram 38 artigos, dentre os quais, 19 apresentaram melhores evidências ao questionamento proposto. Evidenciaram uma pequena redução significativa da perda sanguínea pós operatória, mas sem diminuição consistente da transfusão sanguínea. Estes resultados são consonantes à meta-análise de Canttaneo et $a^{43}$, com estudos clínicos controlados envolvendo 1171 pacientes submetidos à cirurgia cardíaca com CEC.

Mais recentemente, Bignami et al. $^{44}$ realizaram um estudo multicêntrico, avaliando o sangramento cirúrgico com a utilização profilática da desmopressina em 135 pacientes que apresentavam sangramento ativo no pós operatório imediato. Não houve redução do sangramento cirúrgico ou de transfusão sanguínea; entretanto, assim como em nosso estudo, o antifibrinolítico foi administrado em todos os pacientes .

Desborough et al. $^{45}$, realizaram uma revisão sistemática de estudos clínicos controlados e randomizados, avaliando o sangramento cirúrgico e a administração da desmopressina em pacientes que apresentavam disfunção plaquetária confirmada por testes laboratoriais, pelo uso de agentes antiplaquetários ou submetidos à CEC. Observaram a redução significativa do 
sangramento cirúrgico e transfusão sanguínea de hemácias. Já Pleym et al. ${ }^{30}$ mostraram não haver redução do sangramento cirúrgico com a administração profilática da desmopressina em pacientes que permaneciam em tratamento com antiagregante plaquetário (AAS até $300 \mathrm{mg} / \mathrm{dia}$ ) até o dia da cirurgia.

Em nosso estudo, avaliamos o débito dos drenos cirúrgicos, assim como o balanço hídrico, consumo de hemocomponentes e balanço sanguíneo até 24 horas após a cirurgia como método de avaliação da perda sanguínea e controle da volemia do doente. Não foram identificadas diferenças entre o grupo da intervenção (desmopressina) e o grupo controle.

Percebe-se que os resultados, no que concerne à redução do sangramento, são pouco expressivos para justificar o uso da desmopressina profilática com intuito da redução do sangramento cirúrgico e da transfusão de hemocomponentes; tão verdade que, no Guidelines da Sociedade Européia de Anestesiologia, Kozek-Langenecker et al. ${ }^{31}$ já sugeriam não haver evidência convincente de que a desmopressina possa reduzir o sangramento perioperatório ou a transfusão sanguínea alogênica, exceto nos pacientes com distúrbios congênitos específicos de sangramento (nível de evidência 2B).

Entretanto, a maioria dos estudos e revisões citadas não selecionaram pacientes submetidos à cirurgia cardíaca com CEC para correção de defeito valvar exclusivamente. Além disso, não avaliaram a coagulação sanguínea com os modernos testes laboratoriais disponíveis, visando identificar eventuais alterações hemostáticas que possam justificar ou mesmo favorecer um sangramento cirúrgico aumentado. 
Pesquisas estão sendo desenvolvidas a fim de avaliar a relação entre doença valvar e coagulopatias. Vincentelli $A$ et al. ${ }^{7}$ avaliaram em 42 pacientes, a relação da síndrome de von Willebrand adquirida (2A) com o grau de estenose aórtica. Selecionaram pacientes com estenose aórtica grave (área valvar $<0,5 \mathrm{~cm}^{2}$ ) e pacientes com estenose aórtica moderada. Analisaram a função plaquetária, teste de ligação do $F v W$ ao colágeno, antígeno do $F v W$ e a dosagem dos multímeros do FvW. Notaram que o grupo com estenose aórtica severa apresentou níveis do teste de ligação do $F v W$ ao colágeno e função plaquetária menores que no grupo com estenose moderada; entretanto, os níveis do Fator VIII, FvW e dos multímeros do FvW não apresentaram diferença estatística entre os grupos.

Pappalardo et al. ${ }^{8}$ avaliaram a hemostasia primária após emprego da desmopressina entre pacientes submetidos à cirurgia de reparo valvar mitral (por insuficiência) e aórtico (por estenose) analisando a função plaquetária, antígeno do $F v W$ e cofator da ristocetina. Não foram identificadas diferenças entre a utilização do desmopressina com o grupo controle.

No presente estudo, incluímos 108 pacientes consecutivos que se submeteram à cirurgia cardíaca para correção de defeito valvar sem especificar qual a doença ou o tipo valvar. Avaliamos a eficácia da utilização profilática da desmopressina em promover benefícios na condição hemostática dos participantes. Não houve diferenças quanto aos valores dos testes laboratoriais da coagulação analisados no grupo intervenção em relação ao controle. 
Contudo, observou-se que os valores do FvW e do Fator VIII apresentaram-se elevados em relação aos valores normais de referência nos tempos T0 (indução da anestesia) e T1 (2h após a administração da desmopressina ou placebo) nos dois grupos. Este achado é congruente à analise de que tais fatores tendem a se apresentar elevados em estado de inflamação, infecção, neoplasias e estresse, visto que o FvW caracteriza-se como sendo uma proteína de fase aguda ${ }^{3}$.

Além disso, identificamos que os pacientes com doença valvar aórtica apresentavam níveis de Fator VIII e de FvW significativamente menores nos tempos T0 e T1 em relação aos pacientes com doença valvar mitral.

Diante do exposto, realizamos separadamente a análise de acordo com os dois principais tipos valvares do presente estudo (aórtico e mitral) em relação ao uso da desmopressina profilática e o placebo. Os níveis mais elevados de Fator VIII e FvW nos pacientes submetidos à cirurgia valvar mitral, não corresponderam à redução do sangramento cirúrgico ou melhora significativa da hemostasia mensurados através dos testes laboratoriais preconizados.

O tipo 2A da doença de von Willebrand se caracteriza essencialmente pela perda dos multímeros do FvW, devido à proteólise aumentada que as forças de cisalhamento promovem em decorrência da doença da valva cardíaca, podendo ser encontrados valores de dosagem plasmática dos mesmos reduzida em até $90 \%$ dos pacientes ${ }^{4}$. Entretanto, Carrasco et al. ${ }^{46}$ tentaram relacionar a doença de von Willebrand tipo 2A com estenose aórtica. 
O estudo não foi finalizado pois os exames pré-operatórios mostraram que nenhum dos pacientes que seriam submetidos à cirurgia de correção do defeito valvar obtiveram exames alterados a ponto de se caracterizarem portadores da doença de von Willebrand tipo 2A.

A doença valvar e a cirurgia cardíaca com circulação extracorpórea também estão relacionadas com a disfunção plaquetária. No atual modelo celular da coagulação, as plaquetas exercem papel de protagonismo, entretanto, substitutos sintéticos ainda não são uma realidade no arsenal terapêutico e as transfusões plaquetárias permanecem sendo a única forma repositiva do hemocomponente.

Steinlechner et al. ${ }^{6}$ realizaram um estudo controlado para analisar o benefício da administração pré-operatória da desmopressina em melhorar a função plaquetária. Foram incluídos 43 pacientes com estenose aórtica grave e com disfunção plaquetária, mensurada através do teste de análise da função plaquetária PF100, que se submeteriam ao tratamento cirúrgico da condição cardíaca. Revelaram a inexistência de diferenças quanto aos níveis do FvW entre os dois grupos, contudo se notou melhora da função plaquetária de forma significativa com o uso da desmopressina.

Jin et $a l .{ }^{16}$ analisaram 0 efeito da desmopressina administrada profilaticamente em relação à função plaquetária, em pacientes submetidos à cirurgia cardíaca valvar. Foram alocados 102 pacientes entre os grupos intervenção e controle. A função plaquetária foi avaliada através do teste de agregação plaquetária (AggRAM) e não houve diferença estatística entre os 
dois grupos. Os autores propuseram que se a desmopressina é capaz de exercer efeito em reduzir a disfunção plaquetária, esse mecanismo deva ser de outra forma que não através da agregação plaquetária.

No presente estudo, os medicamentos antiplaquetários foram suspensos com dez dias de antecedência da cirurgia. A análise da função plaquetária foi realizada através do teste AggRAM, que analisa a agregação das plaquetas pela transmitância de luz. Identificamos, em todos os participantes do estudo, que a função plaquetária, avaliada no tempo 0 (indução da anestesia), apresentava-se dentro dos limites de normalidade. Não houve alteração significativa da função e do número de plaquetas em todos os tempos de coleta entre os dois grupos da pesquisa. Entretanto, todos os pacientes do nosso estudo se submeteram à infusão do antifibrinolítico, conforme protocolo institucional.

Desborough et al. ${ }^{47}$, numa revisão sobre alternativas para a transfusão alogênica de plaquetas, analisaram que os agentes antifibrinolíticos podem exercer efeitos outros que não o de aumentar a força e resistência do trombo. Ativação do sistema imunológico, ativação do endotélio e até mesmo clivagem dos multímeros de FvW e fibronectina podem estar relacionados com o aumento da plasmina e, assim, com a fibrinólise. Portanto, a utilização do antifibrinolítico em cirurgias cardíacas valvares pode atuar em reduzir a disfunção das plaquetas ${ }^{48,49}$. Esta ação pode ter corroborado na atenuação da disfunção plaquetária que observamos, traduzida pela não observância de discrepâncias nos testes laboratoriais utilizados em nosso estudo. 
Mirmansoori et al. ${ }^{50}$ realizaram um estudo controlado para avaliar a eficácia da desmopressina em reduzir o sangramento cirúrgico relacionado à coagulopatia. Foram selecionados e randomizados 100 pacientes que fizeram uso de medicamentos antiplaquetários em doses profiláticas até 24 horas antes da cirurgia. $O$ trabalho mostrou padrão de homogeneidade entre o grupo intervenção (desmopressina) e o controle quanto da redução do sangramento, como também da análise laboratorial da coagulação. Desborough et al ${ }^{45}$, numa revisão sistemática que analisou o efeito terapêutico da desmopressina em pacientes que sabidamente faziam uso de fármacos antiplaquetários, mostraram resultados semelhantes aos citados anteriormente.

A tromboelastometria rotacional $(R O T E M \Theta)$ e a tromboelastografia (TEG) são testes point-of-care da coagulação que estão sendo amplamente estudados em cirurgias cardíacas com CEC. A associação dos testes à beira leito com os métodos tradicionais da análise laboratorial da coagulação, está auxiliando na confecção de protocolos que estabeleçam critérios para a administração de fármacos e hemocomponentes, no tratamento otimizado das coagulopatias perioperatórias ${ }^{18,51}$.

Deppe et al. ${ }^{52}$ realizaram uma meta-análise com 8332 pacientes para avaliar a utilização da $T E G / R O T E M{ }^{\circledR}$ no manejo da coagulação em cirurgias cardíacas com CEC. Participaram desta meta-análise, estudos randomizados e controlados, como também observacionais, que analisaram a estratégia transfusional entre o grupo intervenção (TEG/ROTEM®) e o grupo controle. Desfechos, tais como mortalidade, taxa de reoperação cirúrgica, IRA, AVC e tempo de internação hospitalar e de UTI foram avaliados. Concluiu-se que o 
manejo da coagulação sanguínea, baseado nos testes TEG/ROTEM®, promoveu redução do risco de exposição a produtos alogênicos do sangue, redução da reoperação por sangramento, taxa de IRA e de eventos tromboembólicos pós operatórios ${ }^{49}$.

Kakouti et al. ${ }^{53}$ conduziram um estudo multicêntrico controlado onde a intervenção foi a utilização de um algoritimo transfusional, baseado nos testes point-of-care. Participaram do estudo 7402 pacientes, de 12 centros médicos canadenses, que foram alocados nos dois grupos da pesquisa. Utilizaram o ROTEMA com os testes EXTEM e FIBTEM. Os autores observaram que a utilização do algoritmo foi eficaz em reduzir significativamente a transfusão de concentrado de hemácias e de plaquetas.

Todavia, nosso estudo não objetivou analisar a eficácia do método da tromboelastometria em reduzir sangramento cirúrgico, mas sim utilizá-lo como adjuvante para analisar, de forma mais criteriosa possível, o perfil hemostático dos pacientes que receberam desmopressina profilática em cirurgia cardíaca valvar em relação ao grupo controle. Realizou-se a análise viscoelástica da coagulação através da tromboelastometria (0). Os reagente INTEM, EXTEM e FIBTEM foram utilizados para a análise das amostras sanguíneas de todos os participantes do estudo nos três tempos de coleta. Os resultados das análises ficaram disponíveis aos médicos assistentes logo que foram sido concluídos. A tomada de decisão, quanto da terapêutica da coagulopatia, seguiu de acordo com critérios institucionais, como descrito em nosso estudo. Não observamos benefícios concernentes aos padrões hemostáticos, nos pacientes submetidos à administração profilática da desmopressina em cirurgias cardíacas valvares, 
em relação ao grupo controle. Este resultado está de acordo com as nossas análises do teste da função plaquetária (AggRAM), como também dos exames clássicos da coagulação (TAP, INR TTPa e contagem de plaquetas).

Portanto, a utilização profilática da desmopressina, mesmo em pacientes que apresentem defeitos plaquetários adquiridos, tais como doença valvar, fármacos anti plaquetários em doses profiláticas, submetidos à CEC não prolongada e em sangramento pós operatório, apresenta resultados inconclusivos quanto do seu benefício na redução do sangramento cirúrgico ou efeito hemostático laboratorial significativo ${ }^{5,6,25,30,43,45,46,47,50}$.

Os principais efeitos colaterais da desmopressina são: hipotensão, retenção urinária, hiponatremia e risco de trombose. Avaliamos em nosso estudo, dados clínicos e laboratoriais que tivessem relação com as eventuais complicações potencialmente ligadas à administração da desmopressina e aos seus efeitos adversos.

O principal efeito adverso da desmopressina é a hipotensão ${ }^{32}$. Por não possuir efeito no receptor $\mathrm{V} 1$ tal qual a vasopressina e sim no receptor $\mathrm{V} 2$, a desmopressina não promove vasoconstrição e hipertensão. Por ter baixa afinidade aos receptores $\mathrm{V} 1$, se a desmopressina for utilizada em altas doses (como acontece para a terapêutica da hemostasia), pode promover inativação dos receptors V1 endoteliais e desencadear hipotensão ${ }^{24}$. No entanto, apresenta um caráter transitório e tênue, relacionado ao momento da infusão venosa $^{32}$. 
No presente estudo, averiguou-se o balanço hídrico, tempo e tipo de fármaco vasoativo administrado. Não se constatou diferença significativa entre os pacientes que utilizaram desmopressina e o grupo controle. O mesmo ocorreu com níveis de sódio plasmático e volume de diurese em todos os tempos do estudo.

O risco de eventos tromboembólicos é descrito na literatura ${ }^{32}$ e foi um dos motivos de terem sido excluídos, da presente pesquisa, pacientes subemtidos à cirurgia de revascularização do miocárdio. Entretanto, diversos autores na literatura vêm demostrando que esse evento é bastante raro, o que implica que o uso da desmopressina com finalidade hemostática, em cirurgias cardíacas valvares, é relativamente seguro ${ }^{6,16}$. Neste estudo não foi identificado aumento do risco de eventos tromboembólicos (IRA, AVC e IAM) do grupo intervenção comparado ao controle.

Nesta investigação, o tempo de internação na UTI, internação hospitalar e mortalidade em 30 dias foram homogêneos entre os dois grupos. Jin et al. mostraram resultados de desfechos clínicos muito semelhantes com os do presente estudo. O tempo de ventilação mecânica foi significativamente menor no grupo intervenção em relação ao controle [897 (820 - 1011) vs. 1010 (846 - 1268) $P=0,031]$. Entretanto, este achado não apresentam nenhuma explicação plausível ou correlação com a literatura vigente.

Portanto, a administração profilática da desmopressina em cirurgias cardíacas valvares mostrou-se segura quanto aos efeito adversos a ela 
descritos, além de não contribuir com o aumento das complicações pós operatórias analisadas. 
7. Conclusão 
A. A utilização profilática da desmopressina em cirurgias cardíacas valvares como um agente hemostático, não mostrou diferença clínica ou laboratorial representativa em relação ao controle no presente estudo.

B. O TP no tempo T2 e os níveis de Fator VIII no tempo T1 foram maiores no grupo desmopressina em relação ao controle. Entretanto, tais achados laboratoriais, não tiveram correlação com os testes viscoelásticos e agregação plaquetária, que tiveram valores semelhantes entre os grupos do estudo, além de não demonstrar diferença clínica significativa.

C. A utilização profilática da desmopressina em cirurgias cardíacas valvares não demonstrou ser eficaz para redução do sangramento cirúrgico e do consumo de hemocomponentes no presente estudo.

D. Quanto aos principais efeitos colaterais esperados com o uso da desmopressina (hipotensão, hiponatremia e oligúria), não houve diferenças entre a utilização e dose de fármacos vasoativos, diurese e os níveis plasmáticos de sódio nas primeiras 48 horas da cirurgia, entre os dois grupos do estudo.

E. O tempo de ventilação mecânica foi significativamente menor no grupo desmopressina em relação ao controle. Já, os níveis de lactato plasmáticos, no tempo T2, foram maiores no grupo intervenção em relação ao controle. Estes achados não contribuíram para o aumento do tempo de internação na UTI e hospitalar, ou mesmo, na taxa de mortalidade em 30 dias. 


\section{Anexo A: APROVAÇÃO DO CEP}

\section{HOSPITAL DAS CLÍNICAS DA FACULDADE DE MEDICINA DA USP - HCFMUSP}

\section{PARECER CONSUBSTANCIADO DO CEP}

\section{DADOS DO PROJETO DE PESQUISA}

Título da Pesquisa: USO PROFILÁTICO DA DESMOPRESSINA EM CIRURGIAS CARDÍACAS VALVARES NA REDUÇÃO DO SANGRAMENTO PERIOPERATÓRIO

Pesquisador: Filomena Regina Gomes Galas

Área Temática:

Versão: 1

CAAE: 24147913.1 .0000 .0068

Instituição Proponente: Hospital das Clínicas da Faculdade de Medicina da USP

Patrocinador Principal: HOSPITAL DAS CLINICAS DA FACULDADE DE MEDICINA DA U S P FUNDACAO DE AMPARO A PESQUISA DO ESTADO DE SAO PAULO

DADOS DO PARECER

Número do Parecer: 488.747

Data da Relatoria: 11/12/2013

Apresentação do Projeto:

Estudo intervencional, clínico, prospectivo, randomizado e duplamente encoberto a respeito do uso profilático da desmopressina em cirurgias cardíacas valvares na redução do sangramento perioperatório.

\section{Objetivo da Pesquisa:}

Avaliar o uso da desmopressina como agente hemostático capaz de atenuar o sangramento excessivo em cirurgias cardíacas valvares com circulação extracorpórea.

\section{Avaliação dos Riscos e Benefícios:}

Os riscos apresentados são inerentes aos procedimentos cirúrgicos realizados, sem que haja qualquer risco relevante relacionado ao protocolo de estudo. Os benefícios podem existir para os pacientes do grupo de estudo em relação a obtenção dos objetivos propostos de diminuição do sangramento pós-operatório.

\section{Comentários e Considerações sobre a Pesquisa:}

Ensaio clínico randomizado a respeito de tema de interesse científico, com metodologia adequada e número adequado de pacientes propostos.

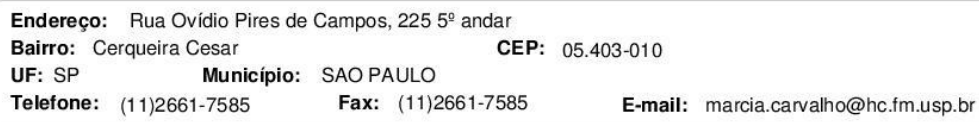




\section{HOSPITAL DAS CLIINICAS DA USP - HCFMUSP}

FACULDADE DE MEDICINA DA Platoforma

Continuação do Parecer: 488.747

Considerações sobre os Termos de apresentação obrigatória:

TCLE em linguagem clara e com conteúdo adequado. Foram apresentados todos os documentos necessários para o desenvolvimento da pesquisa, incluindo aqueles de responsabilidade dos pesquisadores.

Recomendações:

Conclusões ou Pendências e Lista de Inadequações:

Aprovação sem pendências atuais.

Situação do Parecer:

Aprovado

Necessita Apreciação da CONEP:

Não

Considerações Finais a critério do CEP:

Em conformidade com a Resolução CNS n 466/12 ¿ cabe ao pesquisador: a) desenvolver o projeto conforme delineado; b) elaborar e apresentar relatórios parciais e final; c)apresentar dados solicitados pelo CEP, a qualquer momento; d) manter em arquivo sob sua guarda, por 5 anos da pesquisa, contendo fichas individuais e todos os demais documentos recomendados pelo CEP; e) encaminhar os resultados para publicação, com os devidos créditos aos pesquisadores associados e ao pessoal técnico participante do projeto; f) justificar perante ao CEP interrupção do projeto ou a não publicação dos resultados.

SAO PAULO, 11 de Dezembro de 2013

Assinador por:

Luiz Eugênio Garcez Leme

(Coordenador)

Endereço: Rua Ovídio Pires de Campos, $2255^{\circ}$ andar

Bairro: Cerqueira Cesar

CEP: $05.403-010$

UF: SP Município: SAO PAULO

Telefone: (11)2661-7585 Fax: (11)2661-7585 E-mail: marcia.carvalho@hc.fm.usp.br 
Anexo B: Termo de Consentimento Livre e Esclarecido (TCLE)

HOSPITAL DAS CLÍNICAS DA FACULDADE DE MEDICINA DA UNIVERSIDADE DE SÃO PAULO-HCFMUSP

TERMO DE CONSENTIMENTO LIVRE E ESCLARECIDO

(versão 1.0 de 05/07/13)

DADOS DE IDENTIFICAÇÃO DO SUJEITO DA PESQUISA OU RESPONSÁVEL LEGAL

1. NOME:

DOCUMENTO DE IDENTIDADE № :

SEXO:.$M \square F \square$

DATA NASCIMENTO:

ENDEREÇO №. .APTO:

BAIRRO: CIDADE CEP:

TELEFONE: DDD

2. RESPONSÁVEL LEGAL

NATUREZA (grau de parentesco, tutor, curador etc.)

DOCUMENTO DE IDENTIDADE : SEXO: $M \square F \square$

DATA NASCIMENTO.

ENDEREÇO: № APTO:

BAIRRO CIDADE:

CEP: TELEFONE:DDD(................

\section{DADOS SOBRE A PESQUISA}

1. TÍTULO DO PROTOCOLO DE PESQUISA: Uso profilático da desmopressina em cirurgias cardíacas valvares na redução do sangramento perioperatório.

2. PESQUISADOR: Profa. Dra. Filomena Regina Barbosa Gomes Galas CARGO/FUNÇÃO: médica INSCRIÇÃO CONSELHO REGIONAL № 61.249

UNIDADE DO HCFMUSP: Instituto do Coração - InCor PESQUISADOR : Dr. Giovanne Santana de Oliveira CARGO/FUNÇÃO: médico INSCRIÇÃO CONSELHO REGIONAL № 154.614 UNIDADE DO HCFMUSP: Instituto do Coração - InCor 
4.DURAÇÃO DA PESQUISA : 12 meses

\section{HOSPITAL DAS CLÍNICAS DA FACULDADE DE MEDICINA DA UNIVERSIDADE DE SÃO PAULO-HCFMUSP}

Essas informações estão sendo fornecidas para sua participação voluntária neste estudo, para avaliar o efeito do uso de um medicamento chamado desmopressina (DDAVP) na redução da necessidade de transfusão de sangue no pós-operatório em pacientes que apresentem sangramento relacionado à cirurgia para correção da válvula do coração.

O sangramento devido à cirurgia cardíaca é uma complicação freqüente que acontece em cerca de 40 a $90 \%$ dos casos, devido ao uso de medicações que evitam a coagulação do sangue e uso do aparelho coração-pulmão (circulação extracorpórea). A ocorrência de sangramento é um fator de risco para o desenvolvimento de infecções, dificuldade para respirar, problemas nos rins e casos mais graves à morte.

Este estudo tem a intenção de comparar o uso DDAVP para a prevenção de sangramento relacionado à cirurgia do coração. No inicio da anestesia, será coletada uma amostra de sangue para medir um dos componentes da coagulação, e após a retirada do aparelho coração-pulmão, o tratamento será sorteado um grupo de pacientes receberá o medicamento e o outro grupo receberá o soro fisiológico sendo que existe $50 \%$ de chance de pertencer a um dos grupos.

O resultado será medido por meio da observação clínica da diminuição do sangramento, da diminuição da necessidade de recebimento de partes do sangue e de exames laboratoriais de rotina e também pela tromboelastrometria que avalia de maneira mais rápida 0 processo de coagulação do sangue. Serão coletadas amostras de sangue do cateter no inicio da cirurgia, 2 horas e 24 horas depois da administração do medicamento.

Espera-se não haver risco em qualquer um dos grupos de estudo, pois o medicamento em questão já é utilizado no tratamento do sangramento depois da cirurgia e efeitos colaterais são bem tolerados.

Em qualquer etapa do estudo terá acesso aos profissionais responsáveis pela pesquisa para esclarecimento de dúvidas. Os principais investigadores são a Dra. Filomena Regina Barbosa Gomes Galas e a Dr. Giovanne Santana que podem ser encontrados no endereço Avenida Dr. Enéas de Carvalho Aguiar, no 44, InCor_HC-FMUSP CEP: 05403-000, Telefone(s): $2661-5560$ e 2661-5012. 
Se houver alguma dúvida ainda sobre a ética da pesquisa, entre em contato com o Comitê de Ética em Pesquisa (CEP) - Rua Ovídio Pires de Campos, 225 - 5aaㄱ- Telefone: 2661-6442 ramais 16, 17, 18 ou 20, FAX: 2661-6442, ramal 26 - E-mail: cappesq@hcnet.usp.br

É garantida a liberdade da retirada de consentimento a qualquer momento e deixar de participar do estudo, sem qualquer prejuízo à continuidade do seu tratamento na Instituição.

As informações obtidas serão analisadas em conjunto com outros pacientes, não sendo divulgado a identificação de nenhum paciente. Não há despesas pessoais para o participante em qualquer fase do estudo, incluindo exames e consultas. Também não há compensação financeira relacionada à participação.

Acredito ter sido suficientemente informado a respeito das informações que li ou que foram lidas para mim, descrevendo o estudo "Uso profilático da desmopressina em cirurgias cardíacas valvares na redução do sangramento perioperatório".

Eu discuti com a Dra. Filomena/Dr. Giovanne sobre a minha decisão em participar nesse estudo. Ficaram claros para mim quais são os propósitos do estudo, os procedimentos a serem realizados, seus desconfortos e riscos, as garantias de confiabilidade e esclarecimento permanentes. Ficou claro também que a minha participação é isenta de despesas e que terei garantia do acesso a tratamento hospitalar quando necessário. Concordo voluntariamente em participar deste estudo e poderei retirar o meu consentimento a qualquer momento, antes ou durante o mesmo, sem penalidades ou prejuízo ou perda de qualquer benefício que possa ter adquirido, ou no atendimento neste Serviço.

Assinatura do paciente/representante legal Data $1 / 1$

Assinatura da testemunha

Data 11

para casos de pacientes menores de 18 anos, analfabetos, semi-analfabetos ou portadores de deficiência auditiva ou visual.

\section{(Somente para o responsável do projeto)}

Declaro que obtive de forma apropriada e voluntária o Consentimento Livre e Esclarecido deste paciente ou representante legal para a participação neste estudo.

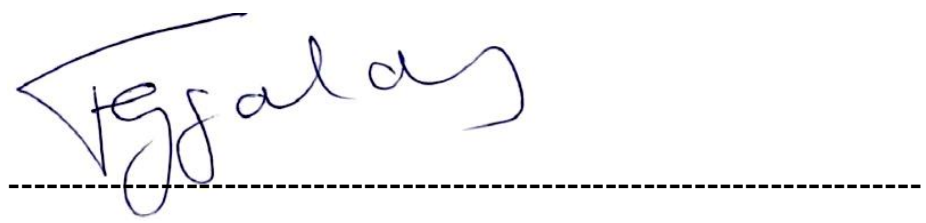




\section{Anexo C: Termo de Outorga FAPESP}

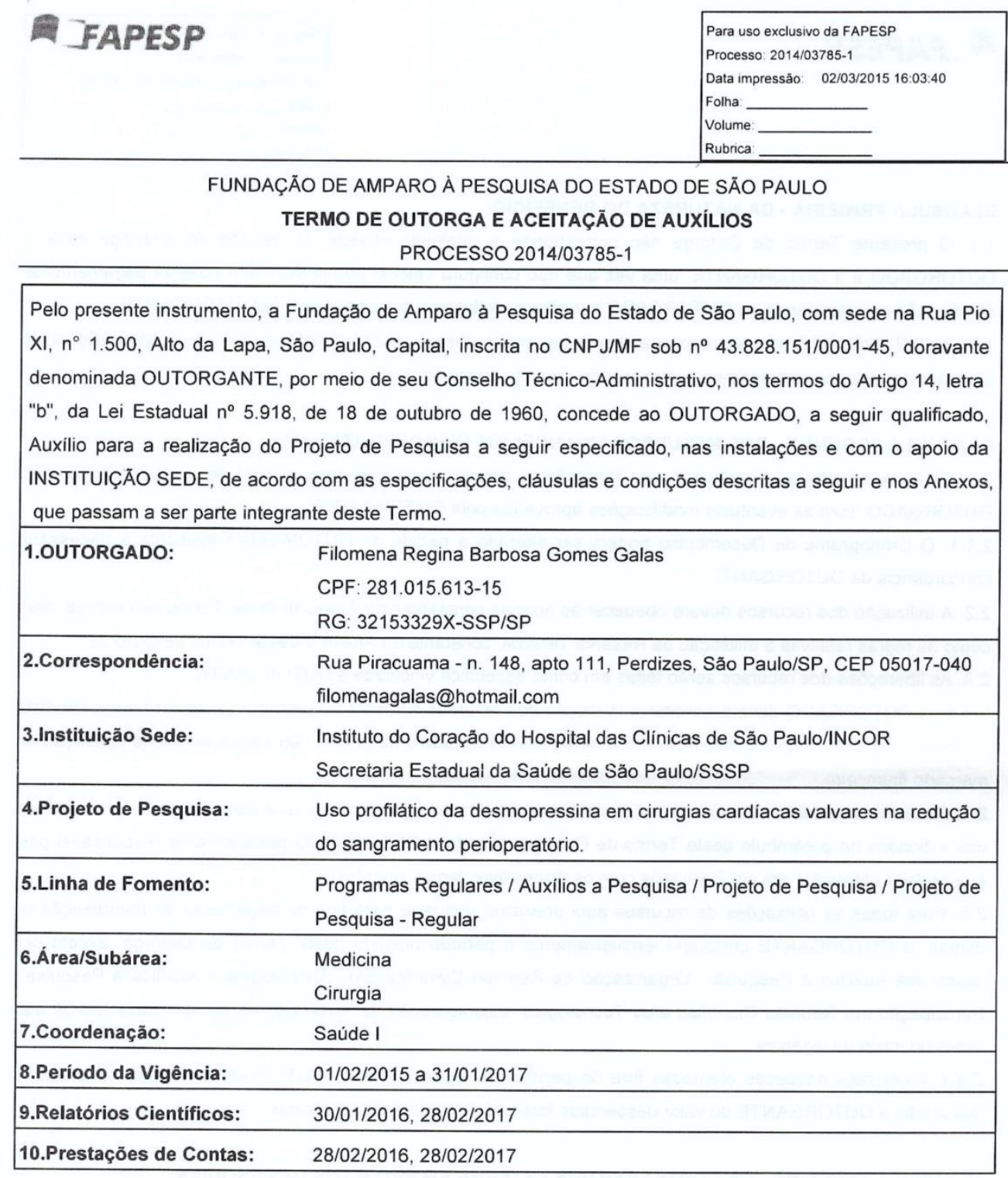

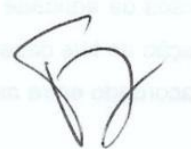




\section{CLÁUSULA PRIMEIRA - DA NATUREZA DO BENEFÍCIO:}

1.1. O presente Termo de Outorga não corresponde a qualquer espécie de relação de emprego entre o OUTORGADO e a OUTORGANTE, uma vez que não configura vínculo trabalhista, nem objetiva pagamento de salário, não se estendendo ao OUTORGADO beneficios exclusivos dos servidores da OUTORGANTE.

1.2. A OUTORGANTE não se responsabilizará por cobrir despesas de assistência médica e odontológica de qualquer natureza, excetuando-se seguro-saúde, quando concedido.

CLÁUSULA SEGUNDA - DOS RECURSOS FINANCEIROS DISPONIBILIZADOS:

2.1. Os recursos estarão disponiveis para liberação de acordo com o cronograma de desembolso proposto pelo OUTORGADO, com as eventuais modificações aprovadas pela OUTORGANTE.

2.1.1. O Cronograma de Desembolso poderá ser alterado a pedido do OUTORGADO mediante a necessária concordância da OUTORGANTE.

2.2. A utilização dos recursos deverá obedecer às normas constantes do Anexo III deste Termo de Outorga, bem como às regras relativas à utilização da Reserva Técnica, constante do Anexo $\mathrm{V}$ deste Termo de Outorga.

2.3. As liberações dos recursos serão feitas em conta especifica vinculada à OUTORGANTE.

2.3.1. O OUTORGADO deverá solicitar a liberação dos recursos somente quando houver necessidade imediata da realização dos gastos, evitando assim a permanência de saldo na conta, não sendo permitida aplicação no mercado financeiro.

2.4. O Auxilio concedido não poderá ser destinado, em hipótese alguma, ainda que parcialmente, a fins diversos dos indicados no preâmbulo deste Termo de Outorga, ficando o OUTORGADO pessoalmente responsável pela sua perfeita utilização, em conformidade com os dispositivos legais vigentes.

2.5. Para todas as utilizações de recursos aqui previstos, inclusive para fins de pagamento de manutenção ou diárias, a OUTORGANTE considera exclusivamente o periodo previsto neste Termo de Outorga, exceto nos casos dos Auxílios à Pesquisa - Organização de Reunião Científica elou Tecnológica e Auxilios à Pesquisa Participação em Reunião Cientifica e/ou Tecnológica, cuja liberação de verba poderá ser solicitada até 30 dias antes do início da vigência.

2.5.1. Caso haja despesas efetuadas fora do periodo de vigência, fica o OUTORGADO obrigado a efetuar a devolução à OUTORGANTE do valor despendido fora das condições estabelecidas.

CLÁUSULA TERCEIRA - DA CONTRAPARTIDA EXTERNA EM PROJETOS DE PESQUISA:

3.1. Se o projeto envolver desembolso direto de recursos de terceiros para a INSTITUIÇÃO SEDE, deverá ser celebrado um Termo de Convênio juntamente com este Termo de Outorga.

3.1.1. O Termo de Convênio deverá ser assinado pela INSTITUIÇÃO SEDE, a entidade parceira e a OUTORGANTE, com a ciência do OUTORGADO.

3.2. No Termo de Convênio deverá ser explicitado o valor total do Convênio, o cronograma e a forma dos desembolsos da entidade parceira e, se for o caso, da Instituição Sede, além dos prazos e instruções quanto à comprovação de tais desembolsos, bem como as cláusulas sobre o tratamento da Propriedade Intelectual.

3.2.1. O acordado entre as partícipes no Termo de Convênio poderá afetar as Cláusulas Segunda, Sexta e Oitava

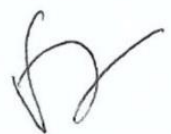




\section{FAPESP}

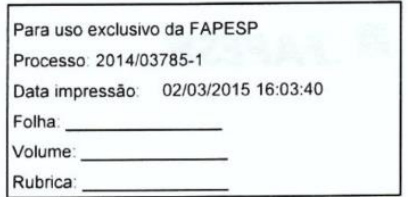

deste Termo de Outorga.

\section{CLÁUSULA QUARTA - DA PARTICIPAÇÃO, DO REGIME DE DEDICAÇÃO E DAS OUTRAS OBRIGAÇÕES DO OUTORGADO:}

4.1. O OUTORGADO se obriga a:

4.1.1. Dedicar-se integralmente à execução do projeto pelo tempo declarado na proposta analisada e aprovada pela OUTORGANTE.

4.1.2. Consultar a OUTORGANTE antes de aceitar qualquer apoio financeiro de qualquer outra fonte de financiamento, pública ou privada, para o desenvolvimento do mesmo projeto de pesquisa a que concerne 0 Auxilio concedido.

4.1.3. Consultar a OUTORGANTE antes de fazer quaisquer modificações no projeto, incluindo, mas não restritas a, aquelas no plano inicial, nas datas ou na designação de recursos.

4.1.4. Consultar a OUTORGANTE antes de assumir compromisso que exija seu afastamento da INSTITUIÇÃO SEDE por mais de 90 dias

4.1.5. Apresentar os Relatórios Cientificos e as Prestações de Contas de progresso e final, nos prazos estipulados neste Termo de Outorga e em conformidade com as normas institucionais da OUTORGANTE, sob pena de ser acionado administrativa e/ou judicialmente pela OUTORGANTE para devolução dos recursos recebidos devidamente corrigidos pelos indices legais em vigor e com incidência das demais sançōes legais (juros honorários advocatícios e custas judiciais).

\section{CLÁUSULA QUINTA - DO TRATAMENTO E GUARDA DO MATERIAL PERMANENTE E DE CONSUMO:}

5.1. A aquisição de material de consumo ou permanente nacional e/ou importado deverá obedecer às normas constantes do Anexo III deste Termo de Outorga, sob pena de ser acionado administrativa e/ou judicialmente pela OUTORGANTE para devolução dos recursos recebidos, devidamente corrigidos pelos índices legais em vigor e com incidência das demais sanções legais (juros, honorários advocatícios e custas judiciais).

5.2. Em caso de sinistro (roubo, furto, avaria ou outro) envolvendo equipamentos destinados à execução do projeto de pesquisa e adquiridos com recursos da OUTORGANTE, o OUTORGADO deverá lavrar boletim de ocorrência e comunicar imediatamente o fato à OUTORGANTE.

5.2.1. Quando o evento/sinistro ocorrer nas dependências da INSTITUIÇÃO SEDE, o OUTORGADO comprometese a solicitar a instauração de sindicância administrativa para apuração da autoria do fato, remetendo à OUTORGANTE cópia da portaria instauradora da sindicância e, posteriormente, cópia do Relatório Final da Sindicância.

\section{CLÁUSULA SEXTA - DAS PRESTAÇÕES DE CONTAS E DOS RELATÓRIOS CIENTÍFICOS:}

6.1. As Prestações de Contas do Auxilio concedido serão feitas pelo OUTORGADO em conformidade com as instruções dos Anexos III e V deste Termo de Outorga, na(s) data(s) de vencimento indicada(s) no Campo 10 do preâmbulo, devendo, nesse momento, efetuar a devolução, em cheque ou depósito bancário identificado, do saldo , se houver. 
6.1.1. As Prestações de Contas serão recebidas pela OUTORGANTE, ficando sua aprovação condicionada à emissão de parecer favorável pela FAPESP.

6.2. Independentemente das Cláusulas 6.1 e 6.1.1, e em conformidade com as normas da respectiva modalidade de Auxilio, o OUTORGADO se obriga a apresentar à OUTORGANTE, nas datas indicadas no Campo 9 do preâmbulo, os Relatórios Cientificos da pesquisa com conclusões sucintas dos resultados até então obtidos.

6.2.1. A continuidade do apoio da OUTORGANTE ao projeto ou seu efetivo encerramento estão condicionados à aprovação dos Relatórios Científicos de Progresso e Relatório Científico Final.

\section{CLÁUSULA SÉTIMA - DAS PUBLICAÇÕES E DIVULGAÇÕES:}

7.1. O OUTORGADO se compromete a fazer referência ao apoio da OUTORGANTE em todas as formas de divulgação (teses, dissertações, artigos, livros, resumos de trabalhos apresentados em reuniões, páginas na Web e qualquer outra publicação ou forma de difusão de atividades) que resultem, total ou parcialmente, de Auxilio ou Bolsa objeto deste Termo de Outorga.

7.1.1. O OUTORGADO deverá indicar, em cada publicação prevista na cláusula 7.1 , além do nome FAPESP, o número do processo FAPESP a que se refere este Termo de Outorga, no modelo: processo $n^{\circ}$ aaaa/nnnnn-d, Fundação de Amparo à Pesquisa do Estado de São Paulo (FAPESP).

7.1.1.1. Os artigos escritos em idioma estrangeiro deverão indicar o apoio da FAPESP em inglês, conforme 0 seguinte modelo: grant \#aaaa/nnnnn-d, São Paulo Research Foundation (FAPESP).

7.2. O OUTORGADO é responsável por garantir que em toda publicitação de materiais (incluindo páginas web) que resultem total ou parcialmente de Auxilio ou Bolsa objeto deste Termo de Outorga, exceto artigos cientificos publicados em revistas cientificas ou técnicas com revisão por pares, conste a seguinte declaração de responsabilidade: "As opiniões, hipóteses e conclusões ou recomendações expressas neste material são de responsabilidade do(s) autor(es) e não necessariamente refletem a visão da FAPESP".

\section{CLÁUSULA OITAVA - DO TRATAMENTO DA PROPRIEDADE INTELECTUAL:}

8.1. O OUTORGADO compromete-se a verificar, em tempo hábil, se a execução do projeto produz ou poderá produzir resultado potencialmente, no todo ou em parte, objeto de proteção por Patente de Invenção, Modelo de Utilidade, Desenho Industrial, Software ou qualquer outra forma de proteção dos direitos de Propriedade Intelectual, observadas as normas constantes do Anexo IV deste Termo de Outorga.

8.2. O OUTORGADO e a INSTITUIÇÄO SEDE declaram estar cientes de que a titularidade ou cotitularidade dos direitos de Propriedade Intelectual fica estabelecida conforme os seguintes critérios especificados nos itens 3.1 , 3.2, 3.3 e 3.4 do Anexo IV deste Termo de Outorga:

8.2.1 A INSTITUIÇÃO SEDE, quando esta possuir, no momento do requerimento da proteção, órgão formalmente constituido para gerir sua politica para Propriedade Intelectual e inovação tecnológica (doravante NIT), devidamente qualificado pela OUTORGANTE; ou

8.2.2. A OUTORGANTE e a INSTITUIÇÃO SEDE, quando a INSTITUIÇÃO SEDE não tiver NIT qualificado no momento do requerimento da proteção;

8.2.3 No âmbito do Programa PIPE, a INSTITUIÇÃO SEDE, no caso do OUTORGADO possuir vinculo

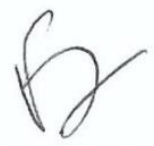


FAPESP

Para uso exclusivo da FAPESP
Processo: 2014/03785-1
Data impressão: 02/03/2015 16:03:40
Folha:
Volume:-
Rubrica:

empregaticio com a empresa, ou a OUTORGANTE, no caso do OUTORGADO ser bolsista da FAPESP; 8.2.4 A OUTORGANTE e/ou a INSTITUIÇÃO SEDE e terceiros, de acordo com o previsto em contrato ou convênio firmado entre as partes ou apresentado como condição para liberação do beneficio.

8.3. O OUTORGADO e a INSTITUIÇÄO SEDE declaram estar cientes de que a OUTORGANTE, independentemente do custeio do registro, terá participação sobre os beneficios decorrentes da exploração dos direitos de Propriedade Intelectual, nos termos da Política para Propriedade Intelectual da FAPESP. Anexo IV deste Termo de Outorga.

8.3.1. Caberá à INSTITUIÇÃO SEDE, de acordo com suas políticas e a legislação aplicável, definir internamente a distribuição dos beneficios entre o OUTORGADO e os demais envolvidos na obtenção do resultado.

CLÁUSULA NONA - DO COMPROMISSO DE EMISSÃO DE PARECER DE ASSESSORIA EM TEMPO HÁBIL:

9.1. Em decorrência do Auxílio que the foi concedido, O OUTORGADO se compromete a emitir pareceres técnicos e cientificos em assuntos de sua especialidade, quando solicitados pela OUTORGANTE, gratuitamente e dentro do prazo estipulado pela OUTORGANTE.

9.1.1. A não observância do disposto na cláusula 9.1 poderá acarretar bloqueio parcial ou total de recursos de Auxilios e Bolsas sob a responsabilidade do OUTORGADO em andamento na OUTORGANTE.

CLÁUSULA DÉCIMA - DO COMPROMISSO DE OBSERVÂNCIA DA LEGISLAÇÃO RELATIVA À PROTEÇÃO DA VIDA HUMANA, UTILIZAÇÃO DE ANIMAIS, MANIPULAÇÃO DE ORGANISMOS GENETICAMENTE MODIFICADOS, UTILIZAÇĀO DE MATERIAL NUCLEAR, BIODIVERSIDADE, PESQUISA EM TERRAS INDIGENAS E CONHECIMENTOS TRADICIONAIS ASSOCIADOS BEM COMO DAS DEMAIS EXIGÊNCIAS LEGAIS APLICÁVEIS:

10.1. Declaram o OUTORGADO e a INSTITUIÇÃO SEDE que è de sua exclusiva responsabilidade solicitar, obter, possuir e demonstrar, quando solicitado pela OUTORGANTE, todas as autorizaçôes legais e exigiveis para a boa execução do projeto, que deverão ser emitidas pelos Órgãos de controle e fiscalização atinentes à natureza da pesquisa quando assim for exigido.

10.2. As declarações a que se refere $o$ item anterior incluem, mas podem não se limitar, àquelas emitidas por: Instituto Brasileiro de Meio Ambiente - IBAMA, Fundação Nacional do Índio - FUNAI, Comitê de Ética em Pesquisa - CEP, Comissão Nacional de Energia Nuclear - CNEN, Agência Nacional de Vigilância Sanitária - ANVISA, Comissão Técnica Nacional de Biossegurança - CTNBIO, Comissão Interna de Biossegurança - CIBIO e outras no caso em que a natureza do projeto exigir.

10.3. Declaram o OUTORGADO e a INSTITUIÇÃO SEDE que esta obteve os certificados exigidos pela Legislação de Biossegurança, estando apta a manipular Organismos Geneticamente Modificados e seus derivados, na hipótese de execução de projetos dessa natureza, podendo comprovar mediante declaração que o ateste, quando solicitada.

10.4. Se a execução do projeto vier a ser obstada ou inviabilizada pelo descumprimento das obrigaçōes aludidas nesta cláusula, e não havendo prévia anuência da OUTORGANTE, caberá à INSTITUIÇÃO SEDE ressarcir à OUTORGANTE a totalidade dos recursos concedidos para a execução do projeto, sob pena de ser acionado

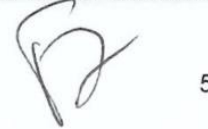


administrativa elou judicialmente pela OUTORGANTE para devolução dos recursos recebidos, devidamente corrigidos pelos indices legais em vigor e com incidência das demais sanções legais (juros, honorários advocaticios e custas judiciais).

\section{CLÁUSULA DÉCIMA PRIMEIRA - DO COMPROMISSO DE OBSERVÂNCIA DA LEGISLAÇÃO RELATIVA À SEGURANÇA:}

11.1. Declaram o OUTORGADO e a INSTITUIÇÃO SEDE que é de sua exclusiva responsabilidade solicitar, obter, possuir e demonstrar, quando solicitado pela OUTORGANTE, todos os alvarás, licenças e demais autorizações exigidas por lei para o funcionamento da INSTITUIÇÃO SEDE, quando assim for exigido.

11.2. Declaram o OUTORGADO e a INSTITUIÇÃO SEDE que esta possui os equipamentos de segurança necessários ao seu funcionamento e à execução do projeto em suas dependências, os quais deverão atender às normas técnicas e às exigências dos órgãos de controle e fiscalização.

CLÁUSULA DÉCIMA SEGUNDA - DO COMPROMISSO DE APOIO INSTITUCIONAL DA INSTITUIÇÃO SEDE DO PROJETO:

12.1. A INSTITUIÇÃO SEDE do projeto especificado no preâmbulo garante todo o apoio institucional necessário para sua realização, segundo informação prévia feita por escrito pelo OUTORGADO, constante do Anexo II deste Termo de Outorga.

12.2. Em particular, será garantida ao OUTORGADO e à equipe constante do projeto aprovado pela OUTORGANTE permissão de uso de todas as instalações (laboratórios, rede de computação, biblioteca, base de dados etc.) e acesso a todos os serviços técnicos (de laboratório, de oficinas, administrativo, de compras e importações etc.) disponiveis na Instituição e relevantes para sua execução.

12.3. A INSTITUIÇÃO SEDE se compromete a dar todo o seu apoio institucional para garantir e facilitar o acesso aos equipamentos adquiridos pela OUTORGANTE a pesquisadores de Instituições do Estado de São Paulo e de fora, para fins de projetos de pesquisa cientifica qualificados.

12.4. A INSTITUIÇÃO SEDE do projeto assume o compromisso de Aceite de Cessão de Uso elou Aceite de Doação dos Equipamentos e Materiais Permanentes adquiridos com recursos do projeto, devendo garantir: 0 acesso a estes pelo OUTORGADO e pela equipe do projeto, a manutenção em bom estado e a contratação de seguro para proteção dos equipamentos e materiais durante a vigência do projeto ou pelo periodo especificado no Termo de Aceite de Cessão de Uso e/ou Aceite de Doação, bem como de suas eventuais prorrogações, por pelo menos 10 anos após o término do projeto no caso de haver doação, exceto quando acordado diferentemente com a autorização da OUTORGANTE.

12.4.1. Em caso de sinistro (roubo, furto, avaria ou outro) nas dependências da INSTITUIÇÃO SEDE envolvendo equipamentos destinados à execução do projeto de pesquisa, a INSTITUIÇÃO SEDE deverá tomar todas as medidas administrativas e judiciais para apurar a ocorrência.

12.4.2. Caso os equipamentos sinistrados não tenham sido segurados pela INSTITUIÇÃO SEDE, eventuais custos de reparo dos danos ou de reposição do equipamento serão suportados exclusivamente pela INSTITUIÇÃO SEDE.

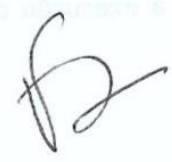


TAPESP

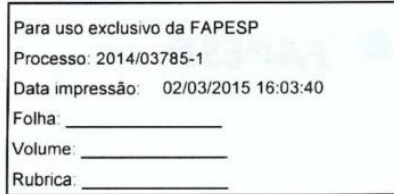

12.5. Em caso de falta ou impedimento do OUTORGADO, cabe à INSTITUIÇÃO SEDE notificar imediatamente a OUTORGANTE.

\section{CLÁUSULA DÉCIMA TERCEIRA - DO COMPROMISSO DE OBSERVÂNCIA DO CÓDIGO DE BOAS PRÁTICAS CIENTIFICAS DA OUTORGANTE:}

13.1. Declaram o OUTORGADO e a INSTITUIÇÃO SEDE estar cientes das diretrizes constantes do Código de Boas Práticas Científicas da FAPESP e que se comprometem a respeitá-las.

13.2. Declara a INSTITUIÇÃO SEDE que se compromete a incluir em seu organograma um ou mais órgãos especificamente encarregados da promoção da cultura de integridade ética da pesquisa entre seus pesquisadores e estudantes (mediante a manutenção de programas regulares de educação, disseminação, aconselhamento e treinamento), assim como da prevenção, investigação e punição das más condutas em pesquisa que ocorram em seu âmbito.

\section{CLÁUSULA DÉCIMA QUARTA - DAS ALTERAÇÕES DA CONCESSÃO DO AUXÍLIO E ADITAMENTOS AO TERMO DE OUTORGA:}

14.1. Quaisquer alterações no estabelecido neste Termo de Outorga só poderão ser implementadas mediante autorização expressa da OUTORGANTE, formalizada por meio de Termo Aditivo a este Termo de Outorga.

14.2. Ordinariamente e por circunstâncias imprevisiveis, solicitações de Aditivos a este Termo de Outorga para suplementação de recursos ou para alteração do prazo de vigência do Auxilio só serão analisadas pela OUTORGANTE desde que apresentadas juntamente com um Relatório Cientifico.

14.2.1. As solicitações de Aditivos para extensão do prazo de vigência do Auxílio só serão analisadas pela OUTORGANTE quando encaminhadas com pelo menos 60 dias antes da data final da vigência inicialmente aprovada.

14.2.1.1. A vigência do projeto de que trata o presente Termo de Outorga só poderá ser prorrogada pelo prazo correspondente a até $25 \%$ (vinte e cinco por cento) do prazo inicial de vigência.

14.3. Solicitações de Aditivos para prorrogações de bolsas, eventualmente concedidas como item de orçamento do Auxilio poderão ser analisadas, desde que enviadas juntamente com o Relatório Científico do Auxilio e acompanhadas do Relatório Individual sintético das atividades desenvolvidas pelo bolsista no período e do Plano de Atividades do bolsista para o próximo periodo.

\section{CLÁUSULA DÉCIMA QUINTA - DAS DISPOSIÇÕES GERAIS:}

15.1. O OUTORGADO declara que aceita, sem restrições, este Auxilio, tal como concedido, e se responsabiliza pelo fiel cumprimento do presente Termo de Outorga em todos os seus itens, cláusulas e condiçōes, e que concorda com qualquer fiscalização que a OUTORGANTE julgar conveniente proceder, de acordo com o inciso III do artigo $3^{\circ}$ da Lei $n^{\circ} 5.918$, de 18 de outubro de 1960.

15.2. O OUTORGADO declara que tem plenas condiçōes de realizar as atividades previstas no projeto de pesquisa e que envidará todos os esforços para que seus objetivos sejam atingidos.

15.2.1. Declara o OUTORGADO também que deu ciência por escrito às instâncias competentes da INSTITUIÇÃO

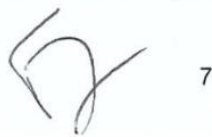




\section{FAPESP}

Para uso exclusivo da FAPESP
Processo: 2014/03785-1
Data impressão: 02/03/2015 16:03:40
Folha:
Volume:-
Rubrica:

infraestruturais e do apoio institucional indispensável para o bom andamento do projeto ananto à garantia deste apoio, conforme o documento constante do Anexo II deste Termo de Outorga.

15.3. Em caso de abandono do projeto, sem prévia autorização da OUTORGANTE, O OUTORGADO se compromete a restituir à OUTORGANTE, imediatamente, todos os recursos concedidos para a execução do projeto, sob pena de ser acionado administrativa e/ou judicialmente pela OUTORGANTE para a devolução dos recursos recebidos, devidamente corrigidos pelos indices legais em vigor e com incidência das demais sanções legais (juros, honorários advocatícios e custas judiciais)

15.4. A violação de qualquer das cláusulas do presente Termo de Outorga importará em suspensão do Auxilio concedido e/ou retirada dos materiais adquiridos.

15.5. As comunicações e solicitações referentes a este Termo de Outorga devem ser apresentadas conforme as instruções para comunicação sobre Auxilios em andamento, disponiveis no portal da FAPESP (www.fapesp.br). 15.6. Fica eleito o foro da Fazenda Pública da Comarca de São Paulo como competente para resolução de eventuais conflitos.

15.7. Após sua assinatura, o presente Termo entrará em vigor na data indicada para início do projeto.

15.8. Integram o presente Termo de Outorga, para todos os efeitos legais, as instruções constantes dos Anexos: 15.8.1. Anexo I: Relação dos Benefícios e Materiais Concedidos.

15.8.2. Anexo I!: Informação aprovada pela Instituição Sede sobre a infraestrutura Institucional.

15.8.3. Anexo III: Manual de Instruções para Uso dos Recursos e Prestação de Contas de Auxilios e de Reserva Técnica concedidos pela FAPESP (Portaria PR $n^{\circ} 03 / 2011$ ).

15.8.4. Anexo IV: Política para Propriedade Intelectual da FAPESP (Portaria PR $n^{\circ} 04 / 2011$ ).

15.8.5. Anexo V: Normas para utilização dos recursos da Reserva Técnica concedidos pela FAPESP (Portaria PR $\left.n^{\circ} 06 / 2011\right)$.

15.8.6. Anexo VI: Código de Boas Práticas Cientificas da Outorgante (Deliberação do CTA $n^{\circ} 02 / 2013$ )

\section{CIÊNCIA SOBRE O DISPOSTO NESTE TERMO DE} OUTORGA:

16.1. O Dirigente da INSTITUIÇÃO SEDE declara estar ciente de que o descumprimento de quaisquer cláusulas deste Termo de Outorga poderá prejudicar o andamento de futuras solicitações apresentadas à OUTORGANTE por pesquisadores associados à INSTITUIÇÃO SEDE. Declara ainda que leu e teve ciência das condições do presente Termo de Outorga, mediante identificação legivel (nome e cargo) e assinatura a seguir.

16.2. O OUTORGADO declara estar ciente de que o descumprimento de quaisquer cláusulas deste Termo de Outorga poderá prejudicar o andamento de futuras solicitações por ele apresentadas à OUTORGANTE. Declara ainda que leu e teve ciência das condições do presente Termo de Outorga, mediante assinatura a seguir.

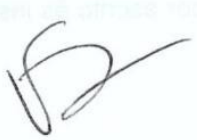




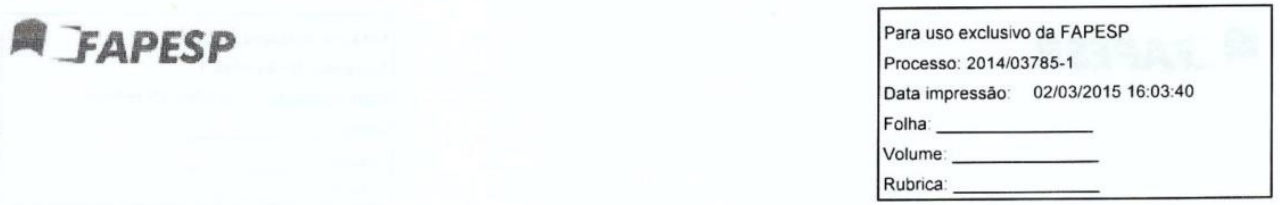

São Paulo, 1 de Fevereiro de 2015

Outorgado

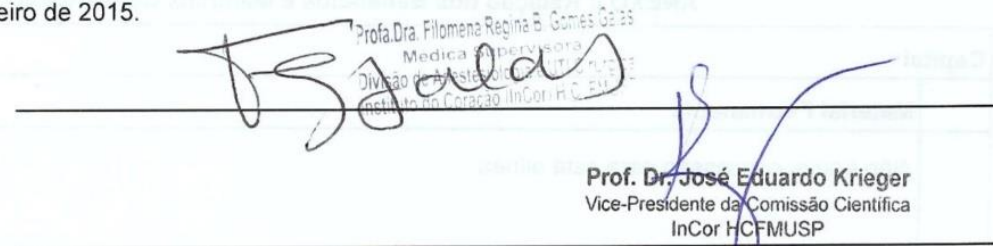

Instituto do Coração do Hospital das Clínicas de São Paulo/INCOR/SSSP

Outorgante

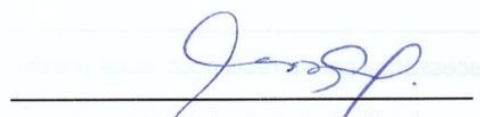

Ascenção Bela Antonio Molinari Por Procuração

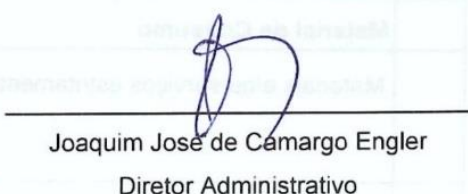

Diretor Administrativo 


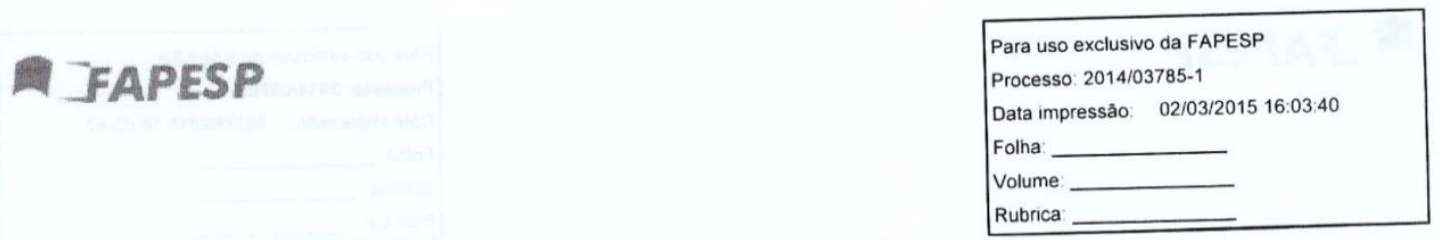

ANEXO I: Relação dos Benefícios e Materiais Concedidos

\begin{tabular}{|c|c|c|c|c|}
\hline \multirow{2}{*}{\multicolumn{5}{|c|}{ Capital }} \\
\hline \multicolumn{4}{|l|}{\begin{tabular}{|l|l|} 
& Material Permanente \\
\end{tabular}} & \\
\hline \multicolumn{5}{|l|}{ Não houve concessão para esta alinea. } \\
\hline \multicolumn{5}{|l|}{ Custeio } \\
\hline \multicolumn{5}{|l|}{ Material de Consumo } \\
\hline \multicolumn{5}{|c|}{ Materiais e/ou serviços estritamente necessários para a realização deste projeto. } \\
\hline \multicolumn{5}{|l|}{ Serviços de Terceiros } \\
\hline \multicolumn{5}{|l|}{ Năo houve concessão para esta alinea. } \\
\hline \multicolumn{5}{|l|}{ Despesas de Transporte } \\
\hline \multicolumn{5}{|l|}{ Não houve concessão para esta alínea. } \\
\hline \multicolumn{5}{|c|}{ Reserva Técnica - Beneficios Complementares } \\
\hline \multicolumn{5}{|c|}{ Utilização conforme normas vigentes. } \\
\hline Pesquisador & Função & Início & \begin{tabular}{l|l} 
Término & $P$ \\
\end{tabular} & Possui BC \\
\hline Filomena Regina Barbosa Gomes Galas & Pesq.Responsável C & $01 / 02 / 2015] 3$ & $31 / 01 / 2017$ & Sim \\
\hline \multicolumn{5}{|c|}{ Reserva Técnica - Custo de Infraestrutura Direta do Projeto } \\
\hline \multicolumn{5}{|c|}{ Utilização conforme normas vigentes. } \\
\hline \multicolumn{5}{|l|}{ Diárias } \\
\hline \multicolumn{5}{|l|}{ Não houve concessão para esta alinea. } \\
\hline Outros & & & & \\
\hline Não houve concessão para esta alinea. & & & & \\
\hline
\end{tabular}

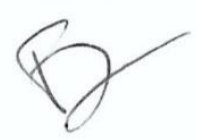




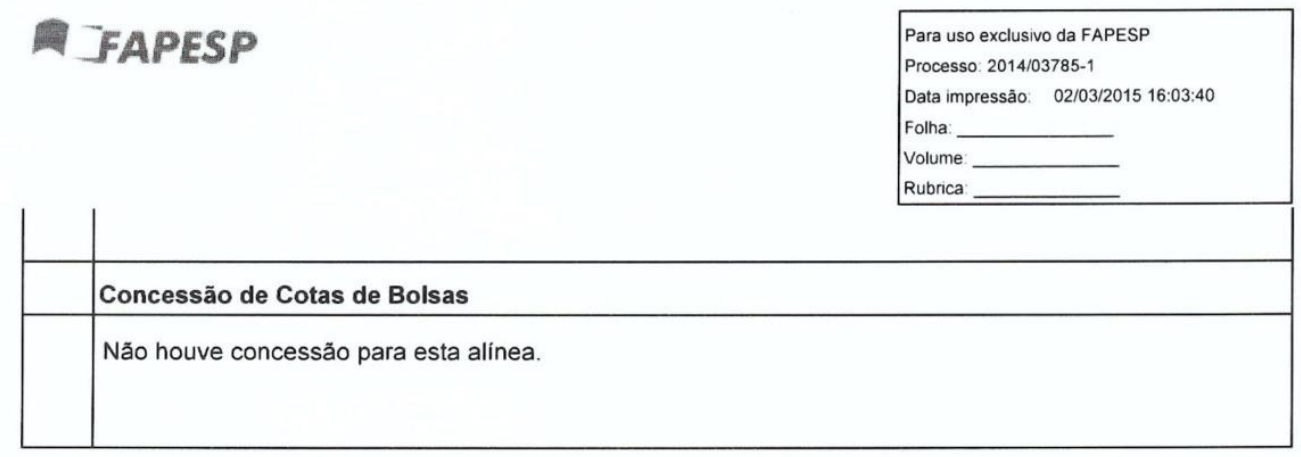

\begin{tabular}{|l|l|}
\hline Concessão Total \\
\hline $\begin{array}{l}\text { Parte em Reais: estão incluidos neste valor os recursos concedidos ou } \\
\text { convertidos para real }\end{array}$ & R\$ 236.110,41 \\
\hline
\end{tabular}

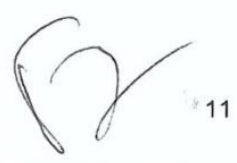




\section{Anexo D: Ficha de Coleta}

\section{DADOS DEMOGRÁFICOS}

1. Número do caso:

2. Grupo:

Placebo (0)

$\square \operatorname{DDAVP}(1)$

3. Nome do paciente:

4. RGHC:

5. Telefone Contato

6. Data de nascimento:

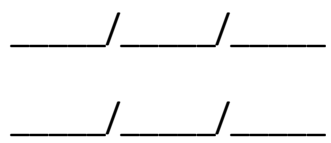

7. Data da internação:

8. Sexo:

Masculino (0)

$\square$ Feminino (1)

9. Raça:

$\square$ Branco (0) $\square$ Negro (1) $\quad \square$ Oriental (2)

10. Peso (kg): IMC:

11. Altura $(\mathrm{cm})$ :

12. EurOSCORE:

\section{CARACTERÍSTICAS CLÍNICAS}

1. FEVE: $\%$

2. IC:

$\square \operatorname{Sim}(1) \quad \square$ Não (0)

NYHA:

$\square$ I $\quad \square$ II $\quad \square$ III $\quad \square$ IV

3. IAM prévio:

$\square \operatorname{Sim}(1) \quad \square$ Não (0)

4. Hipertensão arterial:

$\square \operatorname{Sim}(1) \quad \square$ Não (0)

5. Doença valvar

$\square \operatorname{Sim}(1) \quad \square$ Não (0)

6. Valvopatia reumática

$\square \operatorname{Sim}(1) \quad \square$ Não (0)

7. Doença vascular periférica:

$\square \operatorname{Sim}(1) \quad \square$ Não (0)

8. DPOC:

$\square \operatorname{Sim}(1) \quad \square$ Não (0)

9. Dislipidemia:

$\square \operatorname{Sim}(1) \quad \square$ Não (0)

10. Tabagista atual:

$\square \operatorname{Sim}(1) \quad \square$ Não (0) 
11. Tabagista prévio (> 6 meses):

$\square \operatorname{Sim}(1) \quad \square$ Não (0)

12. Obesidade $(I M C>30)$

$\square \operatorname{Sim}(1) \quad \square$ Não (0)

13. Creatinina $>1,5 \mathrm{mg} / \mathrm{dL}$

$\square \operatorname{Sim}(1) \quad \square$ Não (0)

14. FA:

$\square \operatorname{Sim}(1) \quad \square$ Não (0)

15. Diabetes:

$\square \operatorname{Sim}(1) \quad \square$ Não (0)

16. Doença hepática:

$\square \operatorname{Sim}(1) \quad \square$ Não (0)

17. Hipotireoidismo:

$\square \operatorname{Sim}(1) \quad \square$ Não (0)

18. AVC prévio:

$\square \operatorname{Sim}(1) \quad \square$ Não (0)

19. IECA/BRA: (pril, sartan)

$\square \operatorname{Sim}(1) \quad \square$ Não (0)

20. BBloqueador: (nolol)

$\square \operatorname{Sim}(1) \quad \square$ Não (0)

21. Anticoagulantes/antiplaquetários

$\square \operatorname{Sim}(1) \quad \square$ Não (0)

22. Antiagregantes plaquetários

$\square \operatorname{Sim}(1) \quad \square$ Não (0)

23. Hipertensão Pulmonar

$\square \operatorname{Sim}(1) \quad \square$ Não (0)

24. Exames laboratoriais (pré-operatório):

\begin{tabular}{|l|l|l|l|l|l|l|l|l|l|l|}
\hline $\mathrm{Hb}$ & $\mathrm{Ht}$ & Plaquetas & TTPA & TP & INR & $\mathrm{BT}$ & $\mathrm{BD}$ & $\mathrm{BI}$ & Fibrinogênio & Creatinina \\
\hline & & & & & & & & & & \\
\hline
\end{tabular}

\section{INTRA-OPERATÓRIO}

25. Data da cirurgia:

26. Inicio da cirurgia: Termino da cirurgia:

27. Inicio da anestesia: Termino da anestesia:

28. Tipo de cirurgia
$\square$ Valvar
$\square$ Mitral (1)
Aortica (2)
$\square$ Tricuspide (3)

29. CEC: $\square \operatorname{Sim}(1) \quad \square$ Não (0) Tempo de CEC (minutos):

30. Tempo de pinçamento: (minutos)

31. Heparina dose total:

32. Protamina: $\square \operatorname{Sim}(1) \quad \square$ Não (0) Dose total: 
33. TCA inicial: TCA final:

TCA pós protamina:

34. Cloreto de Cálcio $\square \operatorname{Sim}(1) \quad \square$ Não (0) Dose total:

35. DDAVP não protocolo $\square \operatorname{Sim}(1) \quad \square$ Não (0) Dose total:

36. Balanço hídrico ( $\mathrm{ml})$ :

37. Balanço sanguineo (ml):

38. Diurese (ml):

39. Peso de compressa:

40. Transfusão:

$\square \operatorname{Sim}(1) \quad \square$ Não (0)

Concentrado de hemácias: unidades

Plasma fresco congelado: unidades

Concentrado de plaquetas: unidades

Crioprecipitado: unidades

41. Infusão de líquidos

Cristalóide: $\mathrm{mL}$

Albumina: $\mathrm{mL}$

42. Drogas vasoativas usadas no intra-operatório:
Dobutamina:
$\square \operatorname{Sim}(1)$
Não (0)
Dopamina:
$\square \operatorname{Sim}(1)$
$\square$ Não (0)
Nitroglicerina:
$\square \operatorname{Sim}(1)$
$\square$ Não (0)
Nitroprussiato:
$\square \operatorname{Sim}(1)$
$\square$ Não (0)
Norepinefrina:
$\square \operatorname{Sim}(1)$
$\square$ Não (0)
Epinefrina:
$\square \operatorname{Sim}(1)$
$\square$ Não (0)
Óxido nítrico:
$\square \operatorname{Sim}(1)$
$\square$ Não (0)
Levosimendan:
$\square \operatorname{Sim}(1)$
Não (0)
Milrinone:
$\square \operatorname{Sim}(1)$
$\square$ Não (0)

43. Antifibrinolíticos usados no intra-operatório:

Ypsilon: $\square \operatorname{Sim}(1) \quad \square$ Não (0)

Dose Total: Hora: 
Ácido tranexâmico: $\square \operatorname{Sim}(1) \square$ Não (0) Dose total: Hora:

44. Terapias hemostáticas:

Complexo protrombínico:

Fibrinogênio:

$\square \operatorname{Sim}(1) \quad \square$ Não (0)

Dose total:

Hora:

Novoseven:

$\square \operatorname{Sim}(1) \quad \square$ Não (0)

Dose total:

Hora:

Dose total: Hora:

45. Temperatura central (mais alta): (mais baixa):

46. Exames laboratoriais:

\begin{tabular}{|l|l|l|l|}
\hline & T0 - Indução & $\begin{array}{l}\text { T1 - Pós } \\
\text { Medicamento }\end{array}$ & T2 - 24h após \\
\hline Ph & & & \\
\hline PaCO2 & & & \\
\hline PaO2 & & & \\
\hline SaO2 & & & \\
\hline BIC & & & \\
\hline BE & & & \\
\hline PvCO2 & & & \\
\hline PvO2 & & & \\
\hline SvO2 & & & \\
\hline Lactato & & & \\
\hline Cai & & & \\
\hline Hb & & & \\
\hline Ht & & & \\
\hline TTPA & & & \\
\hline
\end{tabular}




\begin{tabular}{|l|l|l|l|}
\hline TP & & & \\
\hline INR & & & \\
\hline Dímero D & & & \\
\hline Fibrinogênio & & & \\
\hline Fator VIII & & & \\
\hline $\begin{array}{l}\text { Von } \\
\text { willebrand }\end{array}$ & & & \\
\hline $\begin{array}{l}\text { Pgregação } \\
\text { plaquetária }\end{array}$ & & & \\
\hline & & & \\
\hline
\end{tabular}

PARÂMETROS TROMBOELASTOMETRIA (ROTEM)

Tempo 0: Indução da anestesia

\begin{tabular}{|l|l|l|l|l|l|l|l|l|l|l|}
\hline Parâmetros & CT & CFT & $\begin{array}{l}\text { Ângulo } \\
\alpha\end{array}$ & A5 & A10 & MCF & A20 & A30 & ML & LI 30 \\
\hline INTEM & & & & & & & & & & \\
\hline EXTEM & & & & & & & & & & \\
\hline FIBTEM & & & & & & & & & & \\
\hline
\end{tabular}

Tempo 1: 2 horas após medicamento 


\begin{tabular}{|l|l|l|l|l|l|l|l|l|l|l|}
\hline ROTEM & CT & \multicolumn{1}{l|}{ CFT } & $\begin{array}{l}\text { Ângulo } \\
\alpha\end{array}$ & A5 & A10 & MCF & A20 & A30 & ML & LI30 \\
\hline INTEM & & & & & & & & & & \\
\hline EXTEM & & & & & & & & & & \\
\hline FIBTEM & & & & & & & & & & \\
\hline Tempo 2: 24h após o medicamento & & & & & & & & \\
\hline ROTEM & CT & CFT & Ângulo & A5 & A10 & MCF & A20 & A30 & ML & LI30 \\
\hline INTEM & & & & & & & & & & \\
\hline EXTEM & & & & & & & & & & \\
\hline FIBTEM & & & & & & & & & & \\
\hline
\end{tabular}

Abreviações: $\mathrm{CT}=$ Tempo de coagulação; $\mathrm{CFT}=$ Tempo de formação do coágulo; $\mathrm{MCF}=$ Dureza máxima do coágulo; $M L=$ Lise máxima; $r$ = tempo do início do exame até formação do coágulo; $M A=$ maior amplitude alcançada no gráfico; $L Y 30$ = razão entre amplitude máxima e A30 (amplitude após 30 minutos da amplitude máxima).

\section{PÓS-OPERATÓRIO}

47. Data admissão UTI:

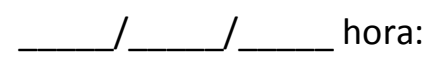

48. Tórax aberto: $\square \operatorname{Sim}(1) \quad \square$ Não (0)

49. Suporte à admissão:

Dobutamina: $\quad \square \operatorname{Sim}(1) \quad \square$ Não (0) 国/ $\mathrm{Kg} / \mathrm{min}$

Dopamina: $\square \operatorname{Sim}(1) \quad \square$ Não (0) ]g $/ \mathrm{Kg} / \mathrm{min}$
Nitroglicerina:
$\square \operatorname{Sim}(1)$
$\square$ Não (0)
]g $/ \mathrm{Kg} / \mathrm{min}$
Nitroprussiato: $\square \operatorname{Sim}(1) \quad \square$ Não (0) ]g/Kg/min
Norepinefrina: $\square \operatorname{Sim}(1) \quad \square$ Não(0) ]g $/ \mathrm{Kg} / \mathrm{min}$
Epinefrina: $\square \operatorname{Sim}(1) \quad \square$ Não (0) ]g $/ \mathrm{Kg} / \mathrm{min}$
Levosimendan: $\quad \square \operatorname{Sim}(1) \quad \square$ Não (0) ppm 国 $/ \mathrm{Kg} / \mathrm{min}$ 
Milrinone: $\square \operatorname{Sim}(1) \quad \square$ Não (0) ?g $/ \mathrm{Kg} / \mathrm{min}$

BIA:

$\square \operatorname{Sim}(1)$

$\square$ Não (0)

50. Balanço sanguineo (ml): $\mathrm{POI}$ $10 \mathrm{PO}$ 2을

51. Balanço hidrico (ml): POI 1으 PO 2ㅇ PO

52. Débito dos drenos (ml): $\mathrm{POI}$ 1ㅇ PO 2을

53. Antifibrinolíticos:

\begin{tabular}{|l|l|l|l|l|l|l|}
\hline & POI & $\begin{array}{l}\text { Dose } \\
\text { total }\end{array}$ & 10PO & $\begin{array}{l}\text { Dose } \\
\text { total }\end{array}$ & 2oPO & $\begin{array}{l}\text { Dose } \\
\text { total }\end{array}$ \\
\hline Ypsilon & $\begin{array}{l}\square \operatorname{Sim}(1) \square \\
\text { Não (0) }\end{array}$ & & $\begin{array}{l}\square \operatorname{Sim}(1) \square \\
\text { Não (0) }\end{array}$ & & $\begin{array}{l}\square \operatorname{Sim~(1)~} \square \\
\text { Não (0) }\end{array}$ & \\
\hline $\begin{array}{l}\text { Ácido } \\
\text { tranexâmico }\end{array}$ & $\begin{array}{l}\square \operatorname{Sim~(1)~} \square \text { Não } \\
\text { (0) }\end{array}$ & & $\begin{array}{l}\square \operatorname{Sim~(1)~} \square \\
\text { Não (0) }\end{array}$ & & $\begin{array}{l}\square \operatorname{Sim~(1)~} \square \\
\text { Não (0) }\end{array}$ & \\
\hline
\end{tabular}

54. Terapias hemostáticas:

\begin{tabular}{|c|c|c|c|c|c|c|}
\hline & $\mathrm{POI}$ & $\begin{array}{l}\text { Dose } \\
\text { total }\end{array}$ & 19PO & $\begin{array}{l}\text { Dose } \\
\text { total }\end{array}$ & 2PO & $\begin{array}{l}\text { Dose } \\
\text { total }\end{array}$ \\
\hline $\begin{array}{l}\text { Complexo } \\
\text { protrombínico }\end{array}$ & $\begin{array}{l}\square \operatorname{Sim}(1) \square \\
\text { Não (0) }\end{array}$ & & $\begin{array}{l}\square \operatorname{Sim}(1) \square \\
\text { Não (0) }\end{array}$ & & $\begin{array}{l}\square \operatorname{Sim}(1) \square \\
\text { Não (0) }\end{array}$ & \\
\hline Fibrinogênio & $\begin{array}{l}\square \operatorname{Sim}(1) \square \text { Não } \\
\text { (0) }\end{array}$ & & $\begin{array}{l}\square \operatorname{Sim}(1) \square \\
\text { Não (0) }\end{array}$ & & $\begin{array}{l}\square \operatorname{Sim}(1) \square \\
\text { Não (0) }\end{array}$ & \\
\hline Novoseven & $\begin{array}{l}\square \operatorname{Sim}(1) \square \text { Não } \\
\text { (0) }\end{array}$ & & $\begin{array}{l}\square \operatorname{Sim}(1) \square \\
\text { Não (0) }\end{array}$ & & $\begin{array}{l}\square \operatorname{Sim}(1) \square \\
\text { Não (0) }\end{array}$ & \\
\hline
\end{tabular}

55. Transfusão:

\begin{tabular}{|l|l|l|l|l|l|l|}
\hline & POI & $\begin{array}{l}\text { Total de } \\
\text { unidades }\end{array}$ & 19PO & $\begin{array}{l}\text { Total de } \\
\text { unidades }\end{array}$ & 2oPO & $\begin{array}{l}\text { Total de } \\
\text { unidades }\end{array}$ \\
\hline $\begin{array}{l}\text { Concentrado de } \\
\text { hemácias }\end{array}$ & $\begin{array}{l}\square \operatorname{Sim}(1) \square \\
\text { Não (0) }\end{array}$ & & $\begin{array}{l}\square \operatorname{Sim}(1) \square \\
\text { Não (0) }\end{array}$ & & $\begin{array}{l}\square \operatorname{Sim}(1) \square \\
\text { Não (0) }\end{array}$ & \\
\hline
\end{tabular}




\begin{tabular}{|c|c|c|c|}
\hline $\begin{array}{l}\text { Plasma fresco } \\
\text { congelado }\end{array}$ & $\begin{array}{l}\square \operatorname{Sim}(1) \square \\
\text { Não (0) }\end{array}$ & $\begin{array}{l}\square \operatorname{Sim}(1) \square \\
\text { Não (0) }\end{array}$ & $\begin{array}{l}\square \operatorname{Sim}(1) \square \\
\text { Não (0) }\end{array}$ \\
\hline $\begin{array}{l}\text { Concentrado de } \\
\text { plaquetas }\end{array}$ & $\begin{array}{l}\square \operatorname{Sim}(1) \square \\
\text { Não (0) }\end{array}$ & $\begin{array}{l}\square \operatorname{Sim}(1) \square \\
\text { Não (0) }\end{array}$ & $\begin{array}{l}\square \operatorname{Sim}(1) \square \\
\text { Não (0) }\end{array}$ \\
\hline Crioprecipitado & $\begin{array}{l}\square \operatorname{Sim}(1) \square \\
\text { Não (0) }\end{array}$ & $\begin{array}{l}\square \operatorname{Sim}(1) \square \\
\text { Não (0) }\end{array}$ & $\begin{array}{l}\square \operatorname{Sim}(1) \square \\
\text { Não (0) }\end{array}$ \\
\hline
\end{tabular}

56. Débito Drenos 6 primeiras horas

\begin{tabular}{|l|l|l|l|}
\hline & DM & DPE & DPD \\
\hline 1 & & & \\
\hline 2 & & & \\
\hline 3 & & & \\
\hline 4 & & & \\
\hline 5 & & & \\
\hline 6 & & & \\
\hline
\end{tabular}

\section{DESFECHOS PÓS-OPERATÓRIOS}

1. Horário de admissão na UTI:

2. Reoperação: $\square \operatorname{Sim}(1) \quad \square$ Não (0)

3. Causa de reoperação: $\square$ Sangramento (1) $\square$ Isquemia (3)

$\square$ Tamponamento (2)

$\square$ Outros (4):

4. VM:

a. IOT data: hora:

EXTdata: hora:

5. Uso de inotrópicos (dobutamina/epinefrina/milrinone):
a. Ligado data: hora:
b. Desligado data: hora:

6. Uso de vasopressor (noradrenalina/vasopressina):

a. Ligado data: hora: 
b. Desligado data: hora: 
7. Baixo Débito Cardíaco

$\square \operatorname{Sim}(1) \quad \square$ Não (0)

8. Choque cardiogênico:

$\square \operatorname{Sim}(1) \quad \square$ Não (0)

9. Necessidade de BIA no pós-operatório:

$\square \operatorname{Sim}(1) \quad \square$ Não (0)

10. Taquiarritmia:

$\square \operatorname{Sim}$ (1) $\square$ Não (0)

11. Bradiarritmia:

$\square \operatorname{Sim}$ (1) $\square$ Não (0)

12. Tempo de internação na UTI:

a. Data da alta da UTI:

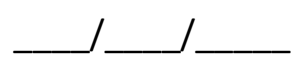

b. Horário da alta da UTI:

13. Complicações pós operatórias:
a. AVC:
$\square \operatorname{Sim}(1) \quad \square$ Não (0)
b. IRA:
$\square \operatorname{Sim}(1) \quad \square$ Não (0)

1. AKIN 1:

2. AKIN 2:

3. AKIN 3:

c. Necessidade de Diálise:

$\square \operatorname{Sim}(1) \quad \square$ Não (0)

d. Complicação Infecciosa:

$\square \operatorname{Sim}(1) \quad \square$ Não (0)

1. Infecção

2. Sepse

3. Sepse Grave

4. Choque séptico

e. Foco infeccioso:

1. ITU:

2. $\mathrm{BCP}$ :

3. Infecção de corrente snaguínea:

4. Ferida Operatória:

14. Data da alta hospitalar:

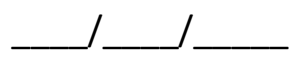

15. Óbito: $\square \operatorname{Sim}(1) \quad \square$ Não (0)

Data: 


\section{EuroSCORE}

Fatores relacionados ao paciente:

Idade: > 60 (01 Ponto) 61-65 (02 pontos) 66-70 (03 pontos) 71-75 (04 pontos) 76-80 (05 pontos) 81-85 (06 pontos) 86-90 (07 pontos) 91-95 (08 pontos)

Sexo: $\square$ Masculino (0 Ponto) $\square$ Feminino (1 Ponto)

DPOC: $\square \operatorname{Sim}(1$ Ponto) $\square$ Não (0 Ponto)

Doença arterial não- cardíaca: $\square \operatorname{Sim}(2$ Pontos) $\quad \square$ Não(0 Ponto)

(Estenose de Carótida $>50 \%$, claudicação, cirurgia ou aneurisma de aorta abdominal, doença vascular periférica)

Doença Neurológica (incapacitante): $\square \operatorname{Sim}(2$ Pontos) $\square$ Não(0 Ponto)

Cirurgia Cardíaca prévia: $\square \operatorname{Sim}(3$ Pontos) $\quad \square$ Não(0 Ponto)

Creatinina prévia >2.0: $\square \operatorname{Sim}(2$ Pontos) $\square$ Não(0 Ponto)

Endocardite ativa: $\square \operatorname{Sim}(3$ Pontos) $\square$ Não (0 Ponto)

Estado pré-operatório crítico: $\square \operatorname{Sim}(3$ Pontos) $\square$ Não(0 Ponto)

(BIA pré-operatório, pós-PCR, arritmia ventricular, VM pré-operatória, IRA pré-operatória)

Fatores Relacionados ao coração:

Angina Instável: $\square \operatorname{Sim}(2$ Pontos) $\square$ Não(0 Ponto)

Função ventricular esquerda:

$\square>=50 \%$ (0 Ponto) $\quad \square<50->=30 \%$ (1 Ponto) $\quad \square<30 \%$ ( 3 Pontos)

Infarto Recente (até 90 dias): $\square$ Sim (2 Pontos) $\square$ Não(0 Ponto)

Hipertensão pulmonar: $\square \operatorname{Sim}(2$ Pontos) $\square$ Não(0 Ponto)

Fatores relacionados à cirurgia:

Cirurgia de emergência: $\square$ Sim (2 Pontos) $\square$ Não ( 0 Ponto)

Outras cirurgias além da RM ou procedimento combinado: $\square \operatorname{Sim}(2$ Pontos) $\square$ Não(0 Ponto)

Cirurgia torácica ou da aorta: $\square \operatorname{Sim}(3$ Pontos) $\square$ Não(0 Ponto)

CIV pós-infarto: $\square$ Sim (4 Pontos) $\square$ Não (0 Ponto)

\section{Total EuroSCORE}

EuroSCORE calculator está disponível em http://www.euroscore.org/calcold.html 
Selecionar standard Euroscore para o cálculo do score 


\section{Anexo E: Aprovação Clinical Trials}

\section{ClinicalTrials.gov PRS \\ Protocol Registration and Results System}

ClinicalTrials.gov PRS DRAFT Receipt (Working Version)

Last Update: 12/20/2017 06:08

ClinicalTrials.gov ID: NCT03343418

Study Identification

Unique Protocol ID: 3962.13 .087

Brief Title: Effects of Prophylactic Desmopressin on Blood Coagulation Parameters in Heart Valve Surgery

Official Title: Placebo-Controlled, Randomized, Double-Blind Trial of Prophylactic Desmopressin in Heart Valve Surgery

Secondary IDs:

Study Status

Record Verification: November 2017

Overall Status: Active, not recruiting

Study Start: February 2015 []

Primary Completion: November 23, 2016 [Actual]

Study Completion: December 23, 2017 [Anticipated]

\section{Sponsor/Collaborators}

Sponsor: Instituto do Coracao

Responsible Party: Principal Investigator

Investigator: Filomena R B G Galas [fgalas]

Official Title: Associate Professor

Affiliation: Instituto do Coracao

Collaborators:

Oversight

U.S. FDA-regulated Drug:

U.S. FDA-regulated Device:

U.S. FDA IND/IDE: No

Human Subjects Review: Board Status: Approved

Approval Number: 24147913.1.0000.0068

Board Name: National Committee of Ethics in Research

Board Affiliation: University of São Paulo

Phone: +55112661-5560

Email:

Address: 
Data Monitoring: No

FDA Regulated Intervention: No

\title{
Study Description
}

Brief Summary: The purpose of this study is evaluate the effect of prophylactic desmopressin on blood coagulation parameters and postoperative bleeding in patients undergoing valve cardiac surgery with cardiopulmonary bypass.

Detailed Description: Patients with important valve disorders may evaluate with coagulopathy induced by mechanical effects (valvular stenosis or valvular insufficiency). Furthermore, frequently is required prophylactic use of antiplatelet drugs due to myocardial remodeling and antiarrhythmic conditions that may be associated. Patients with severe aortic stenosis may also acquired von Willebrand disease type $2 \mathrm{~A}$ due to proteolysis of vonWillebrand factor. Despite of this, the treatment of valve disorders often requires cardiac surgery with cardiopulmonary bypass. On average 50 to $60 \%$ of patients undergoing cardiac surgery receive blood tranfusions. Blood cell transfusion is an independent risk factor for increased morbidity and mortality in critically ill patients. The use of desmopressin seems beneficial only in patients with congenital or acquired platelet dysfunction. In general population, such use is not validated due to inconclusive results of researches.

\section{Conditions}

\author{
Conditions: C.Surgical Procedure; Cardiac \\ Blood Coagulation Disorders \\ Keywords: Bleeding \\ Valve Cardiac Surgery \\ Desmopressin
}

\section{Study Design}

Study Type: Interventional

Primary Purpose: Prevention

Study Phase: Phase 4

Interventional Study Model: Parallel Assignment

Number of Arms: 2

Masking: Triple (Participant, Care Provider, Investigator)

Allocation: Randomized

Enrollment: 108 [Anticipated]

\section{Arms and Interventions}

\begin{tabular}{|l|l|}
\hline \multicolumn{1}{|c|}{ Arms } & \multicolumn{1}{c|}{ Assigned Interventions } \\
\hline Active Comparator: desmopressin & Drug: Desmopressin \\
$\begin{array}{l}\text { Patients randomized to this group receive } \\
\text { desmopressin } 0,3 \text { microgram. } \mathrm{kg}-1 \text { as an intravenous } \\
\text { infusion given during } 20 \mathrm{~min} .\end{array}$ & Desmopressin is to be administered as an intravenous \\
infusion after discontinuation of cardiopulmonary \\
bypass and administration of protamine. Subjects are
\end{tabular}




\begin{tabular}{|c|c|}
\hline Arms & Assigned Interventions \\
\hline & $\begin{array}{c}\text { to be given desmopressin 0,3 microgram.kg-1. After } \\
\text { desmopressin infusion, bleeding treatment will follow } \\
\text { the predefined standardized treatment regimen. }\end{array}$ \\
\hline $\begin{array}{c}\text { Placebo Comparator: Placebo } \\
\text { Patients randomized to the control group will receive }\end{array}$ & $\begin{array}{c}\text { Drug: Placebo } \\
0.9 \% \text { saline is to be administered as an intravenous } \\
\text { infusion after discontinuation of cardiopulmonary }\end{array}$ \\
& bypass and administration of protamine. Patients \\
& randomized to the control group will receive the \\
& infusion of 100 milliliters (mL) $0.9 \%$ saline $(\mathrm{SF} 0,9 \%)$. \\
& After $0.9 \%$ saline infusion, bleeding treatment will \\
& follow the predefined standardized treatment regimen. \\
\hline
\end{tabular}

(1) NOTE : Intervention Other Names have not been specified

(1) NOTE : Intervention Other Names have not been specified

\section{Outcome Measures}

Primary Outcome Measure:

1. Change in coagulation parameters

Laboratory variables: Activated partial thromboplastin time [(aPTT) seconds], prothrombin time [(PT) seconds], haematocrit (\%), haemoglobin(g/dl), fibrinogen(mg/dL), D dimer (ng/L), factor VIII(\%), Von Willebrand factor(\%), ROTEM [(INTEM, EXTEM, FIBTEM) Clotting Time (CT) and Clot Formation Time (CFT) seconds, alpha angle $\left(\alpha^{\circ}\right)$, Maximum Clot Firmness (MCF) mm ] and platelets aggregation (\%)

[Time Frame: Coagulation parameters will be performed: T0: preoperative period; T1 - 2 hours after desmopressin or placebo administration; T2 - 24 hours after desmopressin or placebo administration]

2. Postoperative blood loss

Total chest tube drainage $(\mathrm{mL})$ starting immediately after closure of the chest in the operating theater until 48 hours

[Time Frame: 48 hours]

Secondary Outcome Measure:

3. Blood transfusion

Number of units of red blood cells, fresh frozen plasma,platelets, cryoprecipitate in the operating theater and ICU

[Time Frame: 30 days]

4. Reoperation for bleeding

[Time Frame: 30 days]

5. Duration of Mechanical ventilation

[Time Frame: 30 days]

6. Length of vasoactive drugs

[Time Frame: 30 days]

7. Length of ICU stay

[Time Frame: 30 days]

8. Clinical complications - renal failure, infection, myocardial ischemia, stroke

[Time Frame: 30 days]

9. Length of hospital stay

[Time Frame: 30 days]

10. Mortality

[Time Frame: 30 days]

(4) NOTE : Outcome Measure Description has not been entered.

(4) NOTE : Outcome Measure Description has not been entered.

(4) NOTE : Outcome Measure Description has not been entered. 
(1) NOTE : Outcome Measure Description has not been entered.

(1) NOTE : Outcome Measure Description has not been entered.

(1) NOTE : Outcome Measure Description has not been entered.

(1) NOTE : Outcome Measure Description has not been entered.

4 NOTE : Normally only one Primary Outcome Measure is specified.

\title{
Eligibility
}

\author{
Minimum Age: 18 Years \\ Maximum Age: 80 Years \\ Sex: All
}

Gender Based:

Accepts Healthy Volunteers: No

Criteria: Inclusion Criteria:

- Valve cardiac surgery with cardiopulmonary bypass.

- Written informed consent

\section{Exclusion Criteria:}

- Reoperative valve surgery

- Hematocrit < $35 \%$

- Ventricular dysfunction (EF < 40\%)

- Infection

- Body mass index $>35$

- Renal impairment (Creatinin $>2 \mathrm{mg} / \mathrm{dL}$ )

- Antiplatelet administration within 10 days preceding study surgery

- Participation in another interventional clinical study within 30 days

- Known or suspected hypersensitivity to the desmopressin

- Coagulopathy (INR > 1.5)

\section{Contacts/Locations}

\section{Central Contact Person:}

Central Contact Backup:

Study Officials: NOTE : Study Official is required by the WHO and ICMJE.

Locations: Brazil

Incor - Heart Institute - University of Sao Paulo

Sao Paulo, Brazil, 05403000

Contact: Filomena RG Galas +551126615232 filomenagalas@hotmail.com

\section{IPDSharing}

Plan to Share IPD: 


\section{References}

Citations: Galas FR, de Almeida JP, Fukushima JT, Vincent JL, Osawa EA, Zeferino

S, Câmara L, Guimarães VA, Jatene MB, Hajjar LA. Hemostatic effects of fibrinogen concentrate compared with cryoprecipitate in children after cardiac surgery: a randomized pilot trial. J Thorac Cardiovasc Surg. 2014

Oct;148(4):1647-55. doi: 10.1016/j.jtcvs.2014.04.029. Epub 2014 Apr 18. PubMed 24951020

Links:

Available IPD/Information:

U.S. National Library of Medicine | U.S. National Institutes of Health | U.S. Department of Health \& Human Services 
1. Jin $L$ and Ji Hong-Wen. Effect of desmopressin on platelet aggregation and blood loss in patients undergoing valvular heart surgery. Chin Med $\mathrm{J}$. 2015;128:644-7.

2. Marik PE, Corwin HL. Efficacy of red blood cell transfusion in the critically ill: a systematic review of the literature. Crit Care Med. 2008;36:2667-74.

3. Svensson PJ et al. Desmopressin in treatment of haematological disorders and in prevention of surgical bleeding. Blood rev. 2014;28:95102.

4. Slaughter TF. Coagulation. In: Miller RD. Miller's Anesthesia. 7ed Philadelphia: Churchill livingstone; 2010; 1767-1779.

5. Mazzeffi MA and Stone ME. Perioperative management of von Willebrand disease: a review for the anesthesiologist. J Clin Anest. 2011; 23: 418-26.

6. Casonato A et al. von Willebrand factor abnormalities in aortic valve stenosis: pathophysiology and impact on bleeding. Thromb Haemost. 2011; 106: 58-66.

7. Bolliger $\mathrm{D}$ et al. Impact of loss of high-molecular-weight von Willebrand factor multimers on blood loss after aortic valve replacement. $\mathrm{Br} J$ Anaesth. 2012; 108: 754-62.

8. Weber CF et al. A point-of-care assessment of the effects of desmopressin on impaired platelet function using multiple electrode whole-blood aggregometry in patients after cardiac surgery. Anesth Analg. 2010; 110:702-7. 
9. Steinlechner B et al. Patients with severe aortic valve stenosis and impaired platelet function benefit from preoperative desmopressin infusion. Ann Thorac Surg. 2011; 91:1420-6.

10. Vincentelli A et al. Acquired von Willebrand syndrome in aortic stenosis. N Engl J Med. 2003; 349:343-9.

11. Pappalardo $\mathrm{F}$ et al. Perioperative evaluation of primary hemostasis in patients undergoing mitral valve repair. Care Cardiovasc Anesth. 2010; 2:119-27.

12. Rozental T, Shore-Lesserson L. Pharmacologic management of coagulopathy in cardiac surgery: an update. J Cardiothorac Vasc Anesth. 2012; 26(4):669-79.

13. Ereth $\mathrm{MH}$ et al. The relation between the platelet-activated clotting test (HemoSTATUS) and blood loss after cardiopulmonary bypass. Anesthesiology 1998; 88:962-9.

14. Spiess BD, Horrow J, Kaplan JA. Transfusion medicine and coagulation disorders. In: Kaplan'sCardiacAnesthesia: the eco era. 6ed. Elsevier; $2011 ; 949-991$.

15. Travers RJ, Smith SA and Morrissey JH. Polyphosphate, platelets and coagulation. Int J Lab Hem. 2015; 37(1):31-5.

16. Hessel EA, Ghansah JN. Fisiopatologia da circulação extracorpórea. In: Hensley FA, Martin DE, Gravlee GP. Anestesia Cardíaca: uma abordagem prática. Rio de Janeiro: Revinter; 2012; 559-586.

17. Sniecinski RM, Levy JH. Bleeding and management of coagulopathy. $J$ Thorac Cardiovasc Surg. 2011;142:662-7. 
18. Schulman S. Pharmacologic tools to reduce bleeding in surgery. Hematology 2012.

19. Gorlinger $\mathrm{K}$ et al. First-line therapy with coagulation factor concentrates combined with point-of0care coagulation testing is associated with decreased allogenicbllod transfusion in cardiovascular surgery: A retrospective, single-center cohort study. Anesthesiology 2011;115:117991.

20. Mahdy AM, Webster NR. Perioperative systemic haemostatic agents. $\mathrm{Br}$ J Anaesth. 2004;93:842-58.

21. Mangano DT, Tudor IC, Dietzel C. Multicenter study of perioperative ischemia research group: The risk associated with aprotinin in cardiac surgery. N Engl J Med. 2006;354:353-65.

22. Dhir A. Antifibrinolytics in cardiac surgery. Ann Card Anaesth. 2013; $16: 2$.

23. Saillant NN and Sims CA. Platelet dysfunction in injured patients. Mol Cell Ther. 2014;2:37-43.

24. Zaffar $\mathrm{N}$ et al. The rationale for platelet transfusion during cardiopulmonarybypass: an observational study. Can $J$ Anesth. 2013;60:345-54.

25. Swieringa $\mathrm{F}$ et al. Desmopressin treatment improves platelet function under flow in patients with postoperative bleeding. $J$ Thromb Haemost. 2015;13:1503-13.

26. Treschan TA, Peters J. The vasopressina system. Anesthesiology 2006;105:599-612. 
27. Naidech AM et al. Desmopressin improves platelet activity in acute intracerebral hemorrhage. Stroke 2014;45:2451-3.

28. Soslau $\mathrm{G}$ et al. Desmopressin induced improvement in bleeding times in chronic renal failure patients correlates with platelet serotonin uptake and ATP release. Am J Med Sci. 1990;300:372-9.

29. Cattaneo M. The use of desmopressin in open-heart surgery. Haemophilia 2008;14:40-7.

30. Pleym H. Prophylactic treatment with desmopressin does not reduce postoperative bleeding after coronary surgery in patients treated with aspirin before surgery. Anesth Analg. 2004;98:578-84.

31. Kozek-Langenecker SA et al. Management of severe perioperative bleeding: Guidelines from the European Society of Anaesthesiology. Eur J Anaesthesiol. 2013;30:270-382.

32. Crescenzi et al. Desmopressin reduces tranfusion needs after surgery: a meta-analysis of randomized clinical trials. Anesthesiology 2008;109:1063-76.

33. Avidan MS et al. Comparison of structured use of routine laboratory tests or near-patient assessment with clinical judgement in the management of bleeding after cardiac surgery. Br J Anaesth. 2004;92:178-86.

34. Despotis GJ, Skubas NJ, Goodnough LT. Optimal management of bleeding and transfusion in patients undergoing cardiac surgery. Semin Thorac Cardiovasc Surg. 1999;11(2):84-104. 
35. Miana LA et al. Fatores de risco de sangramento no pós-operatório de cirurgia cardíaca em pacientes adultos. Rev Bras Cir Cardiovasc. 2004;19(3):280-6 .

36. Haase M, Bellomo R, Matalanis G, Calzavacca P, Dragun D, HaaseFielitz A. A comparison of the RIFLE and Acute Kidney Injury Network classifications for cardiac surgery-associated acute kidney injury: A prospective cohort study. J Thorac Cardiovasc Surg. The American Association for Thoracic Surgery; 2009;138(6):1370-6.

37. Klugkist M, Sedemund-Adib B, Schmidtke C, Schmucker P, Sievers HH, Hüppe M. [Confusion Assessment Method for the Intensive Care Unit (CAM-ICU): diagnosis of postoperative delirium in cardiac surgery]. Anaesthesist. 2008;57(5):464-74.

38. Thygesen K, Alpert JS, Jaffe AS, Simoons ML, Chaittman BR, White HD. Third Universal Definition of Myocardial Infarction. Joint ESC/ACCF/AHA/WHF Task force for the redefinition of myocardial infarction. Circulation. 2012; 126(16): 2020-35.

39. Levy MM et al. 2001 SCCM/ESICM/ACCP/ATS/SIS International sepsis definitions conference. Crit Care Med. 2003;31(4):1250-6.

40. Calandra T, Cohen J. The international sepsis forum consensus conference on definition of infection in the intensive care unit. Crit Care Med. 2005;33(7):1538-48.

41. Karlsson $\mathrm{M}$ et al. Prophylactic fibrinogen infusion reduces bleeding after coronary artery bypass surgery. A prospective randomised pilot study. Thromb Haemost. 2009;102(1):137-44. 
42. Wademan $\mathrm{BH}$, Galvin SD. Desmopressin for reducing postoperative blood loss and transfusion requirements following cardiac surgery in adults. Interact Cardiovasc Thorac Surg. 2014;(18):360-70.

43. Cantaneo $\mathrm{M}$ et al. The effect of desmopressin on reducing blood loss in cardiaca surgery - a meta - analysis of double-blind, placebo-controlled trials. Thromb Haemost. 1995;74:1064-70.

44. Bignami E et al. Desmopressin after cardiac surgery in bleeding patients. A multicenter randomized trial. Acta Anaesthesiol Scand. 2016;(60):892900.

45. Desborough MJR et al. Desmopressin for treatment of platelet dysfunction and reversal of antiplatelet agents: a systematic review and meta-analysis of randomized controlled trials. J Thromb Haemost. 2017;15: 263-72.

46. Carrasco E et al. Aortic stenosis and acquired von Willebrand disease: Lack of association. J Cardiothorac Vasc Anesth. 2011;25(4):615-8.

47. Desborough MJR et al. Alternatives to allogenic platelet transfusion. $\mathrm{Br} J$ Haematol. 2016;175:381-92.

48. Ghandimi K, Levy JH, Welsby IJ. Perioperative management of the bleeding patient. Br J Anaesth. 2016;117(S3):iii18-iii30.

49. Galas FRG et al. Hemostatic effects of fibrinogen concentrate compared compared with cryoprecipitate in children after cardiac surgery: A randomized pilot trial. J Thorac Cardiovasc Surg. 2014;148:1647-55. 
50. Mirmansoori A et al. The effect of desmopressin on the amount of bleeding in patients undergoing coronary artery bypass graft surgery with a cardiopulmonar bypass pump after taking anti-platelet medicine. Anesth Pain Med. 2016;6(5):e39226.

51. Orlov $\mathrm{D}$ et al. Utilization and Effectiveness of Desmopressin Acetate After Cardiac Surgery Supplemented with poin-of-care hemostatic testing: A propensity-score-matched analisis. J Cardiothorac Vasc Anesth. 2016;1-13.

52. Deppe A et al. Poit-of-care thromboelastography/ thromboelastometrybased coagulation management in cardiac surgery: a meta-analysis of 8332 patients. J Surg Res. 2016;(203):424-33.

53. Karkouti $\mathrm{K}$ et al. Point-of-care hemostatic testing in cardiac surgery. Circulation. 2016;134:1152-62. 